SERGIO LUIS MOSCKEM

\title{
ANÁLISE DO EMPREGO DE MATERIAIS ALTERNATIVOS NO ALTO FORNO DA ARCELORMITTAL TUBARÃO
}

Dissertação apresentada à Faculdade de Engenharia do Campus de Guaratinguetá, Universidade Estadual Paulista, para a obtenção do título de Mestre em Engenharia Mecânica na área de Transmissão e Conversão de Energia.

Orientador: Prof. Dr. José Antonio Perrella Balestieri Co-orientador: Prof. Dr. João Andrade de Carvalho Jr.

Guaratinguetá 


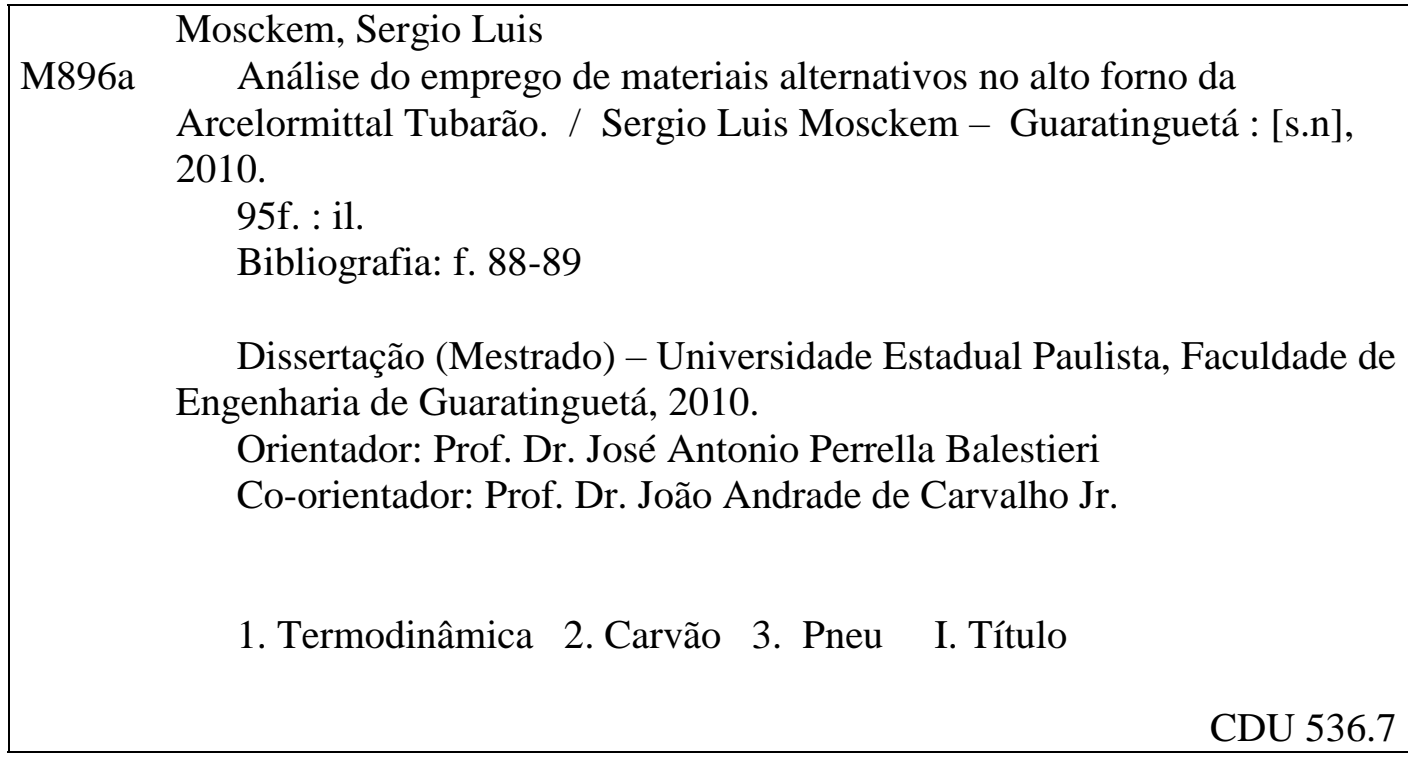




\section{unesp $\stackrel{\Delta}{\forall}$ UNIVERSIDADE ESTADUAL PAULISTA \\ CAMPUS DE GUARATINGUETÁ}

\section{SERGIO LUIS MOSCKEN}

ESTA DISSERTAÇÃO FOI JULGADA ADEQUADA PARA A OBTENÇ̃̃o DO TÍTULO DE "MESTRE EM ENGENHARIA MECÂNICA"

PROGRAMA: ENGENHARIA MECÂNICA ÁREA: TRANSMISSÃO E CONVERSÃO DE ENERGIA

APROVADA EM SUA FORMA FINAL PELO PROGRAMA DE PÓS-GRADUAÇÃO

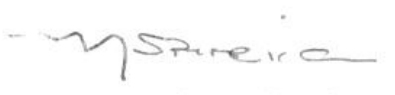

Prof. Dr. Marcelo dos Santos Pereira Coordenador

BANCA EXAMINADORA:

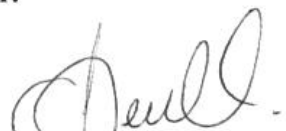

Prof. Dr. JOSÉ ANTONIQ PERRELLLA BALESTIERI

Orientador YUnesp-Feg

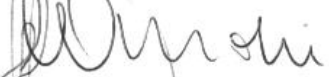

Prof. Dr. LUIZ ROBERTO CARROCCI

Unesp-Fgg

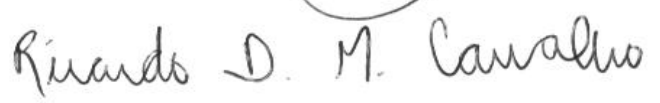

Prof. Dr. RICARDO DIAS MARTINS DE CARVALHO IEM/UNIFEI 


\title{
DADOS CURRICULARES
}

\section{SERGIO LUIS MOSCKEM}

\author{
NASCIMENTO 21.06.1962 - MARILÂNDIA / ES \\ FILIAÇÃO Argentino Mosckem \\ Ermínia Olioza Mosckem \\ 1987/1994 Curso de Graduação \\ Universidade Federal do Espírito Santo \\ 2002 \\ Curso de Especialização em Gestão Empresarial na \\ Fundação Getúlio Vargas.
}


Dedico, de modo especial, à milha esposa Wânia e as minhas filhas Cristina e Marina, que foram as grandes incentivadoras na realização deste trabalho. 


\section{AGRADECIMENTOS}

Em primeiro lugar agradeço a Deus, fonte da vida e da graça. Agradeço pela minha vida, minha inteligência, minha família e meus amigos,

ao meu orientador, Prof. Dr. José Antônio Perrella Balestieri, que jamais deixou de me incentivar. Sem a sua orientação, dedicação e auxílio, o estudo aqui apresentado seria praticamente impossível.

aos meus pais Argentino e Ermínia, que apesar das dificuldades enfrentadas, sempre incentivaram meus estudos.

à dona Ieda Maria Siggelkow de Almeida Perrella, que sempre me acolheu com alegria em sua casa,

aos companheiros de trabalho da ArcelorMittal Tubarão que me auxiliaram na coleta de dados e na correção do trabalho,

ao meu gerente Luiz Antônio Baldon, que sempre apoiou e incentivou a realização deste trabalho,

ao gerente de divisão de operação dos Alto Fornos da ArcelorMittal Tubarão, Jorge Adelino de Faria, que disponibilizou os dados técnicos e operacionais utilizados neste trabalho,

aos engenheiros de operação do Alto Forno 1 da ArcelorMittal Tubarão, Cláudio Cesar da Costa, Ricardo José Tauffer Barros e Mauro Correa da Silva, que forneceram todas as informações e esclarecimentos sobre o processo de produção no Alto Forno,

à ArcelorMittal Tubarão, que acreditou e viabilizou a realização deste trabalho, fornecendo suporte técnico e financeiro em todas as fases do estudo. 
MOSCKEM, S. L. Análise do emprego de materiais alternativos no Alto Forno da ArcelorMittal Tubarão. 2010. 95 f. Dissertação (Mestrado em Engenharia Mecânica) Faculdade de Engenharia do Campus de Guaratinguetá, Universidade Estadual Paulista, Guaratinguetá, 2010.

\section{RESUMO}

O trabalho de análise do uso de materiais alternativos no Alto Forno 1 da ArcelorMittal Tubarão estabelece uma taxa de substituição de cada material alternativo, plástico e pneu, em relação ao uso exclusivo do carvão mineral injetado no Alto Forno através das ventaneiras. A taxa de utilização de plástico e pneu é avaliada considerando o aporte de energia e dos agentes necessários para a reação química de redução do minério de ferro em ferro metálico. No presente trabalho são elaborados os balanços de massa e de energia de acordo com a configuração operacional vigente no segundo semestre de 2009 para o Alto Forno 1 e com os dados de produção do mês de julho de 2009. O resultado mostra a viabilidade técnica do uso de plástico ou pneu e estabelece as condições de uso de cada um em relação à quantidade, tipo e granulometria. A substituição energética decorrente do uso de plástico e pneu estabelece uma forma de aplicação segura e controlada deste resíduo, além de agregar valor a estes materiais normalmente descartados pela sociedade. Contribui também para amenizar os impactos ambientais decorrentes da falta de uma destinação regulamentada e eficaz para plásticos descartados e pneus inservíveis.

PALAVRAS-CHAVE: Balanços de energia. Substituição energética. Alto forno. Combustão de materiais alternativos. 
MOSCKEM, S. L. Analysis of alternative fuels materials in the Blast Furnace of ArcelorMittal Tubarão. 2010. 95 f. Dissertation (Masters in Mechanical Engineering) Faculdade de Engenharia do Campus de Guaratinguetá, Universidade Estadual Paulista, Guaratinguetá, 2010.

\begin{abstract}
The study of alternative fuel materials in the Blast Furnace 1 of ArcelorMittal Tubarão, establishes a rate of each material analyzed, waste plastics packaging and waste tires, in order to replace part of the pulverized coal that is usually injected in to the Blast Furnace through the tuyeres. The injection rate of waste plastic packaging and waste tires is analyzed considering the energy input and the necessary elements for the iron ore reduction chemical reaction. The mass and energy balance is done according to the operational configuration of the Blast Furnace 1 in the second semester of 2009 and operation data from July of 2009. The result of the study shows technical viability to use waste plastics packaging and waste tires and establish requirements for the injection, such as flow rate and particles size. The alternative energy provided from these waste materials builds a safety and controlled way to reach the best utilization for each one. Moreover, the environmental impact can be reduced due to its disposal is normally done in outdoor areas.
\end{abstract}

KEYWORDS: Energy Balance. Alternative Fuels. Blast Furnace. Alternative Materials Combustion. 


\section{LISTA DE FIGURAS}

FIGURA 1 - Fluxo de preparação do carvão pulverizado ..................................... 18

FIGURA 2 - Injeção de carvão pulverizado através das ventaneiras ...................... 18

FIGURA 3 - Fluxo gasoso ascendente no interior do Alto Forno .......................... 19

FIGURA 4 - Perfil térmico das regiões internas do Alto Forno .............................. 20

FIGURA 5 - Perfil das reações químicas no interior do Alto Forno ...................... 20

FIGURA 6 - Fluxo do processo de produção do aço........................................... 21

FIGURA 7 - Zonas internas do Alto Forno .......................................................... 25

FIGURA 8 - Perfil das reações químicas no interior do Alto Forno ....................... 27

FIGURA 9 - Instalação típica para preparação do resíduo de plástico para injeção

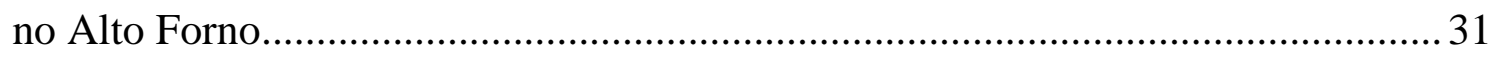

FIGURA 10 - Método de análise flutuação da chama............................................ 32

FIGURA 11 - Imagens da combustão de plástico e carvão nas ventaneiras ........... 33

FIGURA 12 - Efeito da injeção na flutuação de chama ....................................... 34

FIGURA 13 - Região do fluxo de gases em função do tamanho da partícula .........34

FIGURA 14 - Composição de um pneu............................................................. 40

FIGURA 15 - Esquema para injeção de pneu através das ventaneiras ................... 42

FIGURA 16 - Produção anual de pneus no Brasil............................................... 43

FIGURA 17 - Ciclo de vida de um pneu ........................................................ 44

FIGURA 18 - Cadeia de pneus inservíveis..................................................... 45

FIGURA 19 - Produção e destino de pneus no Brasil ............................................. 46

FIGURA 20 - Fluxo de produção da ArcelorMittal Tubarão ................................. 47

FIGURA 21 - Alto Forno 1 e a área de produção de gusa da ArcelorMittal Tubarão 48

FIGURA 22 - Perfil do Alto Forno 1 da ArcelorMittal Tubarão ..............................52

FIGURA 23 - Arranjo esquemático da configuração do Alto Forno 1 da ArcelorMittal

Tubarão 
FIGURA 24 - Fluxograma de carregamento do Alto Forno 1................................54

FIGURA 25 - Fluxograma de preparação do carvão pulverizado ............................55

FIGURA 26 - Desenho em corte de uma ventaneira de Alto Forno .......................55

FIGURA 27 - Ventaneira do Alto Forno 1 mostrando as lanças de injeção de carvão

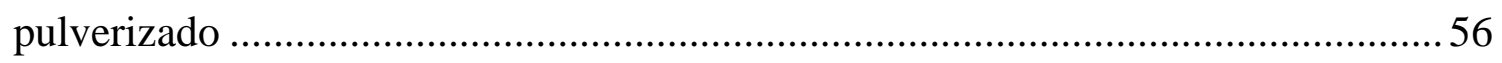

FIGURA 28 - Ilustração da composição dos regeneradores no Alto Forno ...........57

FIGURA 29 - Balanço de massa: Entradas e saídas ............................................... 58

FIGURA 30 - Volume de controle aplicado sobre o Alto Forno 1 .........................60

FIGURA 31 - Gráfico do balanço de vazão em massa.......................................... 63

FIGURA 32 - Gráfico da relação da massa de entrada / saída ................................ 64

FIGURA 33 - Gráfico do balanço de energia do Alto Forno 1 ............................. 80 


\section{LISTA DE TABELAS}

TABELA 1 - Características dos materiais para injeção 17

TABELA 2 - Composição média do gás de Alto Forno da ArcelorMittal Tubarão.26

TABELA 3 - Taxa de redução pelo Hidrogênio no total da Redução Indireta ...... 35

TABELA 4 - Produção e reciclagem de plástico no Brasil ..................................... 36

TABELA 5 - Distribuição regional da produção de plástico pós-uso no Brasil ..... 38

TABELA 6 - Distribuição regional da reciclagem de plástico pós-uso no Brasil... 38

TABELA 7 - Preço de plástico para reciclagem.................................................... 39

TABELA 8 - Composição química do pneu........................................................... 41

TABELA 9 - Composição do pneu por tipo ........................................................ 41

TABELA 10 - Taxa de injeção x índice de combustão do pneu ............................ 42

TABELA 11 - Taxa de injeção x índice de combustão do carvão .........................42

TABELA 12 - Peso de Pneu inservível ............................................................. 46

TABELA 13 - Dados e relação de entrada e saída de vazão em massa .................. 62

TABELA 14 - Composição de carvões e a análise química resultante ................... 65

TABELA 15 - Composição de carvões e plástico com a análise química

resultante 66

TABELA 16 - Composição de carvões e pneu com a análise química resultante .. 67

TABELA 17 - Energia de entrada do Alto Forno 1 da ArcelorMittal Tubarão ...... 75

TABELA 18 - Energia de saída do Alto Forno 1 da ArcelorMittal Tubarão ........... 78

TABELA 19 - Balanço de energia do Alto Forno 1 da ArcelorMittal Tubarão...... 79

TABELA 20 - Estimativa de consumo de carvão + plástico ................................. 81

TABELA 21 - Estimativa de consumo de carvão + pneu .................................... 84 


\section{LISTA DE SÍMBOLOS}

\begin{tabular}{|c|c|c|}
\hline c & calor específico & $\mathrm{kcal} / \mathrm{kg} K$ \\
\hline $\mathrm{g}$ & aceleração da gravidade & $\mathrm{m} / \mathrm{s}^{2}$ \\
\hline $\mathrm{H}, \mathrm{h}$ & entalpia específica & $\mathrm{kcal} / \mathrm{kg}$ \\
\hline $\mathrm{p}$ & pressão & $\mathrm{kgf} / \mathrm{cm}^{2}$ \\
\hline $\mathrm{Q}$ & calor & kcal \\
\hline $\mathrm{t}$ & tempo & $s$ \\
\hline $\mathrm{T}$ & temperatura & ${ }^{\circ} \mathrm{C}$ \\
\hline $\mathrm{m}$ & massa & $\mathrm{kg}$ \\
\hline $\mathrm{v}$ & velocidade & $\mathrm{m} / \mathrm{s}$ \\
\hline $\mathrm{Z}$ & Cota & $m$ \\
\hline VS & vazão de sopro & $\mathrm{Nm}^{3} / \mathrm{t}$ de gusa \\
\hline CR & taxa de carregamento de coque & $\mathrm{kg} / \mathrm{t}$ de gusa \\
\hline IV & Injeção de vapor & $\mathrm{g} / \mathrm{Nm}^{3}$ \\
\hline TS & temperatura de sopro & ${ }^{\circ} \mathrm{C}$ \\
\hline $\mathrm{C}_{\mathrm{p}}(\mathrm{VS})$ & calor específico do ar & $\mathrm{kcal} / \mathrm{Nm}^{3}$ \\
\hline $\mathrm{EO}_{2}$ & enriquecimento com oxigênio & $\%$ \\
\hline $\mathrm{N}_{2}(\mathrm{VS})$ & nitrogênio na vazão de sopro & $\%$ \\
\hline $\mathrm{N}_{2}$ (Topo) & nitrogênio no gás do topo -BFG & $\%$ \\
\hline $\mathrm{CO}$ (Торо) & monóxido de carbono no gás do topo $-\mathrm{BFG}$ & $\%$ \\
\hline $\mathrm{CO}_{2}$ (Topo) & dióxido de carbono no gás do topo - BFG & $\%$ \\
\hline $\mathrm{H}_{2}$ (Topo) & hidrogênio no gás do topo - BFG & $\%$ \\
\hline SR & taxa de Produção de escória & $\mathrm{kg} / \mathrm{t}$ de gusa \\
\hline $\mathrm{C}$ & carbono presente no gusa & $\%$ \\
\hline $\mathrm{Si}$ & silício presente no gusa & $\%$ \\
\hline Mn & manganês presente no gusa & $\%$ \\
\hline $\mathrm{P}$ & fósforo presente no gusa & $\%$ \\
\hline $\mathrm{T}_{\text {gusa }}$ & temperatura do gusa & ${ }^{\circ} \mathrm{C}$ \\
\hline $\mathrm{T}$ gás BFG & temperatura do gás do topo & ${ }^{\circ} \mathrm{C}$ \\
\hline $\mathrm{H}_{\mathrm{i} 1}$ & calor de combustão do carbono & $\mathrm{kcal} / \mathrm{t}$ de gusa \\
\hline $\mathrm{H}_{\mathrm{i} 2}$ & calor sensível do ar de sopro & $\mathrm{kcal/t}$ de gusa \\
\hline $\mathrm{H}_{\mathrm{i} 3}$ & calor da redução indireta & $\mathrm{kcal/t}$ de gusa \\
\hline $\mathrm{H}_{\mathrm{i} 4}$ & calor de formação da escória & $\mathrm{kcal} / \mathrm{t}$ de gusa \\
\hline $\mathrm{H}_{\mathrm{o} 1}$ & calor da reação solution loss & $\mathrm{kcal} / \mathrm{t}$ de gusa \\
\hline $\mathrm{H}_{\mathrm{o} 2}$ & calor da redução do hidrogênio & $\mathrm{kcal} / \mathrm{t}$ de gusa \\
\hline $\mathrm{H}_{03}$ & calor sensível do gás BFG & $\mathrm{kcal} / \mathrm{t}$ de gusa \\
\hline $\mathrm{H}_{04}$ & calor sensível do ferro gusa e da escória & $\mathrm{kcal} / \mathrm{t}$ de gusa \\
\hline $\mathrm{H}_{05}$ & $\begin{array}{l}\text { calor de redução pelo carbono do silício, manganês e } \\
\text { fósforo }\end{array}$ & $\mathrm{kcal} / \mathrm{t}$ de gusa \\
\hline $\mathrm{H}_{06}$ & $\begin{array}{l}\text { calor de decomposição do vapor - presente no ar de } \\
\text { sopro }\end{array}$ & $\mathrm{kcal} / \mathrm{t}$ de gusa \\
\hline $\mathrm{H}_{07}$ & calor de evaporação da água - do coque, minério & $\mathrm{kcal} / \mathrm{t}$ de gusa \\
\hline
\end{tabular}


$\mathrm{H}_{11} \quad$ calor removido pelo sistema de resfriamento carcaça, ventaneiras e cadinho

$\mathrm{H}_{12} \quad$ calor removido por radiação da carcaça

$\mathrm{H}_{13} \quad$ calor cedido pelo ar soprado no anel de vento

$\mathrm{H}_{14} \quad$ variação da entalpia no interior do cadinho do alto

Forno kcal/t de gusa

kcal/t de gusa

kcal/t de gusa

kcal/t de gusa

\section{Subscritos}

$\begin{array}{ll}\text { e ou i } & \text { entrada } \\ \text { s ou o } & \text { saída } \\ 1 & \text { perda } \\ \text { VC } & \text { volume de controle }\end{array}$

\section{LISTA DE SIGLAS}

$\begin{array}{ll}\text { PCI } & \text { pulverized coal injection } \\ \text { PET } & \text { polietileno tereftalato } \\ \text { PEAD } & \text { polietileno de alta densidade } \\ \text { PVC } & \text { policloreto de vinila } \\ \text { PEBD } & \text { polietileno de baixa densidade } \\ \text { PELBD } & \text { polietileno linear de baixa densidade } \\ \text { PP } & \text { polipropileno } \\ \text { PS } & \text { poliestireno }\end{array}$




\section{SUMÁRIO}

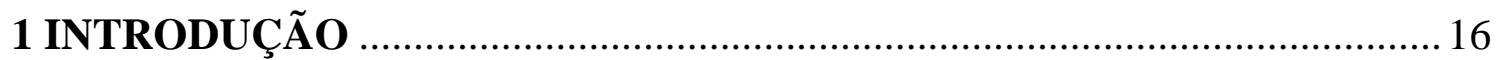

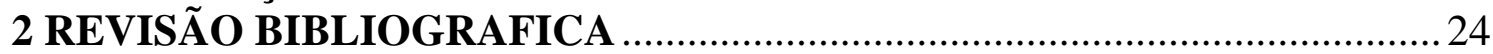

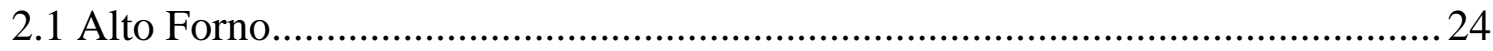

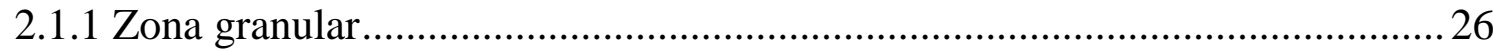

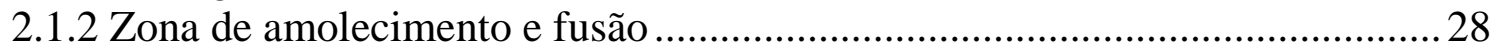

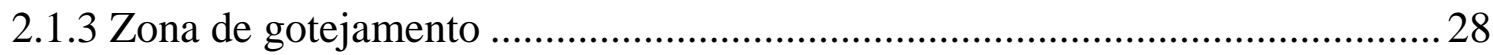

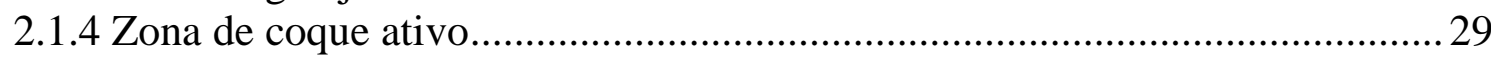

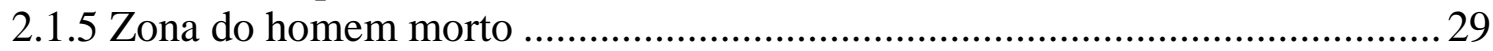

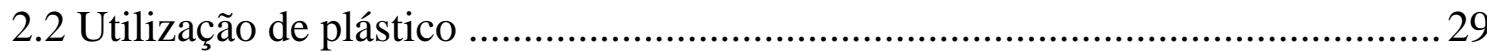

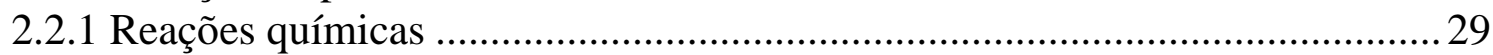

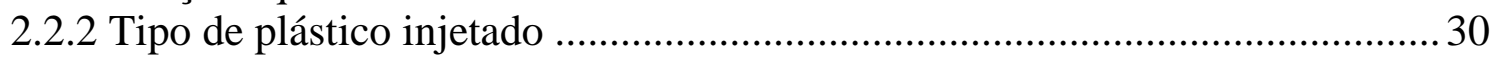

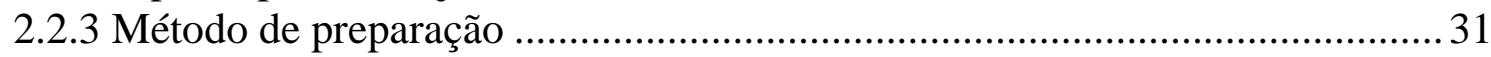

2.2.4 Instalação para preparação e processamento do resíduo …………………….......32

2.2.5 Resultados experimentais da injeção de plástico .............................................. 32

2.2.6 Comportamento da combustão simultânea do carvão quando injetado com

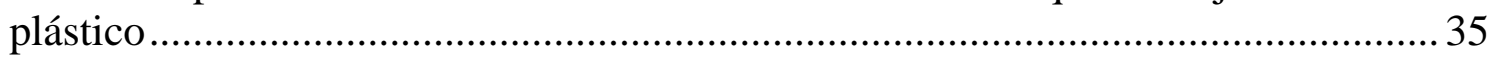

2.2.7 Comportamento do alto forno com a injeção de plástico ..................................... 35

2.2.8 Produção de resíduo de plástico no Brasil.......................................................... 36

2.2.9 Distribuição da produção e reciclagem de plásticos por região no Brasil ....... 38

2.2.10 Preço de resíduo de plástico no Brasil........................................................... 39

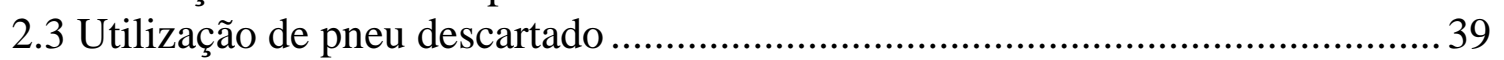

2.3.1 Produção de pneus novos no Brasil................................................................ 43

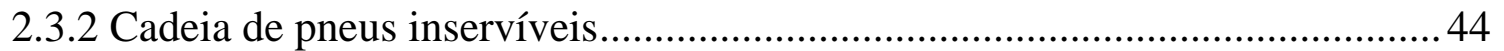

2.3.3 Produção e destino de pneus no Brasil .............................................................. 45

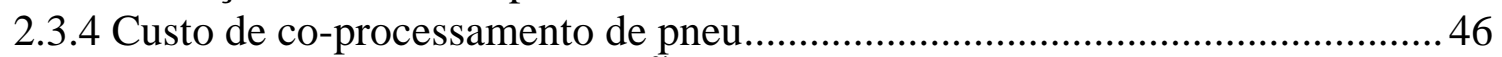

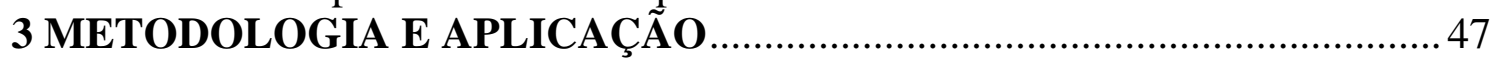

3.1 Características técnicas do Alto Forno 1 …………….......................................4 49

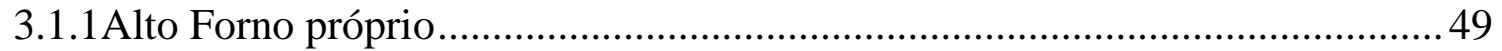

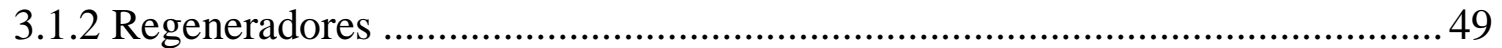

3.1.3 Limpeza de gás ............................................................................................ 49

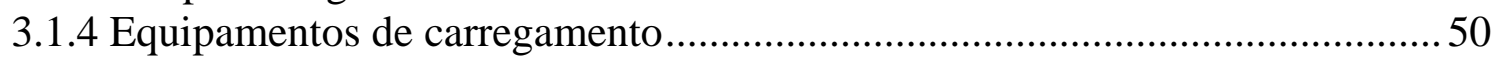

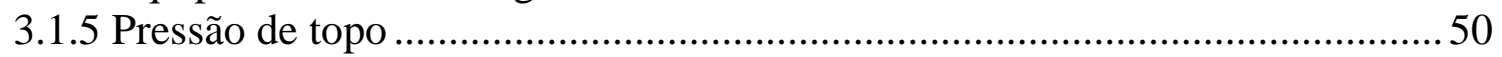

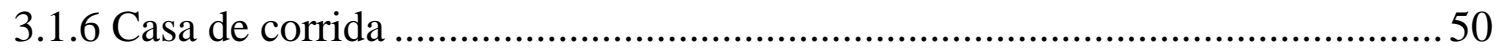

3.1.7 Sistema de injeção de carvão pulverizado....................................................... 51

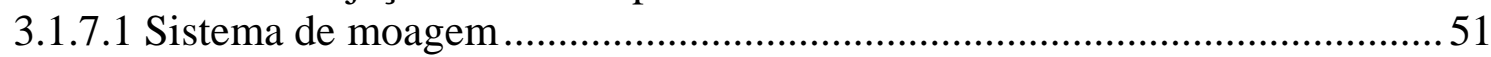

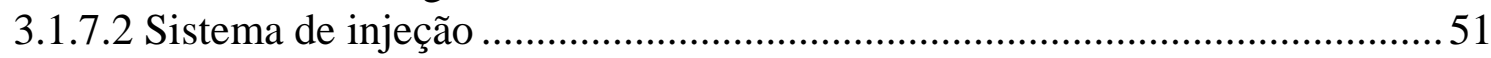

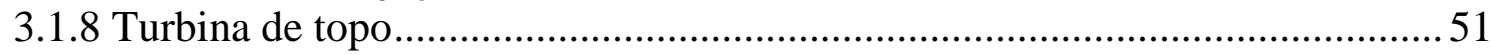

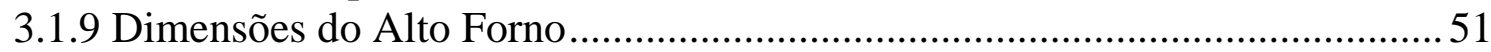

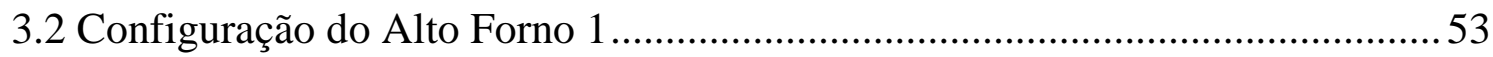


3.2.1 Unidade de carregamento .............................................................................5

3.2.2 PCI -Pulverized Coal Injection - Injeção de carvão pulverizado ....................54

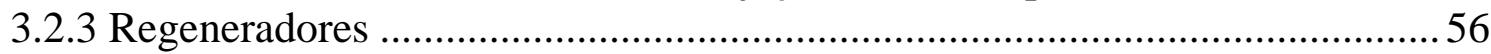

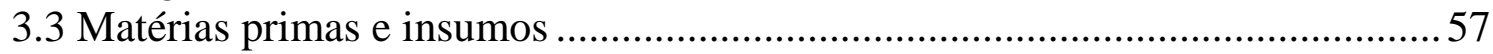

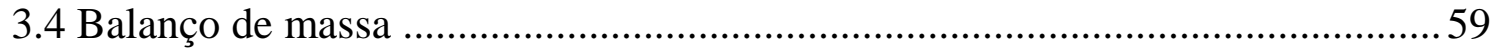

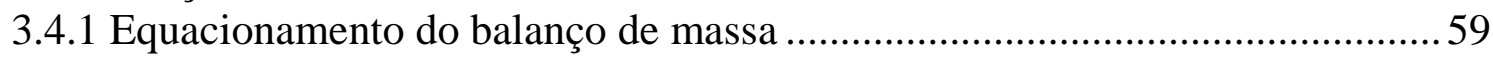

3.4.2 Relação entre a vazão em massa de entrada e de saída .......................................63

3.4.3 Parâmetro de correlação entre a massa de entrada e saída ..................................64

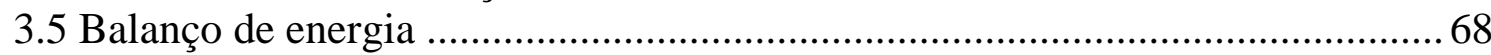

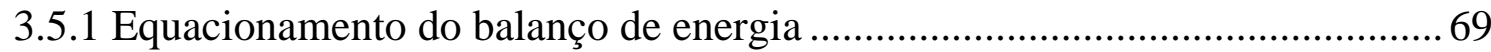

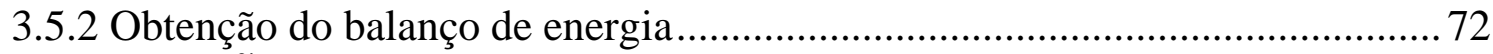

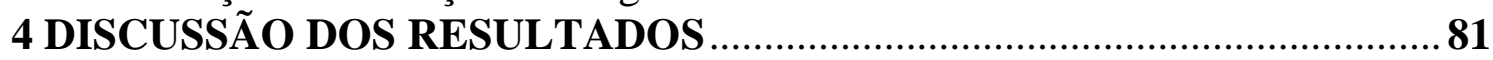

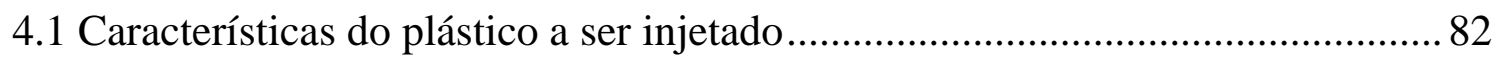

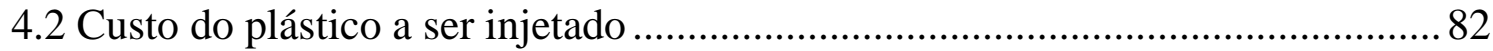

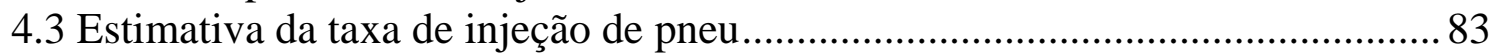

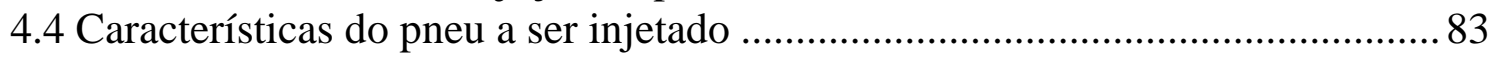

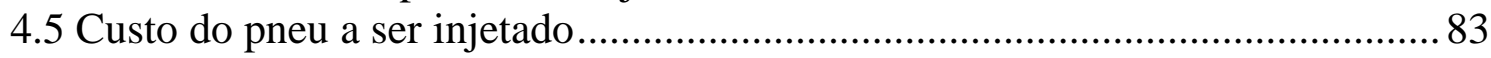

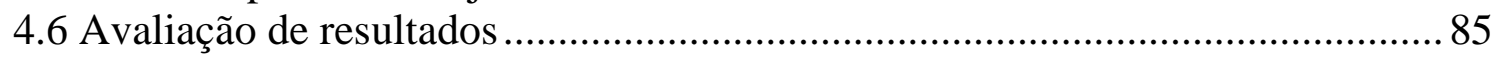

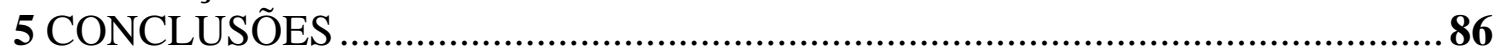

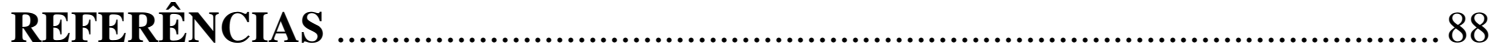

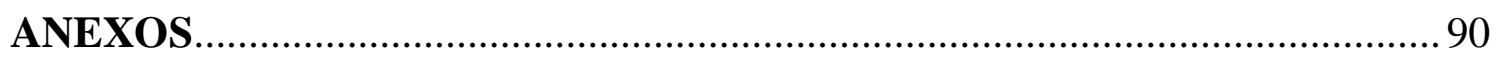




\section{INTRODUÇÃO}

Usinas siderúrgicas integradas são aquelas que possuem todo o ciclo de produção de aço, compreendendo a redução, o refino e a laminação. Produz o aço através do ferro gusa líquido obtido em Alto Forno a partir do minério de ferro com uso de coque ou carvão vegetal como agente redutor. A transformação do ferro gusa em aço (refino) é feita através de fornos a oxigênio.

Usinas siderúrgicas são indústrias de transformação com grande demanda de energia e insumos ao longo de toda a cadeia produtiva, compreendendo desde a matéria prima até o produto acabado final. Em tais unidades de processo, o carvão mineral é responsável pela energia, entregue na forma de coque e de carvão pulverizado, que viabiliza a transformação do minério de ferro em ferro gusa nos Altos Fornos. Além disso, o carvão mineral fornece aos processos de produção que demandam energia térmica um produto combustível, o gás de coque - COG (Coke Oven Gas), que é resultante do processo de coqueificação do carvão nas Coquerias, processo de obtenção do coque.

O uso intensivo de energia no processo siderúrgico vem impondo ao longo do tempo grandes desafios, buscando seu uso racional ou viabilizando novas fontes alternativas de energia, renováveis ou não. A otimização e uso racional do carvão mineral já é uma prática no cenário mundial, caracterizada pela busca contínua em diminuir a dependência exclusiva do carvão mineral. Fontes alternativas de energia, especialmente aquelas provenientes de fontes renováveis, estão sendo investigadas. Fontes provenientes de resíduos gerados pela sociedade ou processos industriais têm presença de destaque nas pesquisas em desenvolvimento. A linha de ação buscada nas pesquisas que tratam deste tema visa prover este tipo de indústria de um material alternativo capaz de realizar o processo como substituto do carvão, reduzir o custo de produção, contribuir e aliar-se na luta pela preservação do planeta.

O carvão mineral pulverizado que é atualmente injetado em Altos Fornos possui, na média, as características descritas na Tabela 1, de forma comparativa com outros materiais com emprego potencial como fonte energética alternativa. 
Tabela 1 - Características dos materiais para injeção

\begin{tabular}{|c|c|c|c|c|c|c|c|c|}
\hline \multirow[t]{2}{*}{ Material } & \multicolumn{7}{|c|}{ Composição \% } & \multirow{2}{*}{$\begin{array}{c}\text { Poder Calorífico } \\
\text { kcal } / \mathrm{kg} \\
(\mathrm{kJ} / \mathrm{kg})\end{array}$} \\
\hline & $\mathrm{C}$ & $\mathrm{H}$ & $\mathrm{S}$ & $\mathrm{Cl}$ & $\mathrm{K}$ & $\mathrm{Na}$ & Cinzas & \\
\hline Carvão & 79,6 & 4,32 & 0,97 & 0,20 & 0,2656 & 0,0816 & 9,03 & $\begin{array}{c}7.760 \\
(1.855)\end{array}$ \\
\hline Plástico & 77,81 & 11,99 & 0,90 & 1,40 & 0,0480 & 0,0920 & 4,90 & $\begin{array}{l}10.382 \\
(2.481)\end{array}$ \\
\hline Pneu & 83,00 & 7,00 & 0,30 & ---- & ------ & ----- & 6,00 & $\begin{array}{c}7.667 \\
(1.832)\end{array}$ \\
\hline
\end{tabular}

Fonte: Lund (1993).

O carvão mineral é injetado no Alto Forno na forma de carvão pulverizado, fornecendo energia e agentes redutores para a transformação do minério de ferro em ferro metálico - ferro gusa. Participa de forma conjunta com o coque no processo de redução do minério de ferro. A utilização do carvão pulverizado visa reduzir custos e aumentar a produtividade do Alto Forno.

O carvão utilizado para injeção é normalmente carvão de baixo custo e que não é adequado para a produção de coque - não coqueificável. Normalmente utiliza-se o antracito.

O antracito é um carvão não coqueificável devido a seu baixo teor de matéria volátil, cerca de 5\% de MV (matéria volátil). Os carvões coqueificáveis estão classificados com teor de matéria volátil entre 22 e $35 \%$ de MV; o médio volátil possui cerca de $22 \%$ de MV e o alto volátil cerca de 35 de MV. (ASSIS, 1993).

O fluxo do processo de preparação do carvão pulverizado é mostrado na Figura 1. 


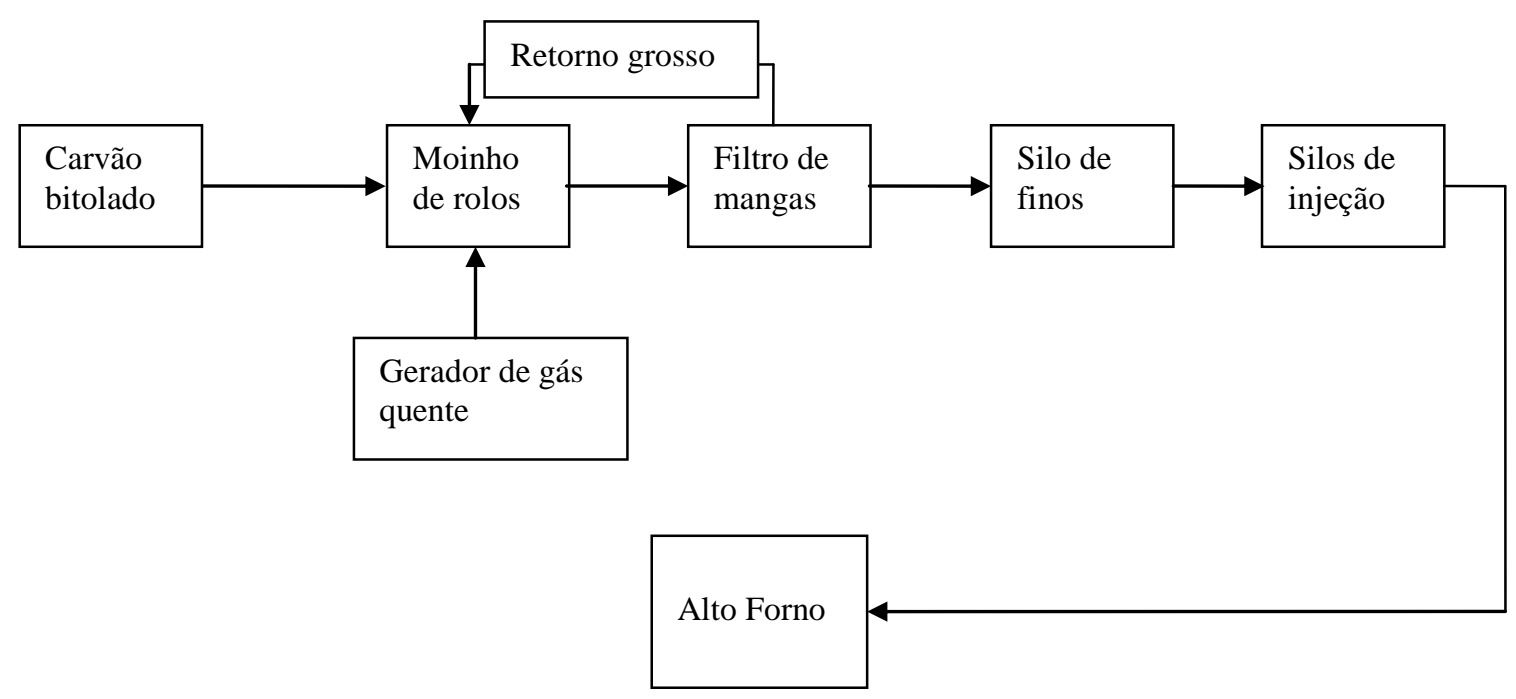

Fonte: ArcelorMittal Tubarão

Figura 1- Fluxo de preparação do carvão pulverizado

Após o processo de preparação, o carvão pulverizado é injetado de forma contínua no Alto Forno através de um fluxo gasoso de nitrogênio, que através de lanças instaladas nas ventaneiras do Alto Forno promovem a injeção do carvão pulverizado diretamente na zona de combustão do Alto Forno, conforme mostra a Figura 2.

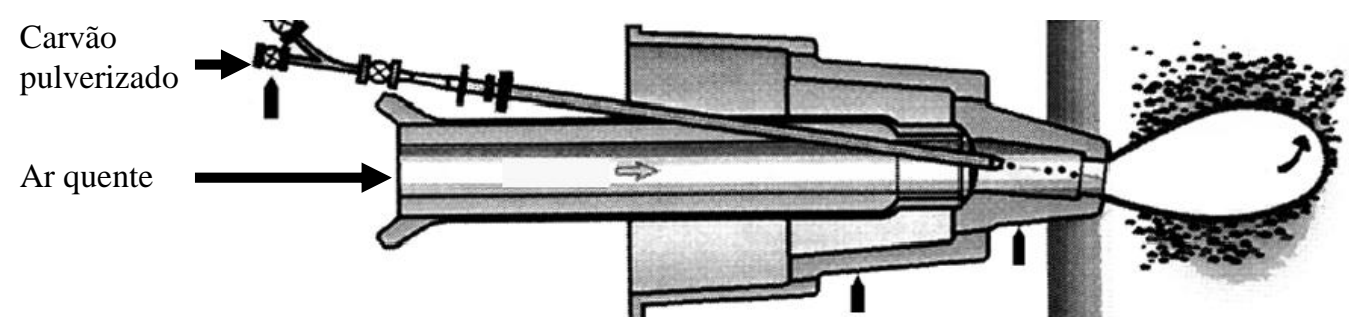

Fonte: OGAKI et al, 2001.

Figura 2 - Injeção de carvão pulverizado através das ventaneiras

O carvão pulverizado, ao ser injetado na região de combustão do Alto Forno, reage com o oxigênio do sopro, formando dióxido de carbono: $\mathrm{C}+\mathrm{O}_{2}=\mathrm{CO}_{2}$. À medida que o fluxo gasoso segue seu fluxo ascendente, conforme mostra a Figura 3, o dióxido de carbono reage com o 
carbono do coque formando o monóxido de carbono: $\mathrm{CO}_{2}+\mathrm{C}=2 \mathrm{CO}$. Das reações acima resulta a reação: $2 \mathrm{C}+\mathrm{O}_{2}=2 \mathrm{CO}$.

Como o ar soprado contém umidade, na presença do carbono do carvão, ocorre a seguinte reação: $\mathrm{C}+\mathrm{H}_{2} \mathrm{O}=\mathrm{CO}+\mathrm{H}_{2}$. Nesta etapa, o monóxido de carbono reage com o minério de ferro gerando o ferro metálico: $3 \mathrm{CO}+\mathrm{Fe}_{2} \mathrm{O}_{3}=2 \mathrm{Fe}+3 \mathrm{CO}_{2}$. O processo ocorre de forma contínua, sendo que as reações ocorrem à medida que o fluxo gasoso permeia toda a carga no interior do Alto forno e as regiões são estabelecidas em função da etapa em que o processo ocorre, bem como suas reações químicas e térmicas.

O perfil destas regiões térmicas está mostrado na Figura 4 e o perfil das regiões com as reações químicas está mostrado na Figura 5. Todo este processo resulta na obtenção de gusa líquido, escória líquida e gás de Alto Forno. O ferro gusa obtido neste processo é a matéria prima para a obtenção do aço, numa cadeia de processo conforme ilustra a Figura 6. Este é o contexto de um Alto Forno no complexo de uma usina siderúrgica integrada.

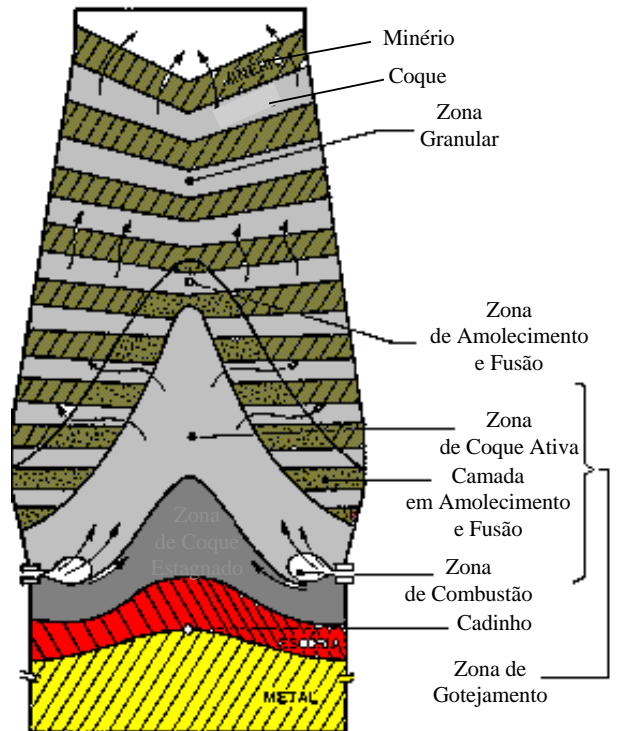

Fonte: www.ufpa.br/getsolda/docs_posGrad/IEMAulaAco.ppt Acesso em 02/03/2009

Figura 3 - Fluxo gasoso ascendente no interior do Alto Forno 


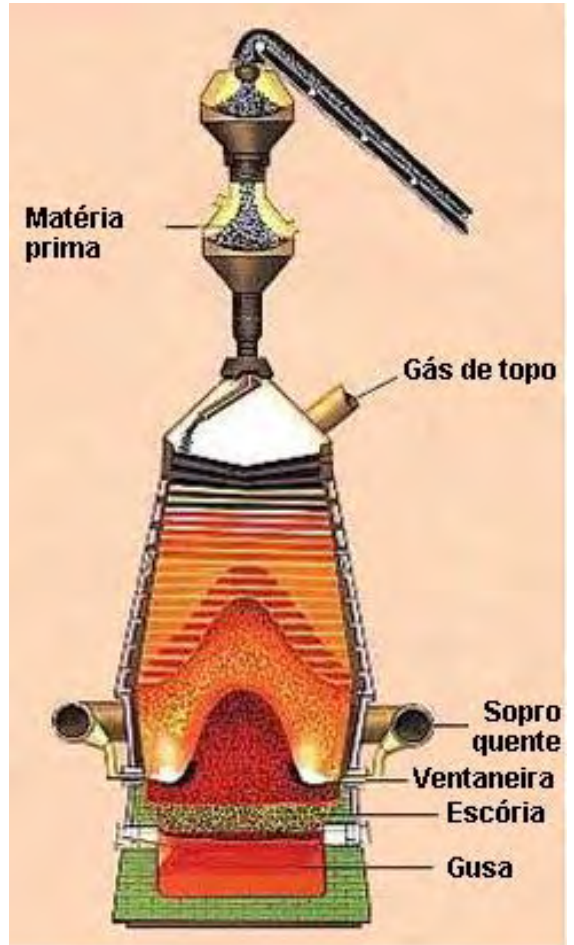

Fonte: www.ufpa.br/getsolda/docs_posGrad/IEMAulaAco.ppt

Acesso em 02/03/2009

Figura 4 - Perfil térmico das regiões internas do Alto Forno

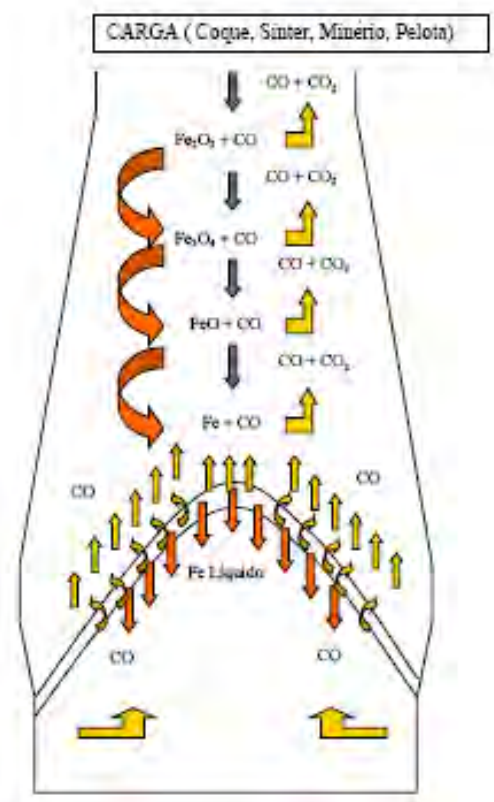

Fonte: Silva (2006)

Figura 5 - Perfil das reações químicas no interior do Alto Forno 


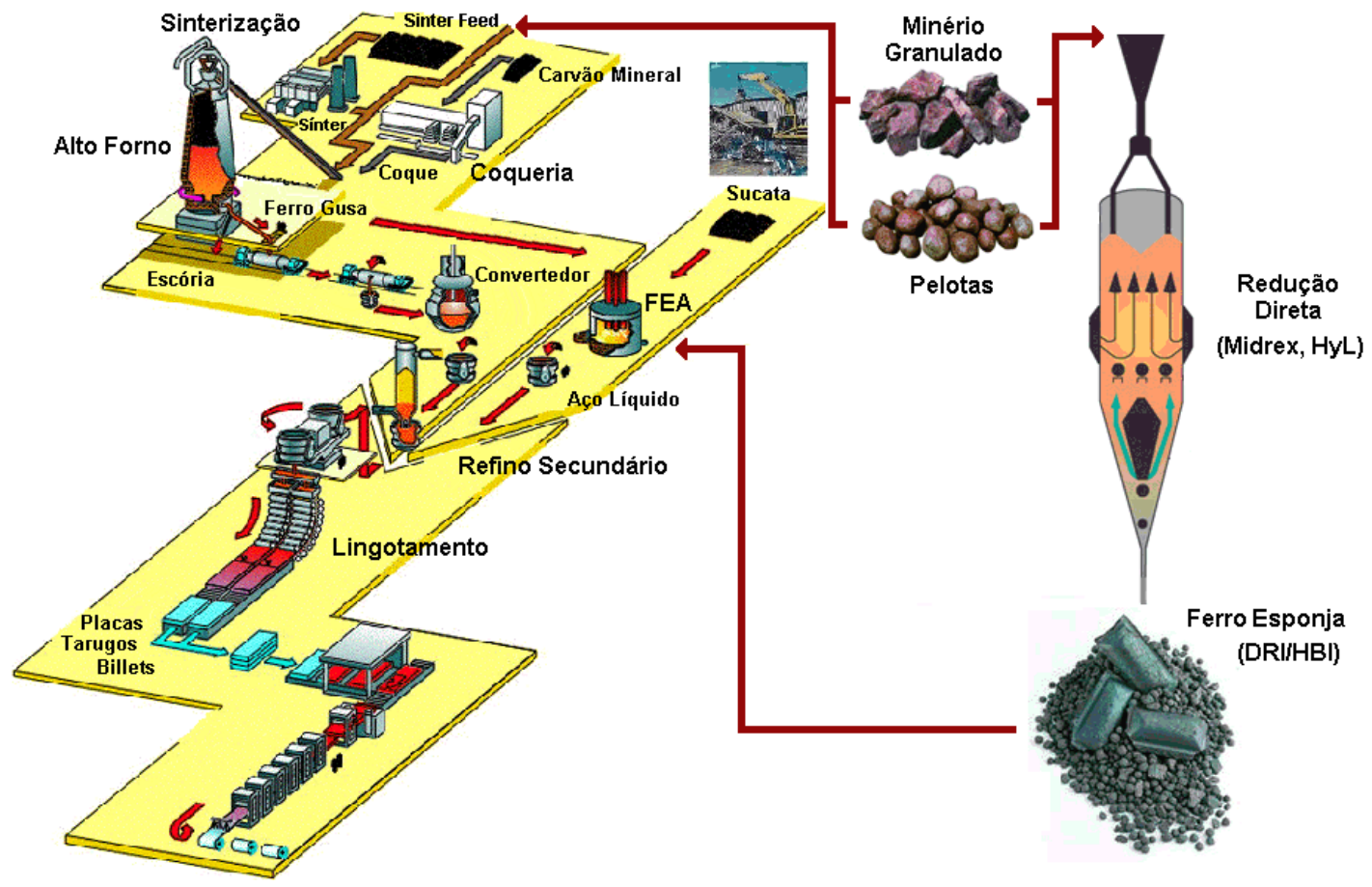

Fonte: www.ufpa.br/getsolda/docs_posGrad/IEMAulaAco.ppt Acesso em 02/03/2009

Figura 6 - Fluxo do processo de produção do aço

Os materiais alternativos a serem injetados nas ventaneiras devem ser capazes de fornecer condição de reação química equivalente à mostrada para o carvão mineral, ou seja, ser boa fonte de carbono. Outra característica importante é a de promover aporte térmico equivalente e viável do ponto de vista econômico e financeiro. A concepção proposta para o presente trabalho será, portanto, de procurar aliar a oportunidade do uso de cada material e o conseqüente impacto decorrente de seu uso.

Dentro deste contexto, apresentam-se algumas informações acerca da empresa que será objeto de investigação; a ArcelorMittal Tubarão é uma usina integrada a carvão mineral, ou seja, sua matriz energética é fundamentada na utilização do carvão mineral, localizada em Jardim Limoeiro - Serra - Espírito Santo - Brasil. Esta empresa pertence ao grupo ArcelorMittal e produz aços planos na forma de bobinas a quente e placas semi-acabadas. Sua capacidade nominal de produção é de 7,5 Mt/a.

A ArcelorMittal Tubarão possui três Altos Fornos, sendo que o presente trabalho deverá considerar em seu desenvolvimento apenas análises referentes ao Alto Forno 1. O Alto Forno 1 
foi construído na fase de implantação da usina, tendo iniciado sua produção (blow in) em 1983 e desde então opera de forma ininterrupta - ou seja, sem reforma.

A carga do Alto Forno 1 é composta de sínter, pelota, minério de ferro, coque, fundentes e carvão pulverizado. A capacidade nominal de produção do Alto Forno 1 é de 10.000 t /dia de gusa líquido. As ventaneiras estão distribuídas uniformemente ao longo do perímetro do Alto Forno localizado na região do anel de vento; no caso do Alto Forno 1 da ArcelorMittal Tubarão, são 38 ventaneiras, cuja função principal é fornecer ar quente ao Alto Forno, suprindo assim a demanda de oxigênio para a reação química de redução do minério de ferro.

Este trabalho analisa a utilização de resíduos industriais, municipais ou agrícolas como fonte energética para Alto Forno siderúrgico. Será analisada a aplicação de resíduos de plástico e pneus usados e inservíveis. A viabilização do uso destes materiais alternativos promoveria a preservação de um recurso natural - o carvão mineral - ao mesmo tempo em que dá destinação nobre e adequada aos resíduos que, na falta desta alternativa, são com freqüência depositados nos lixões das cidades ou armazenados a céu aberto e sem controle.

A análise do emprego de materiais alternativos no Alto Forno 1 da ArcelorMittal Tubarão pretende estabelecer uma taxa de substituição de cada material analisado, plástico, pneu e madeira em relação ao carvão mineral pulverizado. A taxa de utilização do plástico e pneu será avaliada considerando o aporte de energia e de agentes da reação química necessários para a redução do minério de ferro em ferro metálico. A participação de cada material será avaliada de forma a contribuir como uma parcela na redução da utilização do carvão mineral e não de sua substituição.

Serão preservadas as devidas restrições técnicas e econômicas que cada material vier a requerer. A linha de ação buscada neste trabalho é de contribuir fornecendo base para futuras decisões de aplicação em escalas piloto ou de produção de acordo com a viabilidade de cada planta. Serão avaliadas questões como um todo envolvendo o uso destes materiais, como viabilidade técnica, disponibilidade de cada material e custos. 
Os objetivos do presente trabalho estão baseados em:

a) Identificar a viabilidade técnica de uso de cada material (requisito de cada material, forma de utilização, comportamento nas reações químicas, avaliação do balanço de massa e de energia);

b) Estabelecer a taxa de injeção de cada material;

c) Avaliar o impacto no processo de produção de ferro gusa, com a entrada de novo material na matriz de matéria prima, incluindo a avaliação da confiabilidade de seu fornecimento (fontes, demandas, consumo, aplicação, qualidade, custos);

d) Avaliar custos e benefícios da utilização destes materiais. 


\section{REVISÃO BIBLIOGRÁFICA}

\section{1- Alto Forno}

O Alto Forno é um reator químico vertical onde as reações de transformação do minério de ferro ocorrem em contra-corrente com carga metálica descendente, que é carregada no topo com os gases ascendentes que são gerados na região das ventaneiras. Estes gases são gerados na zona de combustão através da injeção de ar quente e combustíveis. A função do Alto Forno é de produzir ferro metálico na fase líquida a partir do minério de ferro in natura.

O ferro metálico, também conhecido como ferro gusa ou simplesmente gusa, possui composição química que varia em função da composição de cada material carregado bem como de suas percentagens na composição da carga. O gusa possui a seguinte composição química média, segundo referência tomada da ArcelorMittal Tubarão, análise média de julho de 2009:

Ferro $=94 \%$

Carbono $=4,9 \%$

Silício $=0,3 \%$

Manganês $=0,45 \%$

Fósforo $=0,077 \%$

Enxofre $=0,023 \%$

O corpo do Alto forno é dividido em regiões basicamente em função da cinética das reações químicas e das temperaturas envolvidas. O Alto Forno e suas zonas internas são mostrados na Figura 7. Na região de combustão onde estão localizadas as ventaneiras, a temperatura em geral é superior a $2.000{ }^{\circ} \mathrm{C}$. Na base inferior do Alto Forno, na região do cadinho a temperatura está em torno de $1500{ }^{\circ} \mathrm{C}$. Este gradiente torna-se mais acentuado nas regiões próximas ao topo, e no ponto próximo ao carregamento da matéria prima, a temperatura está em torno de $200{ }^{\circ} \mathrm{C}$. As regiões do Alto Forno são conhecidas e distribuídas conforme mostra a Figura 7. 


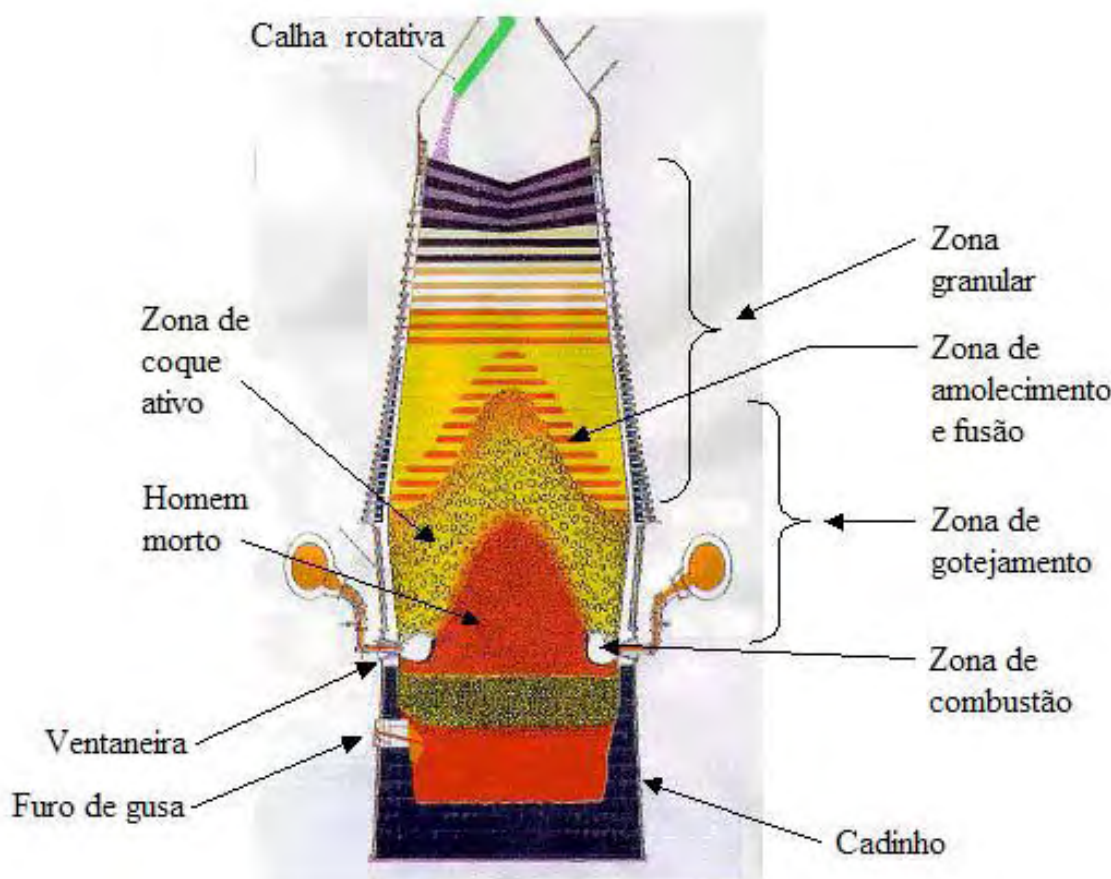

Fonte: Noblat (2006) apud Silva (2006) ${ }^{1}$

Figura 7 - Zonas internas do Alto Forno

A carga do Alto Forno é formada por coque, que é fonte de energia e carbono; sínter, coque, pelota, minério bitolado, que é fonte de ferro; fundentes (calcário, dolomita), que são fontes de elementos para a correção da viscosidade, volume e temperatura da escória. Tais materiais são carregados em camadas sucessivas e alternadas através do equipamento de carregamento e distribuição de carga no topo do Alto Forno. A partir da matéria prima carregada, os seguintes produtos são gerados:

- Gusa líquido: extraído através dos furos de gusa que estão localizados na região do cadinho conforme mostra a Figura 7; é um produto com densidade de $7.800 \mathrm{~kg} / \mathrm{m}^{3}$.

- Escória: extraída através dos canais de escória provenientes também dos furos de gusa conforme mostra a Figura 7. A escória é separada do gusa líquido por diferença de densidade; sua densidade é de $2.500 \mathrm{~kg} / \mathrm{m}^{3}$;

O gusa segue para o carregamento do carro torpedo e a escória para o granulador de escória.

\footnotetext{
${ }^{1}$ NOBLAT, J.X. Curso de alto forno. Apud: SILVA, A.M. Estudo da Combustão dos Carvões e Misturas com Coque Verde de Petróleo Injetadas em Altos Fornos. Dissertação (Mestrado em Engenharia Mecânica). Guaratinguetá, Universidade Estadual Paulista, 2006.
} 
Além destes dois produtos, é importante destacar a Produção do gás de Alto Forno, que é um gás combustível pobre, extraído no topo e conduzido para o sistema de limpeza de gases e posteriormente à distribuição interna na usina para uso como combustível. Sua composição média de referência é apresentada na Tabela 2, de acordo com valores obtidos em ArcelorMittal Tubarão (Julho de 2009).

Tabela 2 - Composição média do gás de Alto Forno da ArcelorMittal Tubarão

\begin{tabular}{|c|c|c|c|c|}
\hline $\mathrm{N}_{2}$ & $\mathrm{CO}_{2}$ & $\mathrm{CO}$ & $\mathrm{H}_{2}$ & $\mathrm{CH}_{4}$ \\
\hline $49,04 \%$ & $22,17 \%$ & $22,86 \%$ & $4,11 \%$ & $1,98 \%$ \\
\hline
\end{tabular}

\subsection{1 - Zona Granular}

É a região mais elevada do Alto Forno. Nela, os materiais carregados através do topo ainda estão no seu estado sólido. É a região definida entre a última camada de material carregada até a região onde ocorre o início do amolecimento da carga metálica. Nesta região, a temperatura varia entre $120^{\circ} \mathrm{C}$ na região de carregamento e $1100^{\circ} \mathrm{C}$ no início de amolecimento.

Ao serem carregados, os materiais estão próximos da temperatura ambiente em torno de $30^{\circ} \mathrm{C}$ e, à medida que entram em contato com o ambiente de temperatura em elevação, iniciam-se as transformações e reações segundo Noblat (2006) apud Silva.

A dinâmica das reações é apresentada na Figura 8. 


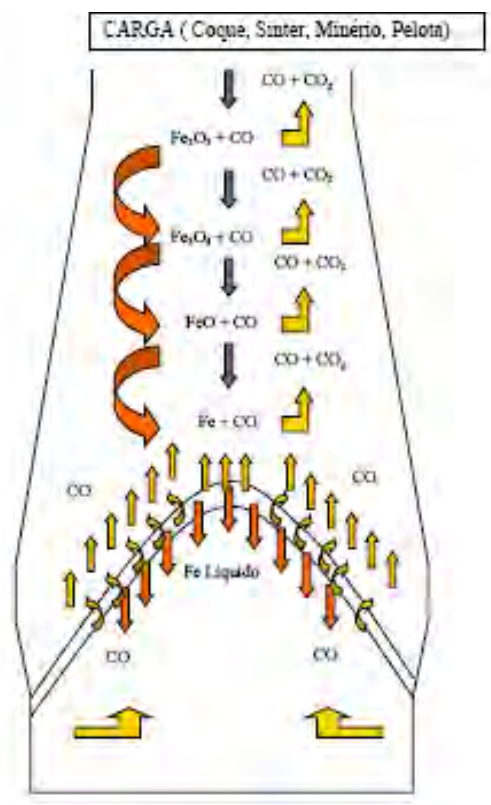

Fonte: Silva (2006)

Figura 8 - Perfil das reações químicas no interior do Alto Forno

a) Evaporação da água contida na carga metálica, coque e fundentes, devido aos gases oriundos da região inferior do forno conforme equação de vaporização

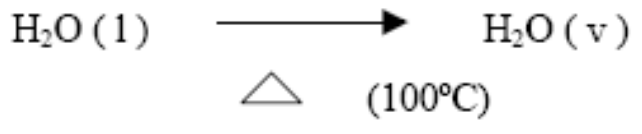

b) Calcinação dos fundentes (calcário e dolomita) por ação da temperatura dos gases. A calcinação ocorre pela perda de $\mathrm{CO}_{2}$ através do aquecimento na reação expressa a seguir.

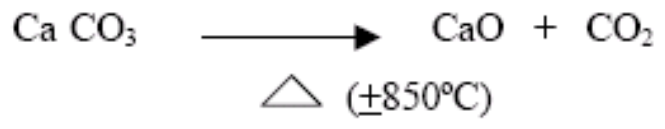

c) Redução dos óxidos metálicos presentes no sínter, pelota, minério bitolado através da ação do monóxido de carbono (CO). Nesta região ocorre uma reação de redução indireta; tal reação ocorre pela ação do $\mathrm{CO}$ ascendente em contracorrente com a carga metálica descendente, conforme reações em cadeia descritas na seqüência. 
$\begin{array}{lll}3 \mathrm{Fe}_{2} \mathrm{O}_{3}(\mathrm{~s})+\mathrm{CO}(\mathrm{g}) & = & 2 \mathrm{Fe}_{3} \mathrm{O}_{4}(\mathrm{~s})+\mathrm{CO}_{2}(\mathrm{~g}) \\ \mathrm{Fe}_{3} \mathrm{O}_{4}(\mathrm{~s})+\mathrm{CO}(\mathrm{g}) & = & 3 \mathrm{FeO}(\mathrm{s})+\mathrm{CO}_{2}(\mathrm{~g}) \\ \mathrm{FeO}(\mathrm{s})+\mathrm{CO}(\mathrm{g}) & = & \mathrm{Fe}(\mathrm{s})+\mathrm{CO}_{2}(\mathrm{~g})\end{array}$

Quando o óxido de ferro é reduzido pelo monóxido de carbono, diz-se que ocorre a reação indireta pela reação descrita em (1).

$\mathrm{FeO}(\mathrm{s})+\mathrm{CO}(\mathrm{g})=\mathrm{Fe}(\mathrm{s})+\mathrm{CO}_{2(\mathrm{~g})}$

Quando o óxido de ferro é reduzido pelo carbono, denominamos que ocorre a reação direta pela reação descrita em (2).

$\mathrm{FeO}(\mathrm{s})+\mathrm{C}(\mathrm{s})=\mathrm{Fe}(\mathrm{s})+\mathrm{CO}(\mathrm{g})$

\subsection{2 - Zona de Amolecimento e Fusão}

É a região localizada abaixo da região granular, compreende o início de amolecimento até o final da fusão da carga metálica. Nesta fase os materiais metálicos se apresentam no estado pastoso.

\subsection{3 - Zona de Gotejamento}

É a região entre a zona de amolecimento e fusão e a região das ventaneiras. Nesta região ocorrem os seguintes fenômenos (SILVA, 2006):

- Os materiais já fundidos gotejam para o cadinho;

- Ocorrem as reações de incorporação dos elementos não ferríticos: silício, manganês, fósforo, carbono e enxofre no ferro gusa;

- Ocorre a maior parte da dessulfuração do ferro gusa;

- O coque no estado sólido é parcialmente consumido pelo dióxido de carbono na reação "solution loss ou bourduard"; $\left(\mathrm{C}_{(\mathrm{s})}+\mathrm{CO}_{2(\mathrm{~g})}=2 \mathrm{CO}_{(\mathrm{g})}\right)$. 


\subsection{4 - Zona de Coque Ativo}

É a região localizada dentro da zona de gotejamento. Esta é a região onde ocorre a reação do monóxido de carbono - $\mathrm{CO}$ com o carbono presente no coque incandescente.

\subsection{5 - Zona do Homem Morto}

É a região abaixo da zona de coque ativo. Esta é a região onde o coque incandescente está misturado com o ferro gusa líquido e a escória. Este composto possui a característica de alta densidade e baixa fluidez. $\mathrm{O}$ volume de material nesta região varia em função da reserva térmica do Alto Forno: se for grande, há acúmulo de coque e está região cresce; se for pequena o coque é consumido e a região decresce.

\section{2 - UTILIZAÇÃO DE PLÁSTICO}

\subsection{1- Reações Químicas}

A reciclagem de plásticos proveniente de embalagens descartadas para uso em Alto Forno foi pesquisada por Ogaki et al. (2001), através da injeção nas ventaneiras do Alto Forno número 1 da empresa japonesa NKK cuja produção de gusa é de 10.000 t/dia. O trabalho desenvolvido estabeleceu a injeção de plástico através das ventaneiras, porém manteve a injeção de carvão pulverizado. Neste caso, o plástico promoveu uma taxa de injeção de substituição do carvão.

O carvão e o plástico são completamente gaseificados na região das ventaneiras. As reações químicas com esta injeção de carvão com plástico são:

- $\mathrm{C}+\mathrm{O}_{2}=\mathrm{CO}_{2}$, reação decorrente do oxigênio com o carvão pulverizado e parte do coque incandescente na região de combustão.

- $\mathrm{C}+\mathrm{CO}_{2}=2 \mathrm{CO}$, reação decorrente da ação do dióxido de carbono no coque.

- $1 / 2 \mathrm{C}_{2} \mathrm{H}_{4}+\mathrm{CO}_{2}=2 \mathrm{CO}+\mathrm{H}_{2}$, reação decorrente do plástico, neste caso o polietileno. 
$\mathrm{O} \mathrm{CO}$ e $\mathrm{o}_{2}$ gerados permeiam de forma ascendente toda a carga do forno e ocorrem as reações com o minério de ferro, resultando na formação do ferro metálico. No caso de somente carvão pulverizado e coque, obtém-se a reação descrita em (3)

- $\mathrm{Fe}_{2} \mathrm{O}_{3}+3 \mathrm{CO}=2 \mathrm{Fe}+3 \mathrm{CO}_{2}$

No caso de plástico, ocorre a reação descrita em (4).

- $\mathrm{Fe}_{2} \mathrm{O}_{3}+2 \mathrm{CO}+\mathrm{H}_{2}=2 \mathrm{Fe}+2 \mathrm{CO}_{2}+\mathrm{H}_{2} \mathrm{O}$

Com o uso do plástico, fornecendo a participação do hidrogênio na reação de redução do minério de ferro, a quantidade de $\mathrm{CO}_{2}$ gerado foi reduzida em $1 / 3$ em comparação com o uso somente do carvão pulverizado e coque.

\subsection{2- Tipo de plástico injetado}

Conforme Ogaki et al. (2001), deve ser minimizada a participação do uso de plásticos que contêm PVC devido a formação do ácido clorídrico $(\mathrm{HCl})$, que pode tornar corrosivo o gás gerado no Alto Forno, o BFG (Blast Furnace Gas), e pode ocorrer a corrosão ácida na instalação de tratamento do gás, bem como em tubulações e queimadores nas plantas onde o gás é queimado como combustível. Não houve a comprovação da presença de dioxinas e furanos no gás de Alto Forno - BFG. Em relação à forma do resíduo de plástico, podem ser utilizados:

- Resíduos sólidos: bombonas, garrafas, potes, caixas, resíduos de fabricação de embalagens, peças e componentes plásticos, embalagens e vasilhames em geral.

- Resíduos em filmes: sacolas, folhas e lâminas de embalagens em geral.

Cada tipo de resíduo tem uma preparação e processamento particular para viabilizar sua injeção no Alto Forno. 


\subsection{3- Método de preparação}

Para os resíduos em filmes, após a separação do resíduo sólido são aquecidos e transformados em pelotas, ou seja, são pelotizados; para os resíduos sólidos, após a separação do resíduo em filmes, são moídos/triturados. A Figura 9 ilustra tal procedimento. As duas formas de processamento são distintas e podem operar simultaneamente ou de forma independente conforme disponibilidade de matéria prima ou das linhas de processamento.

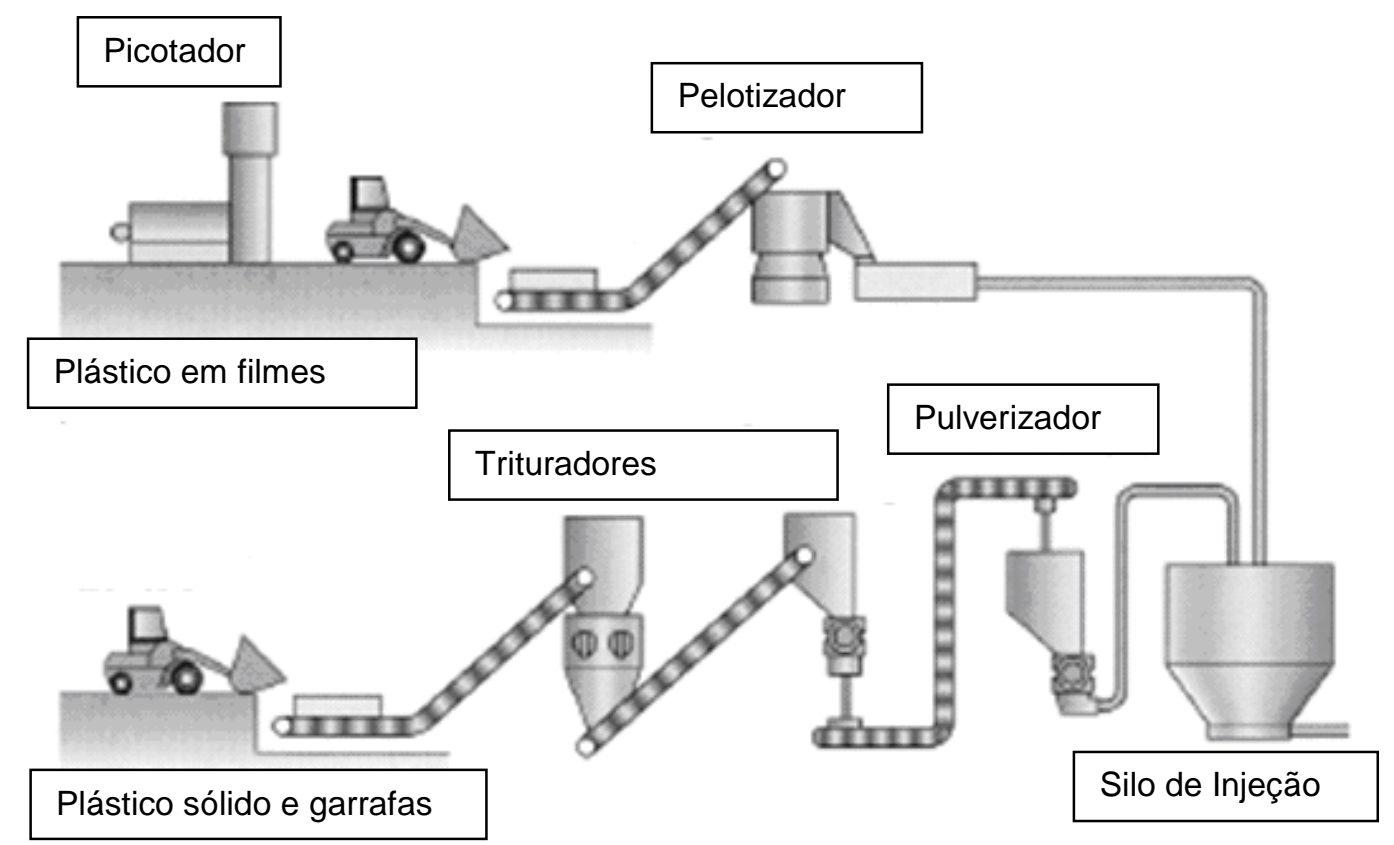

Fonte: Ogaki et al. (2001)

Figura 9- Instalação típica para preparação do resíduo de plástico para injeção no Alto Forno.

Tanto os resíduos sólidos quanto os resíduos em filmes são originados de descarte nas indústrias de fabricação e beneficiamento de produtos plásticos, bem como da Produção de resíduos no comércio e na comunidade municipal em geral. Não há restrição quanto ao estado físico, apresentação ou limpeza do resíduo, isto é, todo resíduo é adequado para este uso. Resíduos de alimentos ou material particulado são toleráveis. 


\subsection{4- Instalação para preparação e processamento do resíduo}

É necessária a instalação de uma unidade de processamento que atenda aos requisitos de preparação e processamento do resíduo de plástico conforme mostra a Figura 9. O dimensionamento da instalação será com base na capacidade de processamento estabelecida bem como da forma de recebimento da matéria prima in natura. A forma sugerida é de receber os resíduos na forma compactada, embalados e prensados em volumes de aproximadamente $1,0 \mathrm{~m}^{3}$ para facilitar o manuseio, transporte e a armazenagem.

\subsection{5- Resultados experimentais da injeção de plástico}

Conforme Asanuma et al. (2000), foi realizado o teste de injeção de plástico no Alto Forno 1 da empresa japonesa NKK. A injeção experimental foi realizada em 5 das 40 ventaneiras. Neste teste foi injetado:

- Plástico triturado = tamanho de partícula de 0,2 a $1,0 \mathrm{~mm}$ e $10,0 \mathrm{~mm}$

- Plástico aglomerado = tamanho de partícula de $10,0 \mathrm{~mm}$

A investigação da queima do plástico em comparação com o carvão pulverizado foi realizada através da captura de imagens através das ventaneiras e com câmera de alta velocidade/resolução. Analisando as imagens pode ser verificada a combustibilidade - grau de facilidade de realizar a combustão - de cada material tomando-se como referência as áreas de domínio da chama, conforme Figura 10. A relação de áreas A/B indica que, quanto maior for esta relação, maior é a combustibilidade do material.

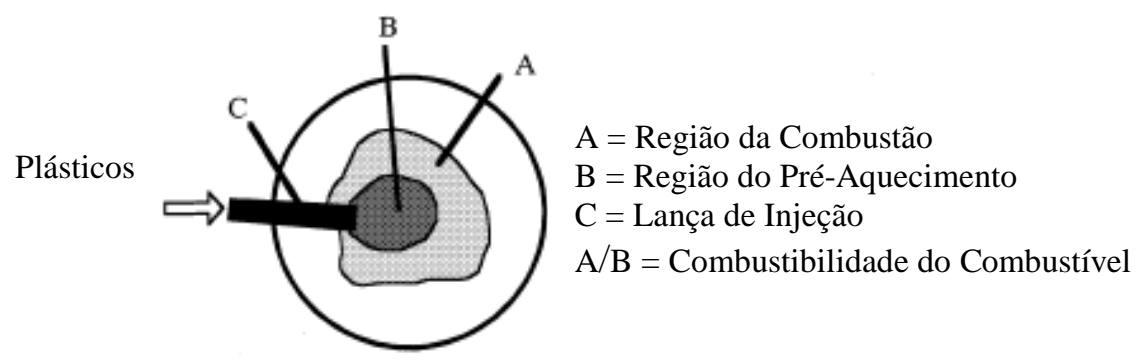

Fonte: Asanuma et al. (2000)

Figura 10 - Método de análise da flutuação da chama 
Com base em tal conceito, o resultado das imagens capturadas através das ventaneiras para os diferentes tipos de fontes de energia é apresentado na Figura 11. Comparativamente para plásticos com $10 \mathrm{~mm}$ (triturado), plásticos com $10 \mathrm{~mm}$ (aglomerado), plásticos com 0,2 a 1,0 mm (triturado), em relação ao carvão pulverizado, o plástico com partícula de 0,2 a 1,0 mm possui a combustibilidade menor que o carvão pulverizado; porém, é o que mais se aproxima deste, conforme Figura 12.

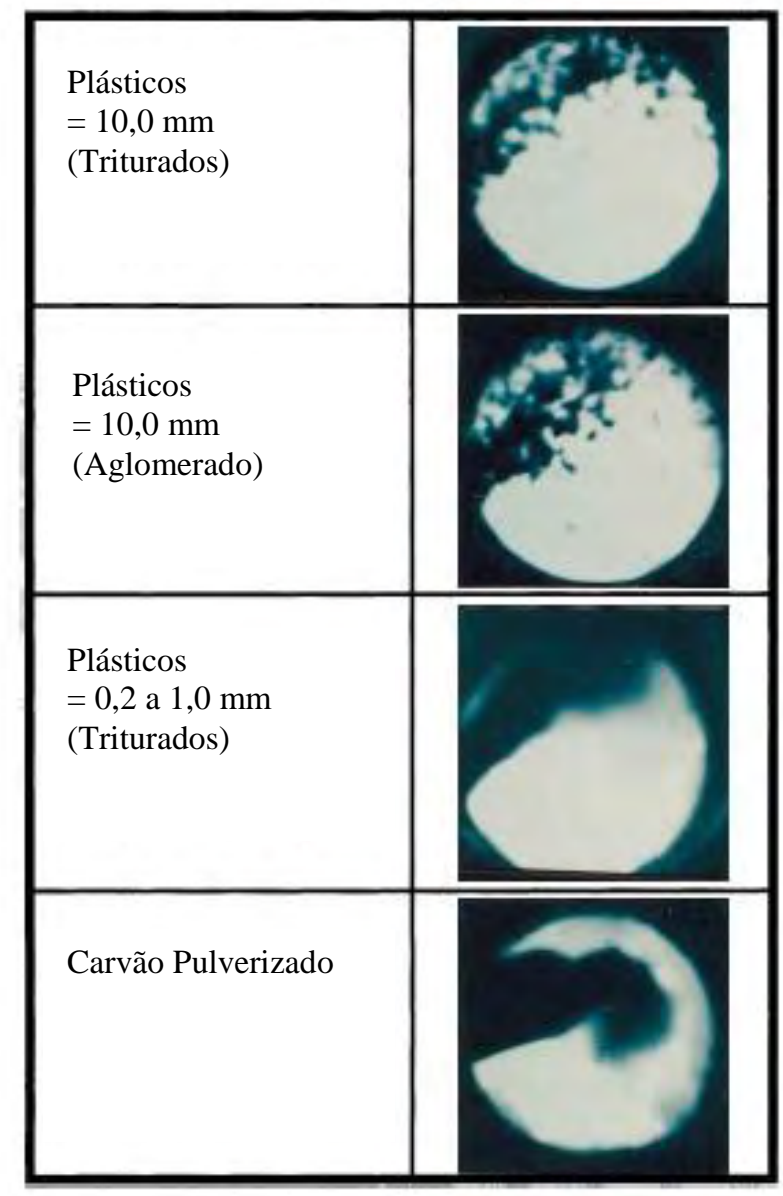

Fonte: Asanuma et al. (2000)

Figura 11 - Imagens da combustão de plástico e carvão nas ventaneiras 


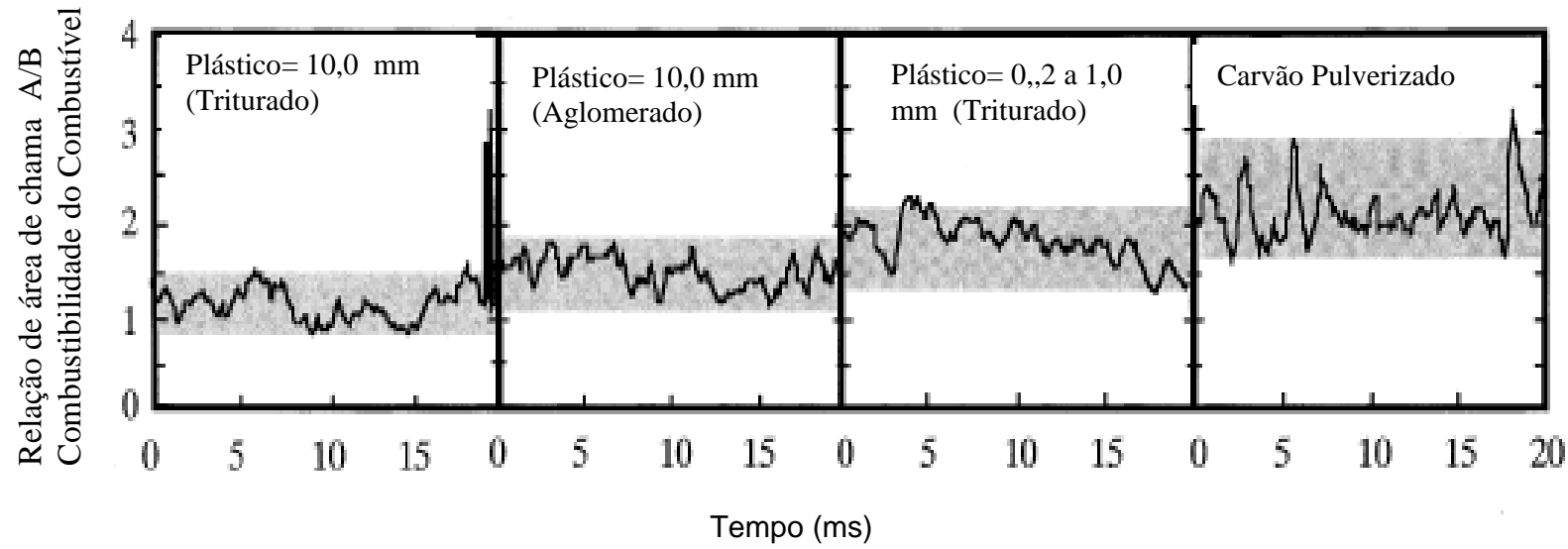

Fonte: Asanuma et al. (2000)

Figura 12 - Efeito da injeção na flutuação de chama

Os resultados obtidos no teste sugerem que a região de combustão e gaseificação do plástico varia em função do tamanho da partícula, influenciando assim a região afetada pelo fluxo dos gases, conforme ilustra a Figura 13.

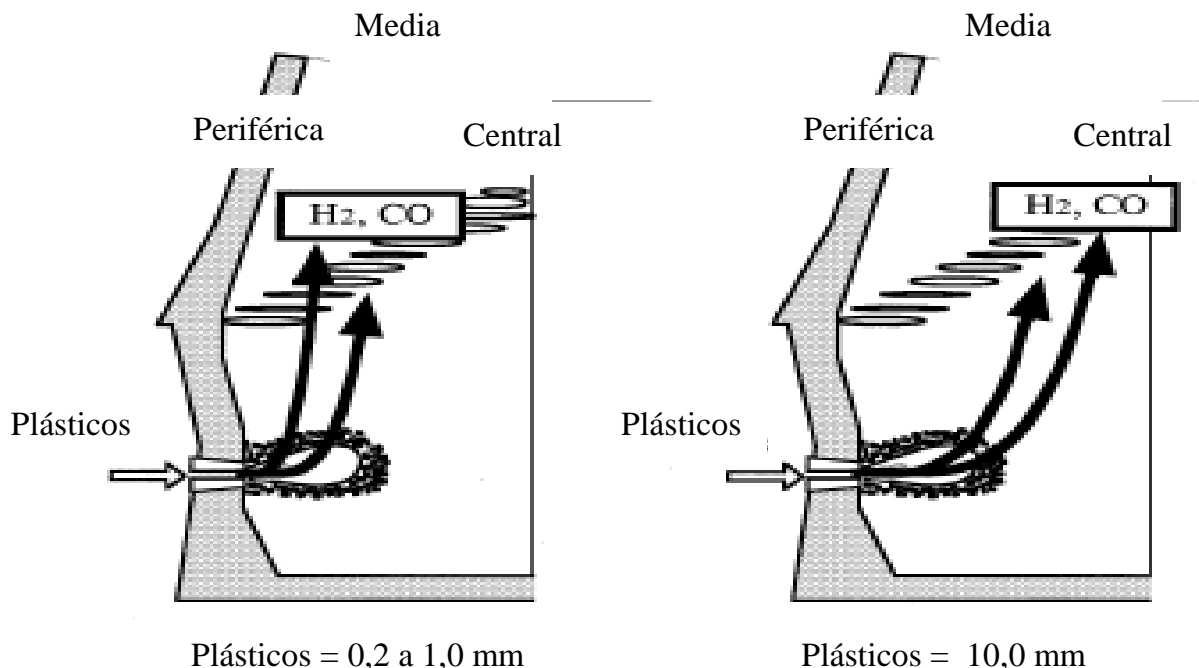

Fonte: Asanuma et al. (2000)

Figura 13 - Região do fluxo de gases em função do tamanho da partícula 


\subsection{6- Comportamento da combustão simultânea do carvão quando injetado com plástico}

Conforme conclui Gupta et al. (2006), em teste realizado utilizando uma mistura composta por carvão e plástico, a eficiência de combustão indicou ser similar àquela somente com uso de carvão embora parte do plástico não tenha sido completamente queimado. O estudo mostra que até $30 \%$ de plástico podem ser adicionados à mistura de carvão sem afetar a eficiência de combustão.

\subsection{7- Comportamento do Alto Forno com a injeção do plástico}

A injeção de plástico no Alto Forno adiciona carbono e hidrogênio às reações que ocorrem no interior do Alto Forno. Shu et al. (2004) mostra em seu estudo o comportamento e os efeitos do hidrogênio proveniente do plástico em teste realizado num Alto Forno de 11,2 $\mathrm{m}$ de diâmetro, 25,2 $\mathrm{m}$ de altura , volume de $2.303 \mathrm{~m}^{3}$ e produção de $4.500 \mathrm{t}$ de gusa/dia. A taxa de injeção de plástico é de $2,0 \mathrm{~kg} / \mathrm{s}$ ou equivalente a $38,4 \mathrm{~kg} / \mathrm{t}$ de gusa.

O resultado obtido em tal estudo demonstrou que através da injeção de plástico houve um aumento na taxa de redução indireta devido a presença do hidrogênio no plástico, quando comparado ao caso All Coke - uso exclusivo de coque - como mostra a Tabela 3, melhorando assim o desempenho do Alto Forno.

Tabela 3 - Taxa de redução pelo hidrogênio no total da redução indireta

\begin{tabular}{|l|c|c|c|}
\hline \multirow{2}{*}{ Caso } & \multicolumn{3}{|c|}{ Taxa de Redução pelo Hidrogênio (\%) } \\
\cline { 2 - 4 } & $\mathrm{Fe}_{2} \mathrm{O}_{3}>\mathrm{Fe}_{3} \mathrm{O}_{4}$ & $\mathrm{Fe}_{3} \mathrm{O}_{4}>\mathrm{FeO}$ & $\mathrm{FeO}>\mathrm{Fe}$ \\
\hline All Coke & 0,4 & 11,2 & 28,6 \\
\hline Injeção de vapor & 2,5 & 34,9 & 53,5 \\
\hline Injeção de Gás Natural & 10,9 & 79,8 & 74,4 \\
\hline Injeção de Plástico & 1,2 & 27,0 & 49,3 \\
\hline
\end{tabular}

Fonte: Shu et al. (2004)

Com isso a operação do Alto Forno obteve os seguintes resultados (Shu et al., 2004): um aumento de produção de 7,7 \% e uma redução na taxa de consumo de coque (coke rate) de $13,4 \%$. O desempenho do Alto Forno melhorou em função da redução do coke rate, que é 
decorrente da diminuição da demanda térmica para a redução direta. A condição da zona de combustão para o caso analisado revelou queda de temperatura de $2098^{\circ} \mathrm{C}$ para $2018^{\circ} \mathrm{C}$, com aumento da Produção de gás de $90,0 \mathrm{Nm}^{3} / \mathrm{s}$ para $93,1 \mathrm{Nm}^{3} / \mathrm{s}$ quando comparando o caso All Coke com o de injeção de plástico.

\subsection{8 - Produção de resíduo de plástico no Brasil}

A produção de resíduos plásticos no Brasil em 2006 está configurada conforme a Tabela 4, que apresenta a produção e a reciclagem de cada tipo de plástico classificado de acordo com a sua resina. Com base nos valores apresentados, fica evidente que há um saldo disponível para futuros reaproveitamento ou reciclagem para todos os tipos de resinas.

Tabela 4- Produção e reciclagem de plástico no Brasil

\begin{tabular}{|l|r|r|r|}
\hline \multicolumn{1}{|c|}{ Resina } & $\begin{array}{c}\text { Produção } \\
\text { (t/ano) }\end{array}$ & \multicolumn{1}{c|}{$\begin{array}{c}\text { Reciclado } \\
\text { (t/ano) }\end{array}$} & $\begin{array}{c}\text { Descartado } \\
\text { (t/ano })\end{array}$ \\
\hline PET & 454.925 & 261.912 & 193.013 \\
\hline PEAD & 335.387 & 94.181 & 241.206 \\
\hline PVC & 103.266 & 14.149 & 89.117 \\
\hline PEBD/PELBD & 788.713 & 185.976 & 239.852 \\
\hline PP & 381.062 & 141.210 & 37.716 \\
\hline PS & 133.441 & 37.725 & 38.793 \\
\hline OUTROS TIPOS & 55.896 & 17.103 & $\mathbf{1 . 5 3 1 . 6 5 6}$ \\
\hline \multicolumn{2}{r|r|}{} \\
\hline TOTAL & 2.299 .159 & 767.503 & \\
\hline
\end{tabular}

Os principais elementos que compõem os produtos descritos na Tabela 4 são (Ambientebrasil, 2009):

PET - Polietileno tereftalato: frascos e garrafas para uso alimentício/hospitalar, cosméticos, bandejas para microondas, filmes para áudio e vídeo, fibras têxteis;

PEAD - Polietileno de alta densidade: embalagens para detergentes e óleos automotivos, sacolas de supermercados, garrafeiras, tampas, tambores para tintas, potes, utilidades domésticas; 
PVC - Policloreto de vinila: embalagens para água mineral, óleos comestíveis, maioneses, sucos. Perfis para janelas, tubulações de água e esgotos, mangueiras, embalagens para remédios, brinquedos, bolsas de sangue, material hospitalar;

PEBD - Polietileno de baixa densidade e PELBD - Polietileno linear de baixa densidade: sacolas para supermercados e lojas, filmes para embalar leite e outros alimentos, sacaria industrial, filmes para fraldas descartáveis, bolsa para soro medicinal, sacos de lixo;

PP - Polipropileno: filmes para embalagens e alimentos, embalagens industriais, cordas, tubos para água quente, fios e cabos, frascos, caixas de bebidas, autopeças, fibras para tapetes e utilidades domésticas, potes, fraldas e seringas descartáveis;

PS - Poliestireno: potes para iogurtes, sorvetes, doces, frascos, bandejas de supermercados, geladeiras (parte interna da porta), pratos, tampas, aparelhos de barbear descartáveis, brinquedos;

Para efeito da utilização de plásticos no Alto Forno 1, no presente trabalho está sendo excluída a resina PVC, como anteriormente citado em Ogaki et al (2001), devido à possibilidade de Produção de corrosão ácida nas instalações de lavagem de gases do Alto Forno, bem como em tubulações e queimadores das caldeiras que utilizam este gás como combustível na ArcelorMittal Tubarão. Observa-se uma grande fonte potencial de matéria prima, suficiente para suprir a demanda da injeção de plástico no Alto Forno da ArcelorMittal Tubarão, que neste momento é estimada como sendo quantificada na seguinte proporção:

- Injeção de plástico conforme Shu et al. (2004) = 38,4 kg/t de gusa.

- Produção de gusa do Alto Forno 1 da ArcelorMittal Tubarão = 10.000 t gusa / dia

- Quantidade máxima estimada de plástico injetado = 38,4 kg / t gusa x 10.000 t gusa / dia $=384.000 \mathrm{~kg} / \mathrm{dia}$. 


\subsection{9 - Distribuição da Produção e reciclagem de plásticos por região no Brasil}

A produção de resíduo plástico pós-uso no Brasil está distribuída conforme mostra a Tabela 5 .

Tabela 5- Distribuição regional da Produção de plástico pós-uso no Brasil

\begin{tabular}{|l|c|c|c|c|c|c|}
\hline $\begin{array}{l}\text { Tipo de resíduo } \\
\text { plástico }\end{array}$ & $\begin{array}{c}\text { Centro - } \\
\text { Oeste }\end{array}$ & Norte & Nordeste & Sul & Sudeste & Brasil \\
\hline PET & 24.979 & 22.903 & 84.953 & 59.747 & 187.816 & 380.398 \\
\hline PEAD & 24.714 & 22.660 & 84.053 & 59.113 & 185.824 & 376.364 \\
\hline PVC & 6.772 & 6.209 & 23.030 & 16.197 & 50.916 & 103.124 \\
\hline PEBD/PELBD & 39.851 & 36.539 & 135.534 & 95.320 & 299.641 & 606.885 \\
\hline PP & 32.935 & 30.197 & 112.012 & 78.777 & 247.637 & 501.558 \\
\hline PS & 8.807 & 8.075 & 29.952 & 21.065 & 66.217 & 134.116 \\
\hline Outrostipos & 4.948 & 4.537 & 16.829 & 11.836 & 37.207 & 75.357 \\
\hline Total & 143.006 & 131.120 & 486.363 & 342.055 & 1.075 .258 & 2.177 .802 \\
\hline
\end{tabular}

Fonte: MaxiQuim Assessoria de Mercado (2004)

A reciclagem de resíduo plástico pós-uso no Brasil está distribuída conforme mostra a Tabela 6.

Tabela 6- Distribuição regional da reciclagem de plástico pós-uso no Brasil

\begin{tabular}{|l|c|c|c|c|c|c|}
\hline $\begin{array}{l}\text { Tipo de resíduo } \\
\text { plástico }\end{array}$ & $\begin{array}{c}\text { Centro - } \\
\text { Oeste }\end{array}$ & Norte & Nordeste & Sul & Sudeste & Brasil \\
\hline PET & 0 & 0 & 23.221 & 37.472 & 88.615 & 149.308 \\
\hline PEAD & 3.742 & 0 & 10.817 & 14.177 & 33.871 & 62.607 \\
\hline PVC & 0 & 0 & 4.903 & 4.669 & 7.481 & 17.053 \\
\hline PEBD/PELBD & 3.575 & 0 & 5.796 & 24.198 & 46.272 & 79.841 \\
\hline PP & 1.618 & 0 & 7.480 & 5.383 & 26.558 & 41.039 \\
\hline OS & 0 & 0 & 0 & 2.753 & 3.550 & 6.303 \\
\hline Outros tipos & 0 & 0 & 0 & 925 & 2.058 & 2.983 \\
\hline Total & 8.935 & 0 & 52.217 & 89.577 & 208.405 & 359.134 \\
\hline
\end{tabular}

Fonte: MaxiQuim Assessoria de Mercado (2004) 


\subsubsection{0 - Preço de resíduo de plástico no Brasil}

O preço do material reciclado é classificado pelo mercado de reciclagem e varia de acordo com a região e o tipo de material. Para o uso na injeção do Alto Forno não são necessários requisitos de limpeza ou uniformidade; assim sendo, este preço é apenas uma referência. Um fator importante na composição do preço do plástico é o de escala; para grandes volumes negociados o preço pode ser menor e mais atrativo. A Tabela 7 apresenta preços referenciais para plástico reciclado em diferentes cidades do Brasil.

Tabela 7- Preço de plástico para reciclagem

\begin{tabular}{|l|c|c|c|}
\hline Localização & $\begin{array}{c}\text { Plástico Rígido } \\
\mathbf{R} \$ \mathbf{~ t ~}\end{array}$ & $\begin{array}{c}\text { PET } \\
\mathbf{R} \mathbf{~ / ~ t ~}\end{array}$ & $\begin{array}{c}\text { Plástico Filme } \\
\mathbf{R} \mathbf{~ / ~ t ~}\end{array}$ \\
\hline Guarapari & $530 \mathrm{PL}$ & $700 \mathrm{PL}$ & 300 \\
\hline Brasilândia & $350 \mathrm{~L}$ & $400 \mathrm{PL}$ & $150 \mathrm{PL}$ \\
\hline Itabira & $870 \mathrm{PL}$ & $850 \mathrm{PL}$ & $1200 \mathrm{PL}$ \\
\hline Lavras & 800 & 500 & 900 \\
\hline Recife & $1100 \mathrm{PL}$ & $500 \mathrm{P}$ & 1000 \\
\hline Porto Alegre & $300 \mathrm{PL}$ & $700 \mathrm{PL}$ & $400 \mathrm{P}$ \\
\hline Blumenau & 200 & $800 \mathrm{P}$ & 600 \\
\hline Campinas & $600 \mathrm{PL}$ & $850 \mathrm{PL}$ & $1000 \mathrm{PL}$ \\
\hline Guarujá & $800 \mathrm{PL}$ & $850 \mathrm{PL}$ & $700 \mathrm{PL}$ \\
\hline Santo André & - & $1000 \mathrm{~L}$ & $800 \mathrm{PL}$ \\
\hline São Bernardo & $800 \mathrm{P}$ & $750 \mathrm{P}$ & $500 \mathrm{P}$ \\
\hline São Paulo & $200 \mathrm{~L}$ & $750 \mathrm{PL}$ & $400 \mathrm{PL}$ \\
\hline Aracaju & $500 \mathrm{~L}$ & $300 \mathrm{~L}$ & $500 \mathrm{PL}$ \\
\hline
\end{tabular}

Fonte: CEMPRE - Compromisso Empresarial para a Reciclagem

\section{3 - UTILIZAÇÃO DE PNEUS DESCARTADOS}

A utilização de pneus descartados como combustível em Alto Forno apresenta um grande potencial de desenvolvimento. Atualmente a Produção de pneus descartados /inservíveis é grande e crescente. Em geral este acúmulo gera problemas de saúde pública, ambiental e social na medida em que não são adequadamente armazenados, reciclados ou lhes é dada uma destinação final própria. 
A injeção de pneus em Altos Fornos é aplicada para os casos de pneus sucateados, danificados e que não apresentam qualidade e características de reaproveitamento para remoldagem. Como rejeito, este pneu possui baixo valor agregado, mas como combustível pode se transformar em um produto com elevado valor agregado.

Segundo Araújo Filho (2006), os resultados preliminares da injeção de pneu moído através das ventaneiras do Alto Forno indicam boa capacidade de combustão, evidenciando ser um bom material para substituir o carvão pulverizado mineral ou vegetal. Outro fator importante a ser levado em conta é conhecer a composição do pneu, visando viabilizar sua participação como elemento fornecedor dos elementos químicos necessários para a reação de redução do minério de ferro. Da composição básica de um pneu constam borracha, aço e fibras, conforme mostra a Figura 14.

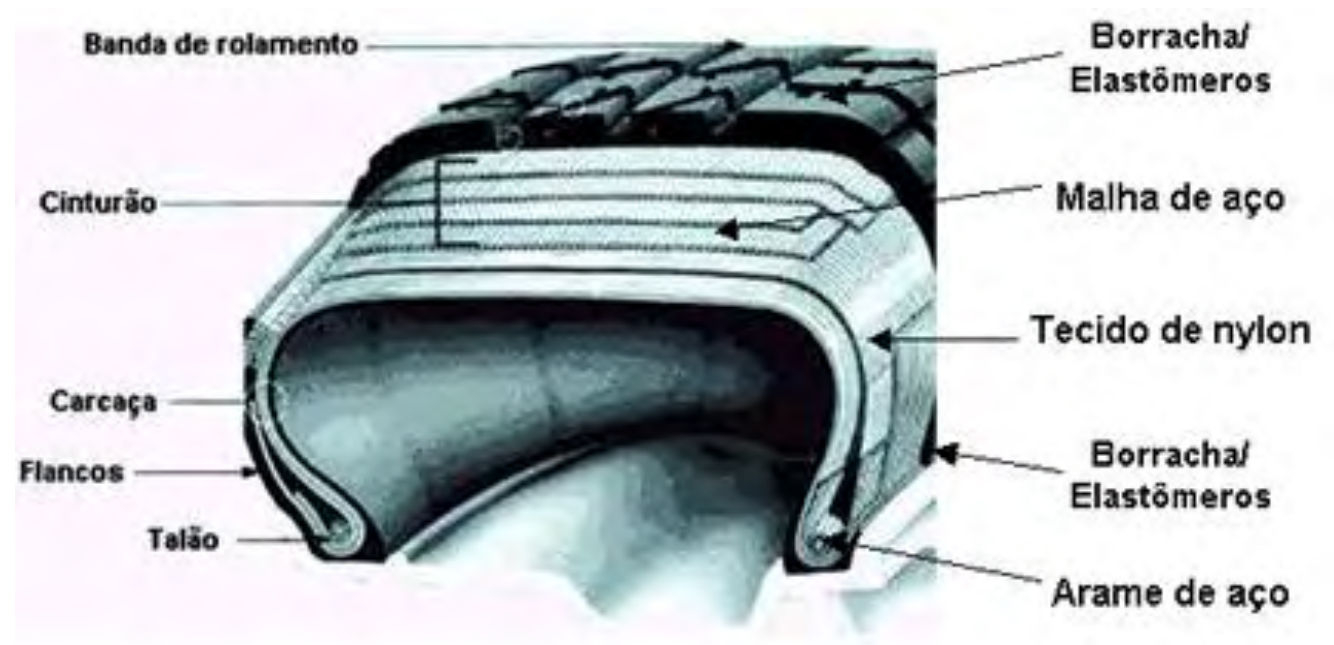

Fonte: Andrietta (2002)

Figura 14 - Composição de um pneu

Conforme apresentado na Tabela 8, a composição química do pneu fornece ao processo de redução do ferro gusa carbono e hidrogênio, elementos químicos necessários para a reação redutora do minério de ferro em ferro metálico. Os elementos químicos óxido de zinco e enxofre são indesejáveis no processo de redução do minério de ferro e devem ser dosados em quantidades 
pré-estabelecidas para que não provoquem danos ao corpo do Alto Forno, bem como às suas instalações auxiliares.

Tabela 8 - Composição química do pneu

\begin{tabular}{|l|c|}
\hline \multicolumn{1}{|c|}{ Elemento } & \% massa \\
\hline Carbono & 70,0 \\
\hline Hidrogênio & 7,0 \\
\hline Ferro & 15,0 \\
\hline Óxido de Zinco & 1,2 \\
\hline Enxofre & 1,3 \\
\hline Outros & 5,5 \\
\hline
\end{tabular}

Fonte: Andrietta (2002)

A composição do pneu varia em função do seu tipo, conforme mostra a Tabela 9.

Tabela 9 - Composição do pneu por tipo

\begin{tabular}{|l|c|c|}
\hline \multicolumn{1}{|c|}{ Material \% } & Automóvel & Caminhão \\
\hline Borracha / Elastômeros & 48 & 45 \\
\hline Negro de fumo & 22 & 22 \\
\hline Aço & 15 & 25 \\
\hline Tecido de nylon & 5 & - \\
\hline Óxido de Zinco & 1 & 2 \\
\hline Enxofre & 1 & 1 \\
\hline Aditivos & 8 & 5 \\
\hline
\end{tabular}

Fonte: Andrietta (2002)

O processo de utilização de pneus em Altos Fornos consiste na injeção de pneu moído diretamente na ventaneira. Para este fim o pneu precisa ser triturado, moído e a parcela metálica removida através de separação magnética. O trabalho desenvolvido por Araujo Filho et al. (2006) apresenta o esquema de injeção de materiais no Alto Forno conforme Figura 15. O pó de pneu armazenado no silo é transportado através de uma mistura fluida com ar até o Alto Forno. Esta mistura é introduzida na ventaneira através de uma lança, direcionando o pó diretamente na região de combustão do Alto Forno onde a temperatura está acima de $2.000^{\circ} \mathrm{C}$. Nesta temperatura, ocorre a gaseificação imediata da borracha com a dissociação do carbono e do hidrogênio. 


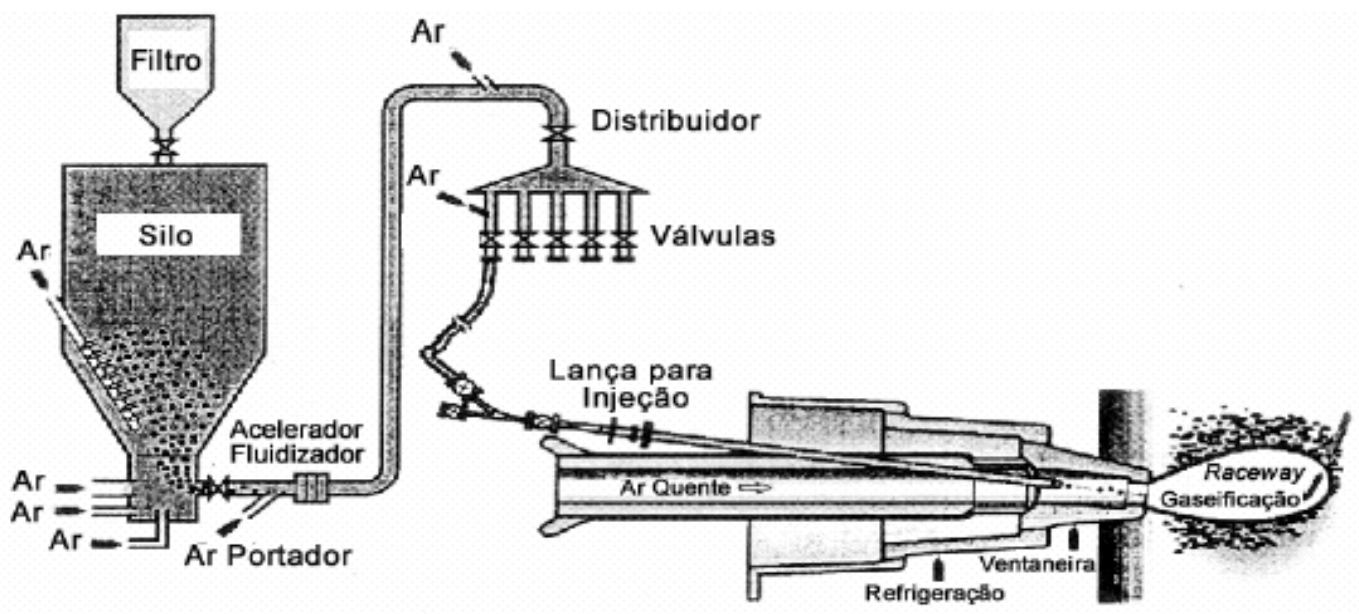

Figura 15 - Esquema para injeção de pneu através das ventaneiras

O trabalho desenvolvido por Araújo Filho et al. (2006) simulou a injeção através de um simulador composto por um forno de pré-aquecimento, que simula o regenerador, um forno de temperatura elevada que simula a região de combustão do Alto Forno e de um ponto para a alimentação da amostra a ser ensaiada que simula a lança de injeção. A granulometria do material injetado apresenta tamanho de partícula entre 0,074 e 0,104 mm. Os resultados da injeção de pneu moído e a taxa de combustão são mostrados na Tabela 10. A taxa de combustão é a quantidade de carbono elementar oxidado a $\mathrm{CO} / \mathrm{CO}_{2}$.

Tabela 10 - Taxa de injeção x índice de combustão do pneu

\begin{tabular}{|l|c|c|}
\hline Quantidade injetada (kg/t gusa) & 40 & 120 \\
\hline Taxa de combustão & 92 & 78 \\
\hline
\end{tabular}

A Tabela 11 mostra os resultados da injeção de carvão mineral e a taxa de combustão. $O$ carvão mineral é um material normalmente injetado e cuja granulometria de referência é 76,2\% do total de partículas menores que 0,104 mm.

Tabela 11 - Taxa de injeção x índice de combustão do carvão

\begin{tabular}{|l|c|}
\hline Quantidade injetada (kg / t gusa) & 160 \\
\hline Taxa de combustão & 87 \\
\hline
\end{tabular}


Comparativamente ao carvão mineral, o pneu moído apresenta taxa de combustão equivalente para valores de injeção de pneu moído próximo de $40 \mathrm{~kg} / \mathrm{t}$ gusa, indicando possibilidade de se praticar valores de injeção de pneu moído da ordem de $50 \mathrm{~kg} / \mathrm{t}$ gusa.

\subsection{1- Produção de pneus novos no Brasil}

$\mathrm{O}$ volume de produção de pneus novos é um indicador importante para se determinar a disponibilidade futura desta fonte energética alternativa no contexto do presente trabalho. A Figura 16 apresenta a produção anual de pneus novos no Brasil e estima-se que, desde o início de sua produção na década de 1930, já se tenha chegado ao valor acumulado de 860 milhões de unidades produzidas até o ano 2000. Embora os dados se limitem ao ano 2000, com defasagem de uma década nos dados apresentados na Figura 16, observa-se uma forte tendência de crescimento no número de unidades por ano no período entre 1980 e 2000, fato corroborado pelos sucessivos recordes de vendas de veículos novos no país ao longo dos últimos anos.

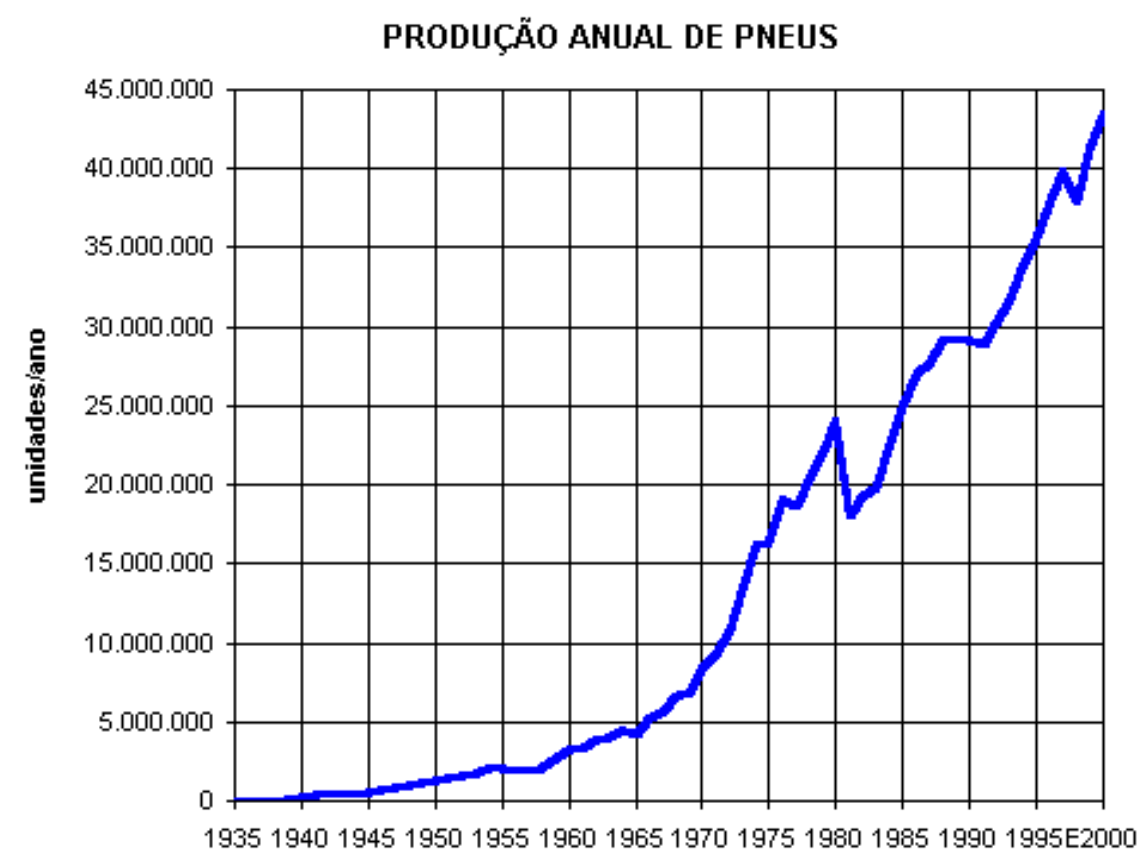

Fonte: ANIP/Dados finais do período de 1993-1997/ Fonte:Geipot

Figura 16 - Produção anual de pneus no Brasil 
O ciclo de vida de um pneu pode ser estabelecido em uma sucessão de estágios, desde a extração da matéria prima até sua destinação final, como descrito na Figura 17.

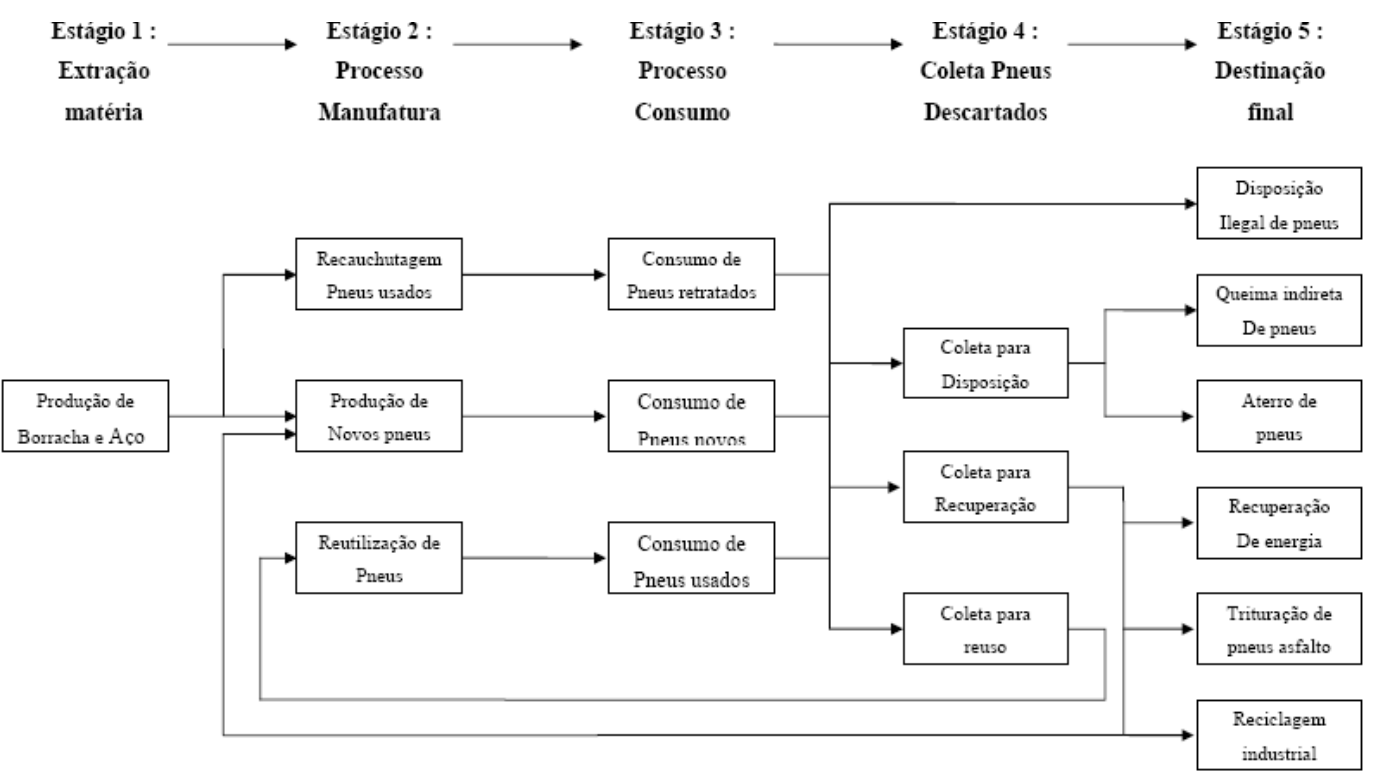

Fonte: Beukering; Janssen (2001).

Figura 17 - Ciclo de vida de um pneu

\subsection{2- Cadeia de pneus inservíveis}

Segundo Serra (2004), a cadeia de reciclagem de pneus no Brasil é representada na Figura 18. A reciclagem como regra é incipiente, sendo a exceção composta por agentes de reforma de pneus (borracheiros, recauchutadores, recapadores e remoldadores), atuando principalmente em pneus de ônibus e caminhões. 


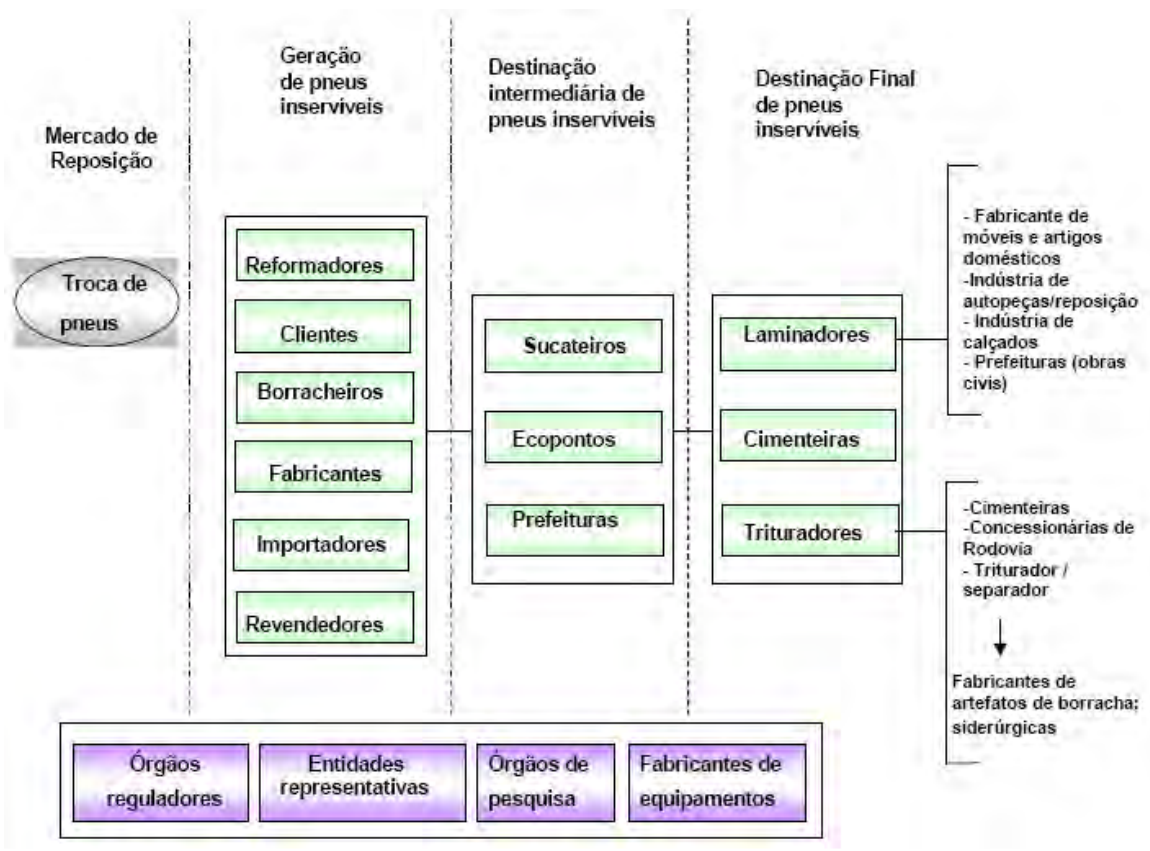

Fonte:IPT,2004

Figura 18 - Cadeia de pneus inservíveis

A cadeia de reciclagem secundária é composta pela coleta, armazenamento temporário, a laminação para pneus convencionais e trituração para os pneus radiais. A coleta é a parcela mais crítica devido a limitações e dificuldades de manuseio e transporte, sendo realizada principalmente por sucateiros que recolhem os pneus de revendedores, borracheiros, empresas de transporte de carga frota de ônibus ou táxi. Destinam-se a reciclagem primária, secundária ou para voltar ao mercado como pneu usado.

\subsection{3- Produção e destino de Pneus no Brasil}

A Figura 19 apresenta a o destino dos pneus, conforme IPT (2004); tal pesquisa revela que 3,8 milhões de pneus inservíveis não têm destino conhecido, sendo, portanto, uma potencial fonte de suprimento de matéria prima para futuro aproveitamento. 


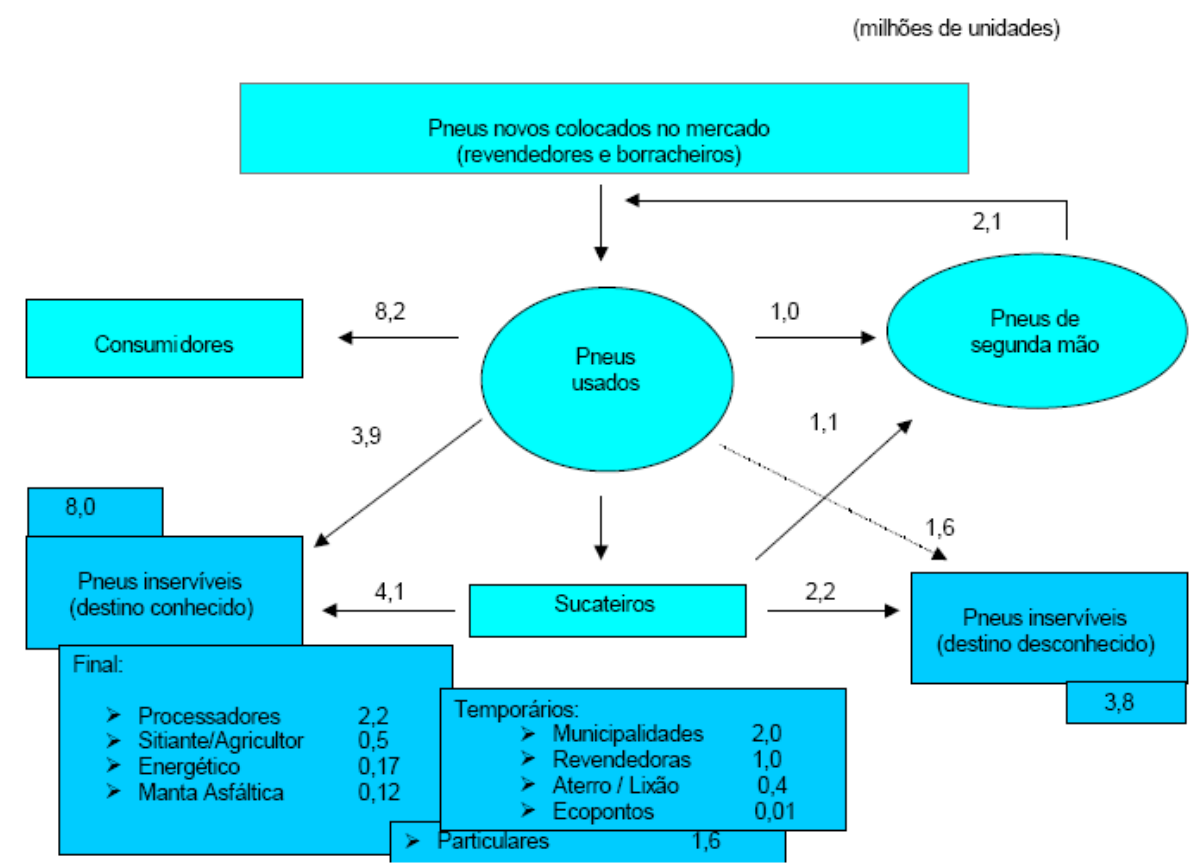

Fonte: IPT (2004)

Figura 19 - Produção e destino de pneus no Brasil

Conforme instrução normativa número 8 do IBAMA de 15 de maio de 2002, o peso de um pneu inservível é conforme mostra a Tabela 12.

Tabela 12 - Peso de Pneu inservível

\begin{tabular}{|l|c|}
\hline Tipo do Pneu & Peso (kg) \\
\hline Pneu de automóvel & 5 \\
\hline Pneu de Carga & 40 \\
\hline
\end{tabular}

Fonte: IBAMA (2004)

\subsection{4- Custo de Co-processamento de pneu}

De acordo com Lagarinhos (2008), o custo para o co-processamento de pneus usado como substituto do óleo combustível e do carvão, em fornos de usinas cimenteiras, é de US\$ 15 a 20 por tonelada de pneu. Este custo serve como referência para uso no Alto Forno. 


\section{METODOLOGIA E APLICACÃO}

Usinas siderúrgicas integradas são aquelas que possuem todo o ciclo de produção, compreendendo a redução, o refino e a laminação. A ArcelorMittal Tubarão é uma siderúrgica do tipo integrada localizada em Jardim Limoeiro - Serra - Espírito Santo - Brasil. É uma empresa que pertence ao grupo ArcelorMittal e produz aços planos na forma de bobinas a quente e placas semi-acabadas. Sua capacidade nominal de produção é de 7,5 Mt/a.

A ArcelorMittal produz aço através do processamento do ferro gusa líquido obtido em Alto Forno a partir do minério de ferro, do coque e do carvão mineral como agente redutor. A transformação do ferro gusa em aço, processo conhecido como refino, é feita através de fornos a oxigênio na aciaria. A configuração e o fluxo de produção completo da ArcelorMittal tubarão são mostrados na Figura 20.

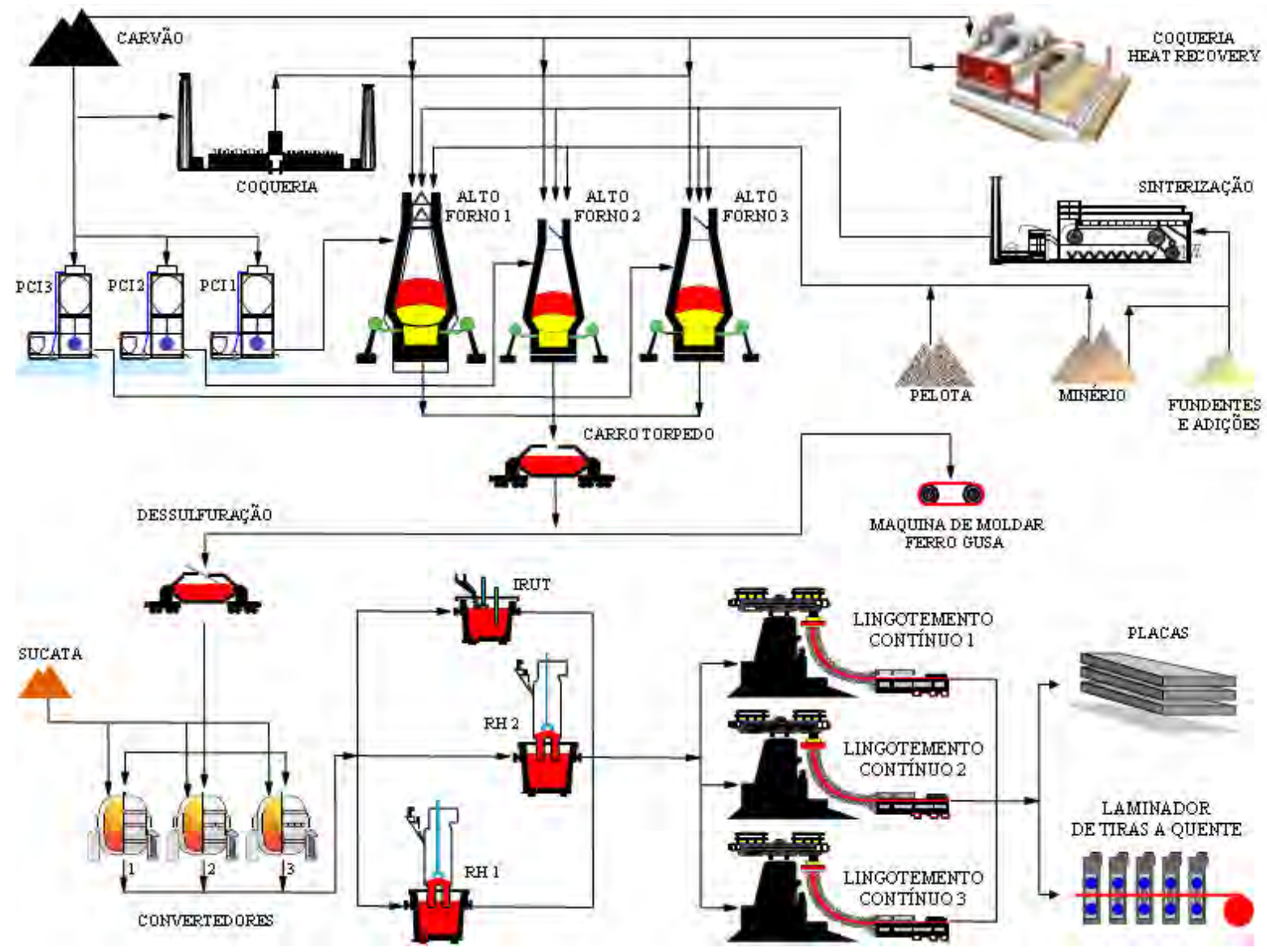

Figura 20 - Fluxo de produção da ArcelorMittal Tubarão 
O Alto Forno 1 faz parte da área de produção de gusa, a qual engloba 03 unidades produtivas: Alto Forno 1, Alto Forno 2 e Alto Forno 3. O Alto Forno 1 foi implantado na fase inicial da ArcelorMittal Tubarão e sua produção de gusa - blow in - se iniciou em 30 de novembro de 1983 com produção anual prevista de 3,0 Mt/a de gusa líquido. Inicialmente sua campanha (período contínuo de produção sem parada para reforma) era de 7 anos. Entretanto, devido ao seu bom desempenho técnico e operacional, tornou-se o alto forno mais produtivo do mundo ao alcançar a marca acumulado de 70 milhões de toneladas de ferro gusa produzidos em uma única campanha (período de tempo de produção sem sofrer parada para a reforma).

Atualmente, sua campanha está em 26 anos de produção sem sofrer reforma. A previsão é de que esta ocorra em 2012, quando então o mesmo terá completado 30 anos de campanha. O Alto Forno 1 está mostrado na parte central da área de produção de gusa da Figura 21.

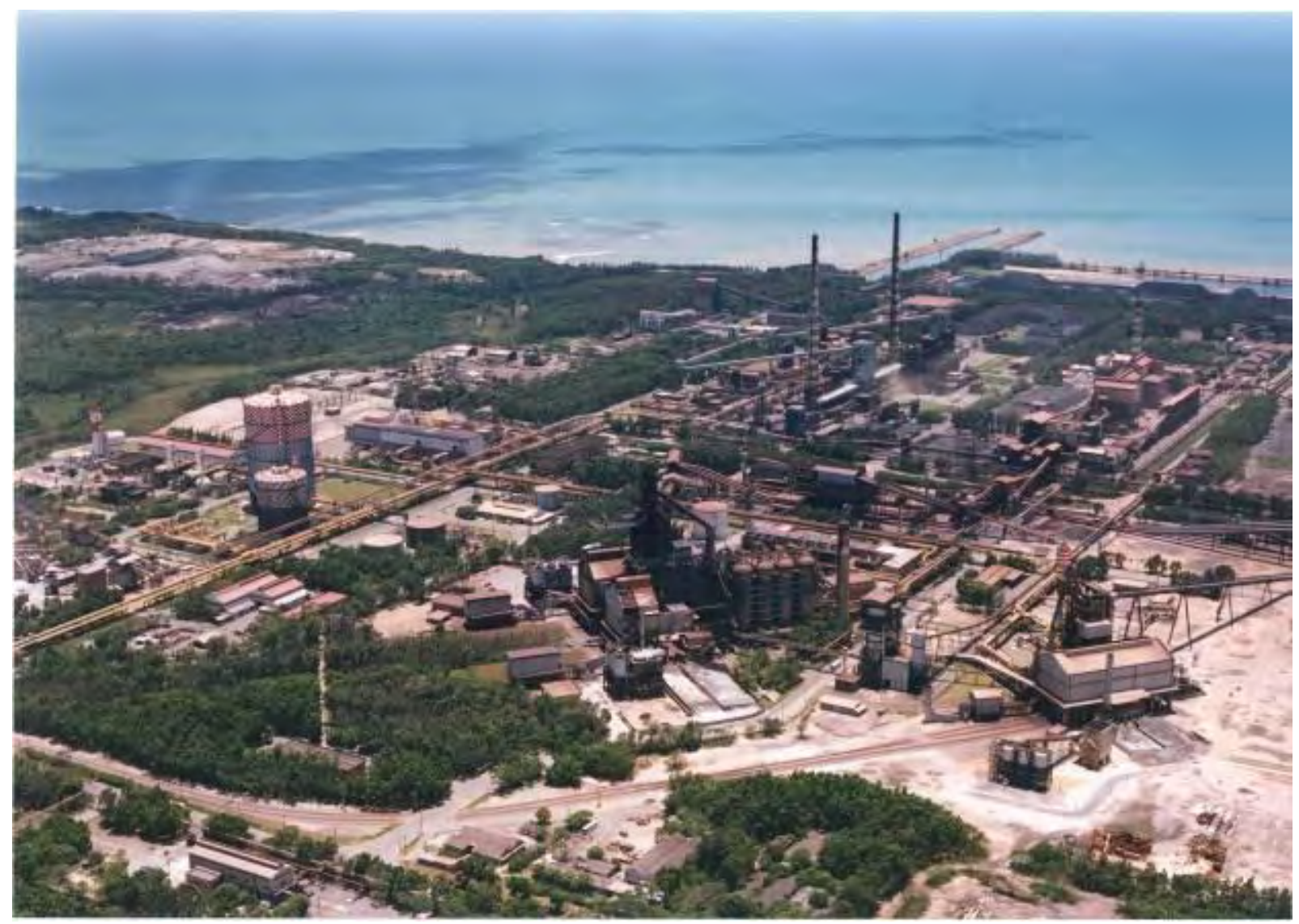

Figura 21 - Alto Forno 1 e a área de produção de gusa da ArcelorMittal Tubarão 


\section{1 - Características Técnicas do Alto Forno 1}

Apresentam-se, na seqüência, características técnicas do Alto Forno 1, objeto da análise do presente trabalho.

\subsubsection{Alto Forno Próprio}

Produção:

Tipo:

Volume interno:

Volume de trabalho

Diâmetro do cadinho:

Furos de gusa:

Ventaneiras:

$$
\text { 3.000.000 t/ano }
$$

Throat bracket type

$4415 \mathrm{~m}^{3}$

$3707 \mathrm{~m}^{3}$

$14 \mathrm{~m}$

4

38

Sistema de refrigeração - cadinho: Tubo de refrigeração (água recirculada)

Sistema de refrigeração - carcaça: Trocadores de calor ( staves) com água desmineralizada Analisador de gás de cuba: $\quad$ Émbolo de $9800 \mathrm{~mm}$

\subsection{2 - Regeneradores}

Tipo:

Koopers com câmara de combustão externa

Quantidade: 4

Área de aquecimento:

$4 \times 89.900 \mathrm{~m}^{2}$

Temperatura do gás de combustão: $1463^{\circ} \mathrm{C}$

Temperatura de sopro: $1300{ }^{\circ} \mathrm{C}$

Modo de operação:

Staggered parallel

\subsection{3 - Limpeza de gás}

Coletor de pó:

Tipo separador por gravidade vertical

Venturi Scrubber:

2 - Venturi Scrubbers com arranjo em série

Particulado no gás de saída:

$5 \mathrm{mg} / \mathrm{Nm}^{3}$ 


\subsection{4 - Equipamento de carregamento}

Tipo:

Systema de carregamento:

Capacidade de carregamento:

Cone Grande:

Cone pequeno:

Revolving Chute:

Placas Móveis:

\subsection{5 - Pressão de Topo}

Tipo:

Pressão de topo:

Sistema de equalização:

\subsection{6 - Casa de corrida}

Mud Guns:

Capacidade:

Opener:

Runner:

Tilting Runner:

Slag Granulating:

Slag Dry Pit:

Dedusting System:
2 cones - Gas Seal Valve

Correia transportadora

222 cargas/dia

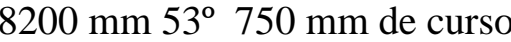

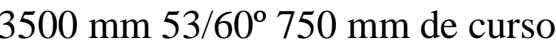

Single Port $12 \mathrm{rpm}$

Tipo GHH - 18 placas - $1000 \mathrm{~mm}$ de curso

4 válvulas Septum tipo borboleta $600 \mathrm{~mm}$ x $2-850 \mathrm{~mm}$ x 2

$2.5 \mathrm{kgf} / \mathrm{cm}^{2}$ - máxima

Primário: Gás semi-limpo

Secundário: Nitrogênio

tipo acionamento hidráulico

$0.27 \mathrm{~m} 3$

Boom swing pneumatic driven type

Main Iron Trough: Replaceable type

$22,000(\mathrm{~L}) \times 2,200(\mathrm{~W})$

electric driven type

Nagata type $2,800 \mathrm{t} / \mathrm{d} \times 2$

$1200 \mathrm{~m} 2 \times 4$

Bag Filter type $10,000 \mathrm{Nm}^{3} / \min \times 2$ 
3.1.7 - Sistema de injeção de carvão pulverizado

\subsubsection{1- Sistema de Moagem}

Tipo:

Tipo:

Capacidade:

Gás de transporte:

Silo de estocagem de carvão:

Transporte de carvão:

\subsubsection{2 - Sistema de injeção}

Tipo:

Fase Densa

Capacidade:

Gás de transporte:

Consumo:

Pressão:

Vaso de injeção:

Silo de estocagem de carvão fino:
Kuttner

Rolos fixos (03)

$94 \mathrm{t} / \mathrm{h}$

Combustão de BFG

$500 \mathrm{~m}^{3}$

Correia transportadora

\subsection{8 - Turbina de topo}

Tipo:

Capacidade:

Fornecedor:
$60 \mathrm{t} / \mathrm{h} \times 2$ linhas

Nitrogênio

$200 \mathrm{Nm}^{3} / \mathrm{t}$ - carvão

Max: $15 \mathrm{kgf} / \mathrm{cm}^{2}$

3 vasos em paralelo

$2300 \mathrm{~m}^{3}$

\subsection{9 - Dimensões do Alto Forno}

O perfil dimensional do Alto Forno está mostrado na Figura 22. 


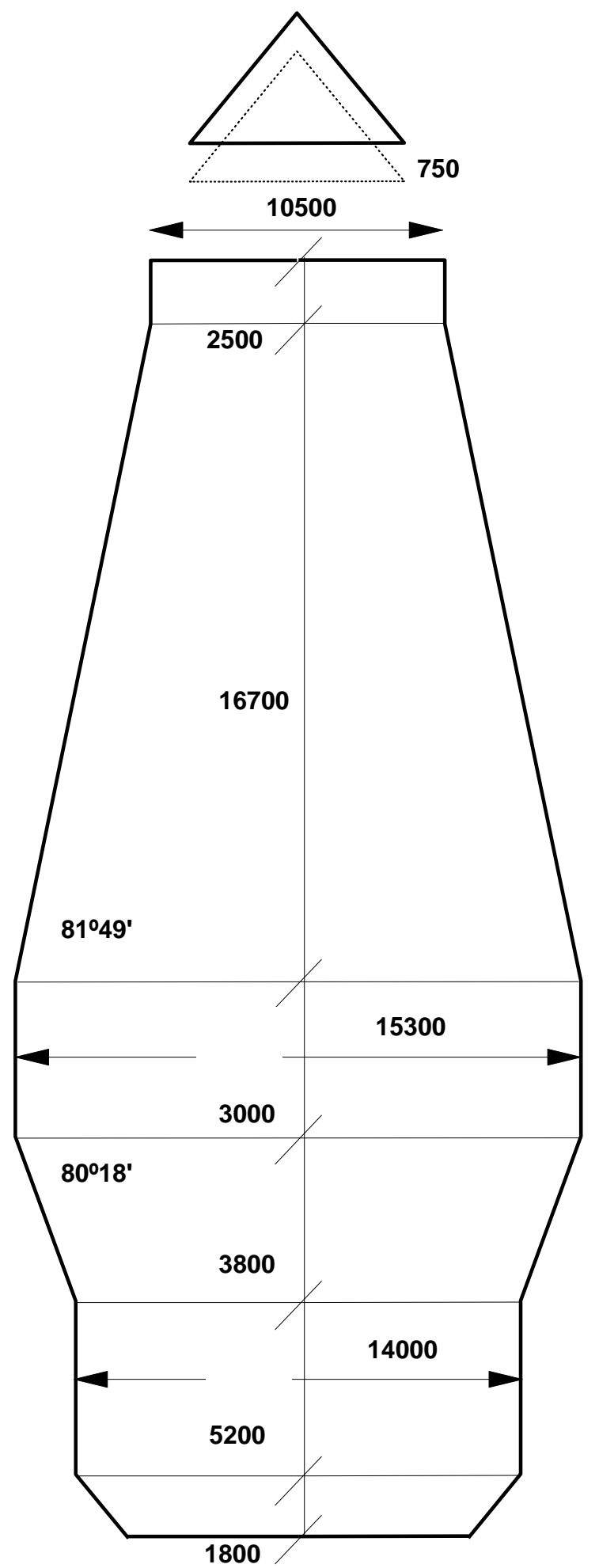

Obs: medidas em milímetros

Figura 22 - Perfil do Alto Forno 1 da ArcelorMittal Tubarão 


\section{2 - Configuração do Alto Forno 1}

O Alto Forno 1 está configurado conforme mostra a Figura 23. Possui todas as unidades periféricas essenciais ao seu funcionamento do ponto de vista de fornecer os produtos de entrada bem como receber os produtos de saída. O gusa é utilizado na produção do aço, a escória é utilizada na produção de cimento e a lama e o pó são destinados a produção de telhas e tijolos.

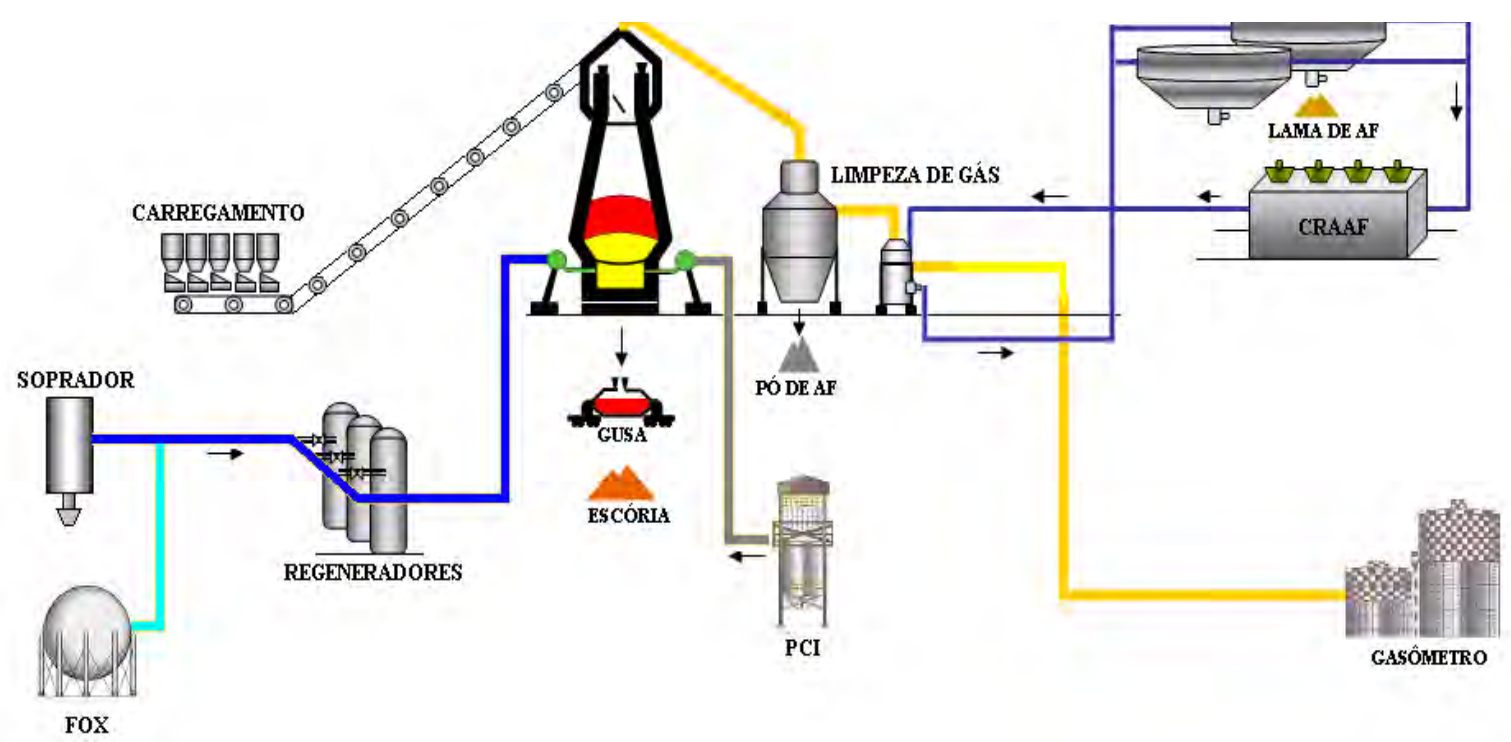

Figura. 23 - Arranjo esquemático da configuração do Alto Forno 1 da ArcelorMittal Tubarão

\subsection{1 - Unidade de Carregamento}

É a responsável pelo envio de matéria prima sólida do Alto Forno: sínter, pelota, minério bitolado, coque e fundente. Composta por silos de abastecimento, balanças, peneiras e correias transportadoras, além de sistemas de despoeiramento e de controle ambiental. Nesta unidade, a carga do Alto Forno é selecionada e preparada em função da quantidade e do material a ser carregado em cada fase do programa de carregamento do alto forno. Cada material é descarregado numa correia transportadora única que envia de forma seqüencial cada material selecionado pelo Alto Forno de acordo com a quantidade e tipo. 
Para alimentação de materiais no alto forno utiliza-se o sistema de carregamento em lotes (batches), lotes bem definidos, normalmente separados em coque e minérios (sínter, pelotas, minérios). Para a formação dos lotes, os materiais que os compõem são pesados e armazenados num silo de espera (surge hopper) até o momento de enviá-los ao topo do Alto Forno 1. A Figura 24 ilustra o carregamento dos materiais no topo do Alto Forno 1.

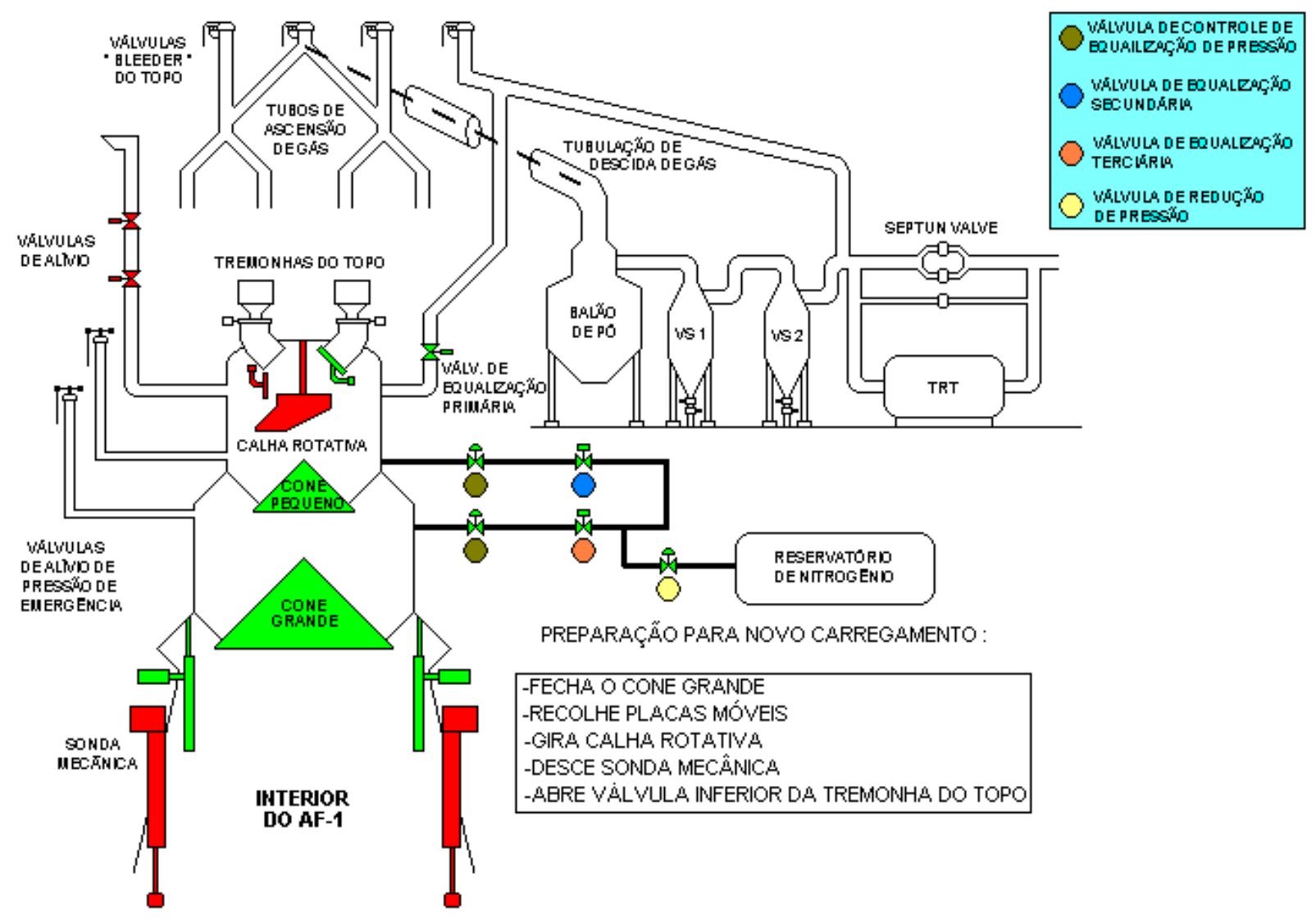

Figura 24 - Fluxograma de carregamento do Alto Forno 1

\subsection{2 - PCI - Pulverized Coal Injection - Injeção de Carvão Pulverizado}

É responsável pelo processamento e preparação do carvão a ser injetado nas ventaneiras, conforme mostra a Figura 25. A mistura de carvões é preparada em função da qualidade esperada do gusa e do custo da mistura. Geralmente é uma composição de carvões de baixo custo e não 
coqueificáveis, incluindo os antracitos. Após a preparação, a mistura é injetada no corpo do Alto Forno através de suas 38 ventaneiras; a Figura 26 ilustra uma ventaneira em corte. Cada ventaneira possui 02 lanças de injeção, como é apresentado na Figura 27.

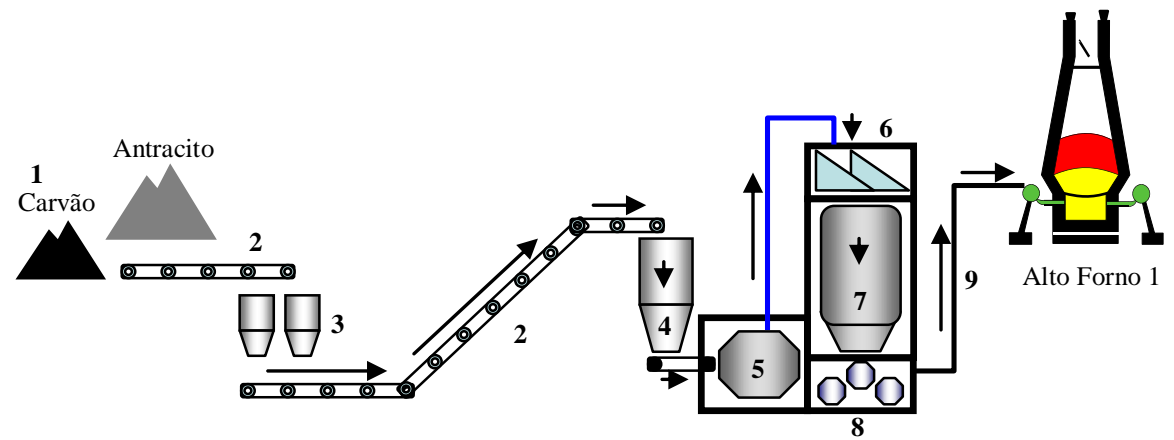

1- Pátio de Carvão e/ou Antracito

2- Correia Transportadora

4- Silo do Moinho

5- Moinho

7- Silo de Finos

3- Silos de Regularização

6- Peneiras

8- Vasos de Injeção

9- Rota de Injeção AF-1

Figura 25 - Fluxograma de preparação do carvão pulverizado

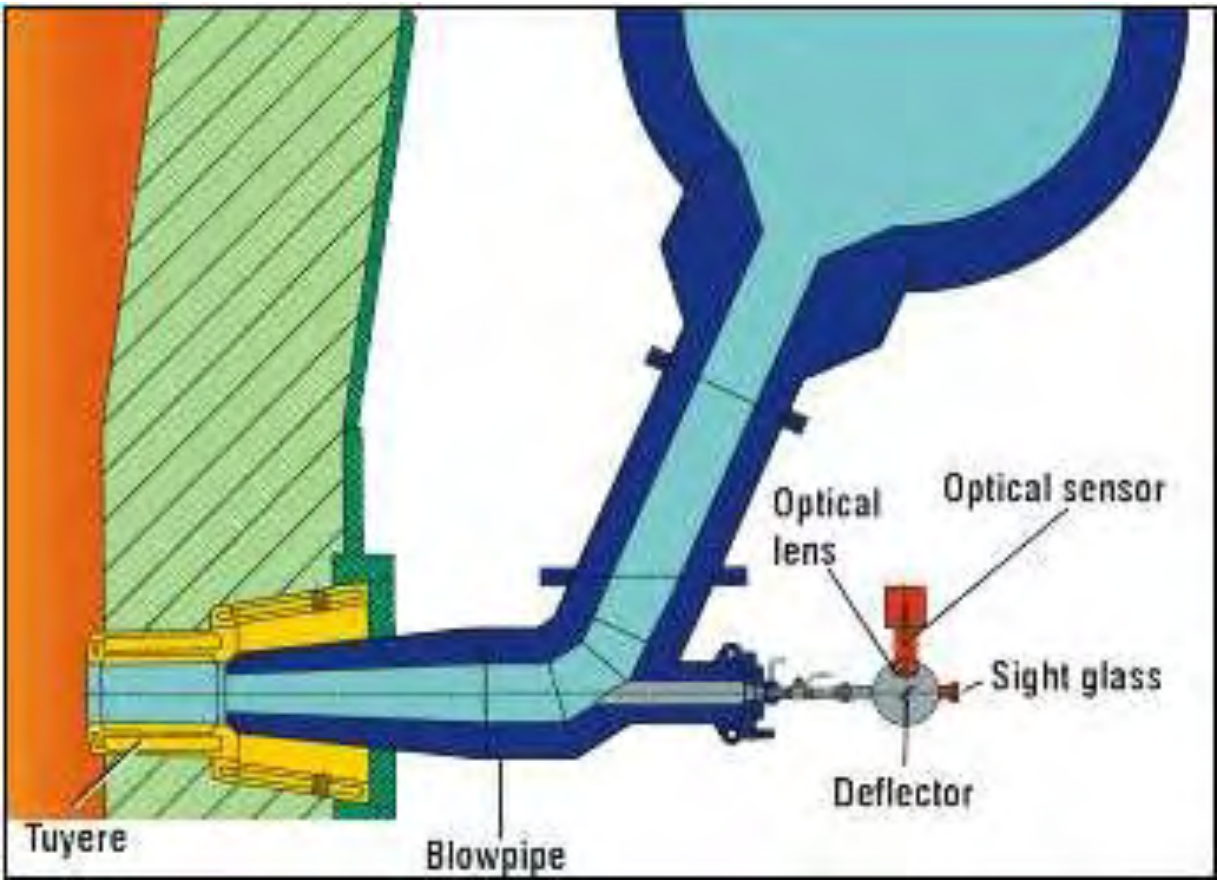

Figura 26 - Desenho em corte de uma ventaneira de Alto Forno 


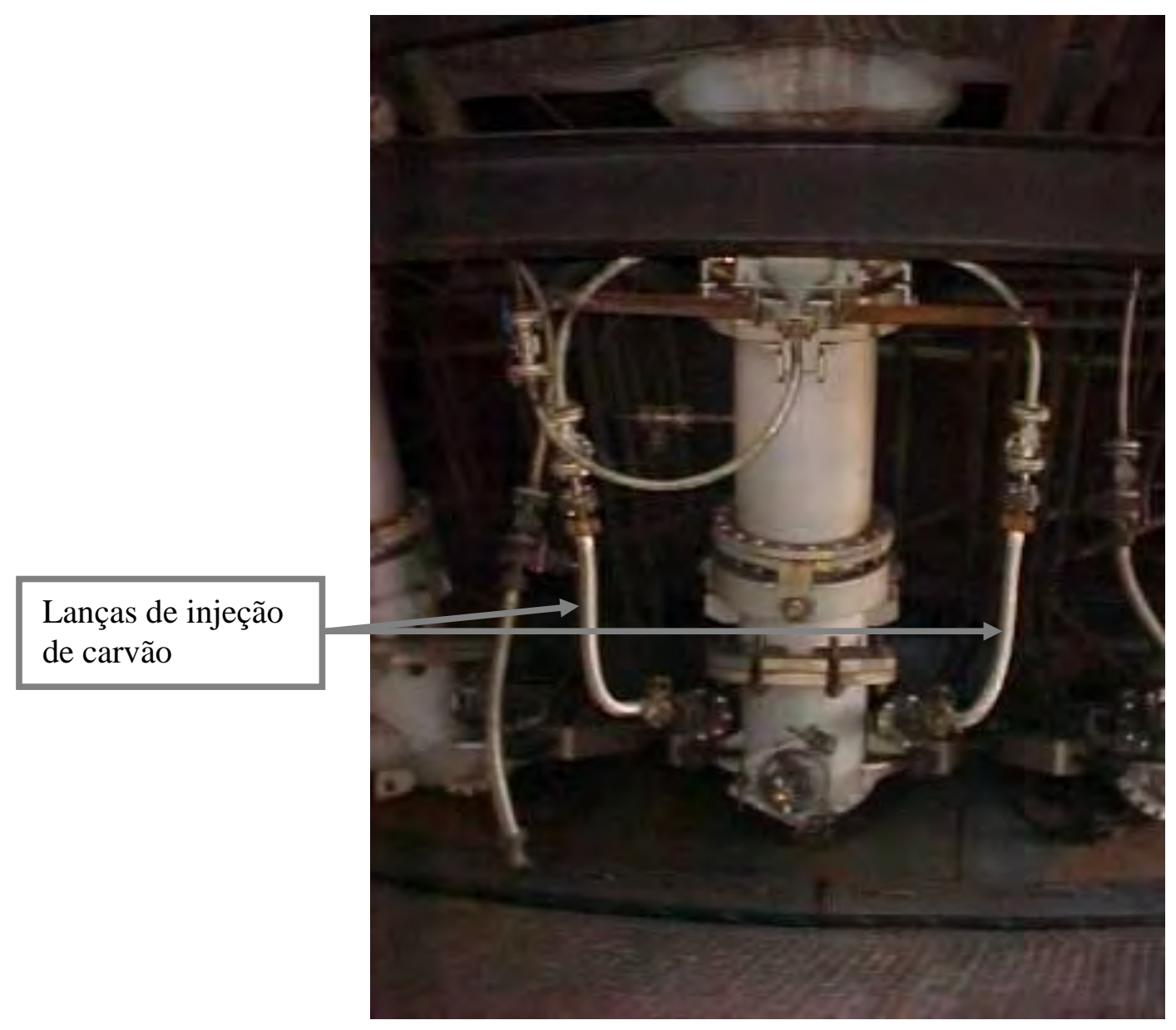

Figura 27 - Ventaneira do Alto Forno 1 mostrando as lanças de injeção de carvão pulverizado

\subsection{3 - Regeneradores}

Os regeneradores são responsáveis pelo aquecimento do ar de sopro do Alto Forno. A troca térmica é feita pela combustão de uma mistura de gás de coqueria e de Alto Forno. $\mathrm{O}$ ar entra nos regeneradores à temperatura média de $200^{\circ} \mathrm{C}$ e sai a $1300^{\circ} \mathrm{C}$, para ser então enviado para o processo de redução do minério no Alto Forno, como ilustrado na Figura 28. 


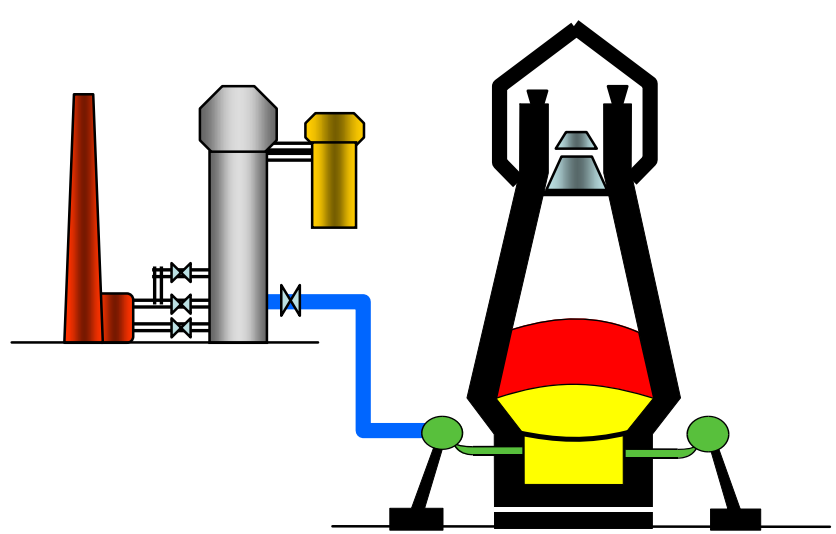

Figura 28 - Ilustração da composição dos regeneradores no Alto Forno

\section{3 - Matéria prima e insumos}

A coleta de dados realizada no mês de julho de 2009 registra a relação completa dos materiais que compõem a carga do Alto Forno 1 . Todos os dados operacionais no período de 01 a 31/07/09 estão disponíveis nas tabelas mostradas no Anexo 1. Neste período a participação de cada elemento varia em função da demanda de produção e da qualidade e desempenho operacional do Alto Forno, que por sua vez depende da estabilidade do processo de redução e equilíbrio térmico. Discriminam-se, em seguida, os materiais que compõem as entradas 1 e 2 , bem como a saída do Alto Forno, tal como é apresentado esquematicamente na Figura 29. Adotou-se tal estrutura de entradas e saídas pelo fato de ser a mesma adotada para a coleta de parâmetros do sistema supervisório de produção. 


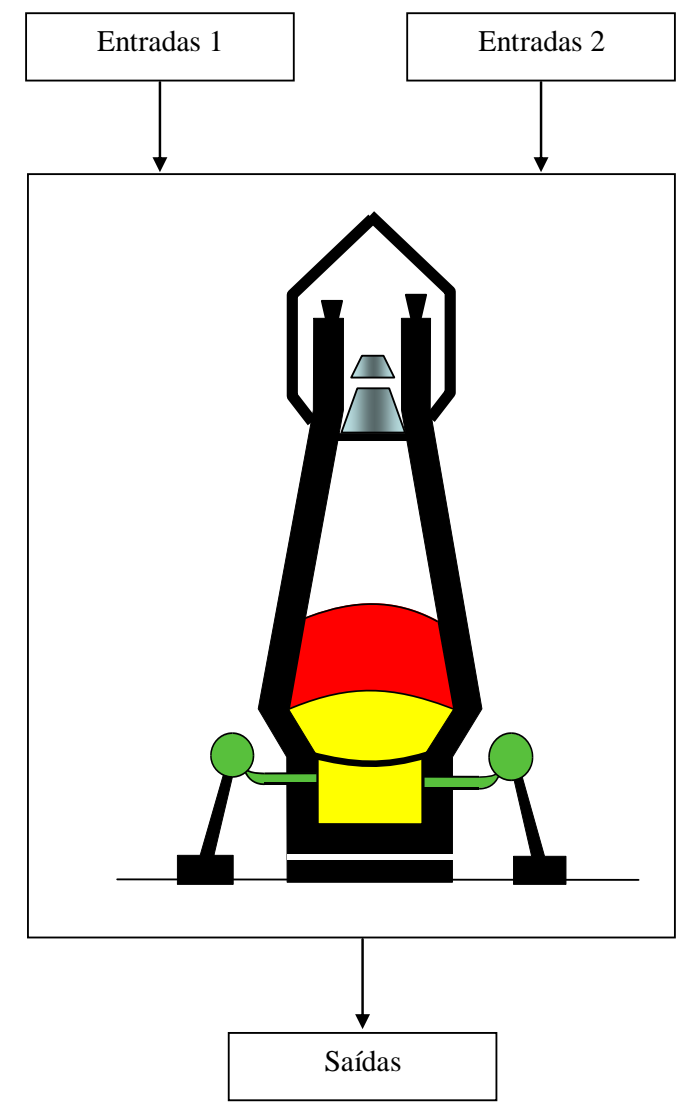

Figura 29 - Balanço de massa: Entradas e saídas

Entradas 1:

1- Minério;

2- Sínter Direto;

3- Sínter do Pátio;

4- Pelota;

5- Sucata de Aço;

6- Sucata de Gusa;

7- Small Sinter;

8- Quartzo;

9- Coque do CDQ;

10-Small Coke;

11- Carvão do PCI; 


\section{Entradas 2:}

1- Volume de sopro - ar;

2- Umidade de sopro - injeção de vapor;

3- Taxa de enriquecimento - injeção de oxigênio;

Saídas:

1- Gusa;

2- Escória;

3- Gás de Alto Forno - BFG;

4- Pó do coletor;

\section{4 - Balanço de Massa}

A primeira etapa de levantamento da viabilidade técnica para a injeção de plástico e/ou pneu no Alto Forno 1 da ArcelorMittal Tubarão é a elaboração do balanço de massa real com base na informação da produção do Alto Forno 1 no mês de julho de 2009 segundo dados coletados a partir do sistema supervisório de produção.

Não é objetivo do presente trabalho obter o balanço de massa completo do Alto Forno 1, mas sim obter e estabelecer um parâmetro de controle que possibilite avaliar comparativamente o impacto, ou seja, a variação neste balanço ao se adicionar ou modificar a composição da massa de entrada em relação à massa de saída.

\subsection{1 - Equacionamento do balanço de massa}

O Alto forno é um processo de produção contínuo, porém suas entradas e saídas são programadas e periódicas ao longo do dia. O equilíbrio entre as entradas e saídas ocorre efetivamente de modo a garantir a estabilidade operacional do Alto Forno. A estabilidade ocorre pelo atendimento das condições necessárias para a realização da reação de redução do minério ferro em ferro metálico. 
O corpo do Alto Forno 1 é o volume de controle VC que permanece fixo com massa em regime permanente. Nele entra a vazão em massa $\dot{\mathrm{m}}_{\mathrm{e}}=$ Entradas $1+$ Entradas 2 e sai a vazão em massa $\dot{\mathrm{m}}_{\mathrm{s}}=$ Saídas, como ilustrado na Figura 30. Assim sendo, pela equação da continuidade tem-se que a taxa de variação de massa no volume de controle VC é igual ao somatório das vazões em massa de entradas menos o somatório das vazões em massa de saída:

$$
\frac{\mathrm{dm}_{\mathrm{vc}}}{\mathrm{dt}}=\sum \dot{\mathrm{m}}_{\mathrm{e}}-\sum \dot{\mathrm{m}}_{\mathrm{s}}
$$

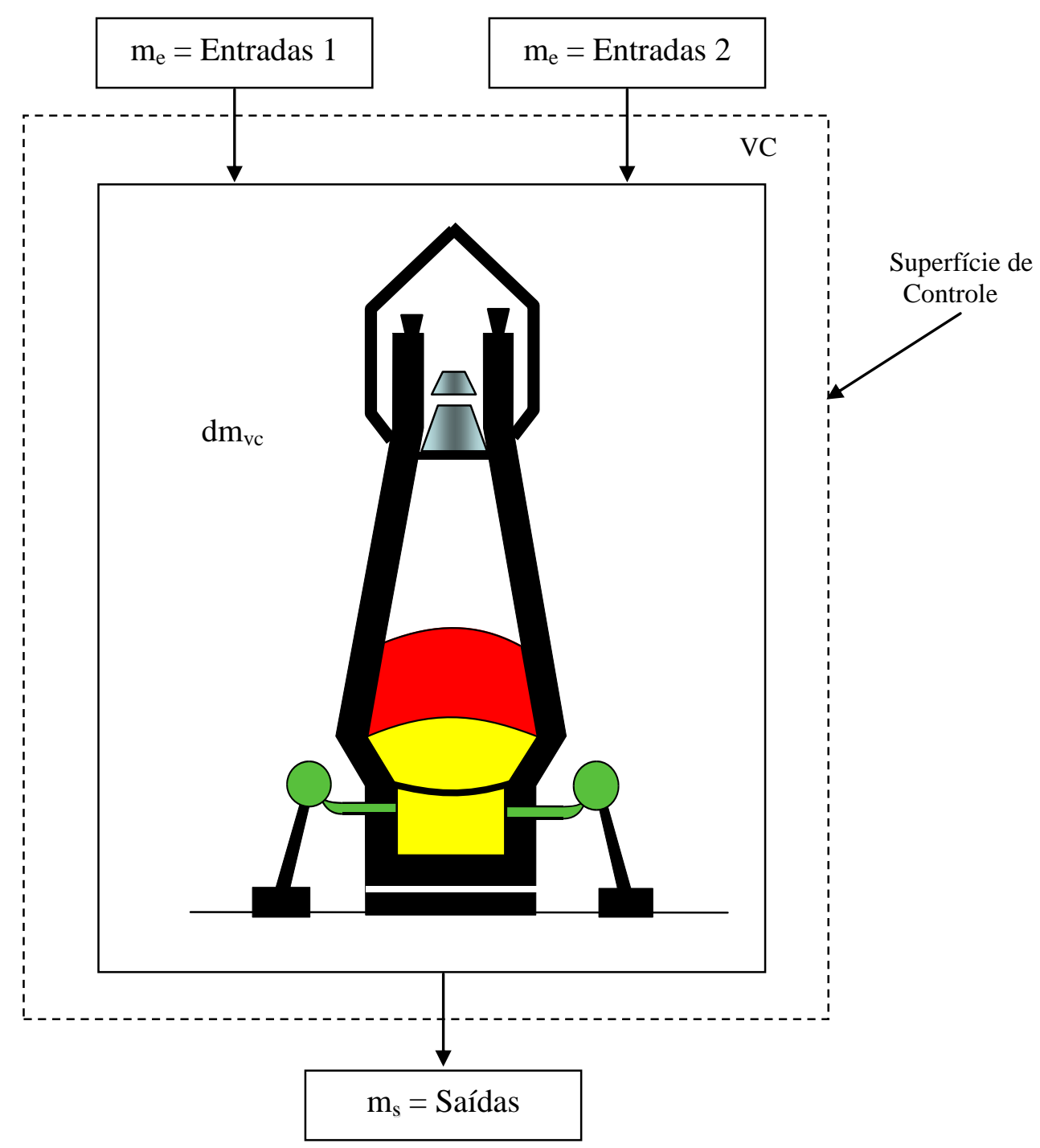

Figura 30 - Volume de controle aplicado sobre o Alto Forno 1 
O Alto Forno apresenta um volume de controle relativamente a um processo de produção que é contínuo, embora as entradas e saídas sejam feitas de forma periódicas ao longo do dia. Desta forma, é uma condição essencial que não haja acúmulo de massa no seu interior. Embora seja verdade que entre uma retirada e outra há acumulo das massas de saída, o Alto Forno é projetado para permitir este armazenamento momentâneo entre o intervalo de uma e outra retirada. Cada retirada é denominada de corrida e nela é drenado gusa e escória suficiente para permitir volume interno suficiente para a próxima acumulação.

No período em avaliação e contabilização das massas, que é de 24 horas, a taxa de variação de massa no volume de controle é igual a zero - regime permanente; desta forma, tem-se que o somatório de vazão em massa na entrada é igual ao somatório de vazão em massa na saída.

$$
\sum \dot{m}_{e}=\sum \dot{m}_{s}
$$

sendo:

$$
\begin{aligned}
\sum \dot{m}_{e} & =\text { vazão em massa de minério + vazão em massa de Sinter Direto } \\
& + \text { vazão em massa de Sinter do Pátio + vazão em massa de pelota } \\
& + \text { vazão em massa de Sucata de Aço + vazão em massa Sucata de Gusa } \\
& + \text { vazão em massa de Small Sinter + vazão em massa de Quartzo } \\
& + \text { vazão em massa de Coque CDQ + vazão em massa de Small Coke } \\
& + \text { vazão em massa de carvão injetado ( PCI) + vazão em massa de ar soprado } \\
& + \text { vazão em massa de oxigênio injetado } \\
\sum \dot{m}_{s} & =\text { vazão em massa de Gusa + vazão em massa de Escória } \\
& + \text { vazão em massa de pó do coletor de pó + vazão em massa de gás BFG. }
\end{aligned}
$$

A tabela completa com todas as vazões em massa de entrada é apresentada no Anexo 2, ao passo que a tabela completa com todas as vazões em massa de saída é listada no Anexo 3.

Com os valores das entradas e saídas obtidos através dos dados operacionais do mês de julho/2009 do Anexo 1 - Dados operacionais do Alto Forno 1 - e substituindo na equação (6), são obtidos os resultados apresentados na Tabela 13 e graficamente representadas na Figura 31. 
Tabela 13 - Dados e relação de entrada e saída de vazão em massa

\begin{tabular}{|c|c|c|c|}
\hline Data & $\sum \dot{m}_{s}(\mathrm{t} / \mathrm{dia})$ & $\sum \dot{m}_{e}(\mathrm{t} / \mathrm{dia})$ & Taxa entrada / saída \\
\hline 01/07/2009 & 7805,43 & 5513,44 & 0,706 \\
\hline 02/07/2009 & 0,00 & 220,05 & 0,000 \\
\hline 03/07/2009 & 9667,21 & 9275,99 & 0,960 \\
\hline 04/07/2009 & 21227,43 & 20299,63 & 0,956 \\
\hline 05/07/2009 & 17528,79 & 17251,12 & 0,984 \\
\hline 06/07/2009 & 31580,43 & 31196,92 & 0,988 \\
\hline 07/07/2009 & 32540,74 & 32465,92 & 0,998 \\
\hline 08/07/2009 & 32523,75 & 32678,15 & 1,005 \\
\hline 09/07/2009 & 33598,08 & 32938,12 & 0,980 \\
\hline 10/07/2009 & 33044,76 & 32975,45 & 0,998 \\
\hline $11 / 07 / 2009$ & 32852,40 & 32778,36 & 0,998 \\
\hline 12/07/2009 & 33162,28 & 33031,12 & 0,996 \\
\hline 13/07/2009 & 33126,26 & 32823,29 & 0,991 \\
\hline $14 / 07 / 2009$ & 33373,52 & 32987,05 & 0,988 \\
\hline 15/07/2009 & 33000,68 & 32911,66 & 0,997 \\
\hline 16/07/2009 & 33115,85 & 32944,05 & 0,995 \\
\hline 17/07/2009 & 33164,42 & 33115,97 & 0,999 \\
\hline 18/07/2009 & 32986,79 & 33045,02 & 1,002 \\
\hline 19/07/2009 & 32068,73 & 32368,16 & 1,009 \\
\hline 20/07/2009 & 32675,67 & 32653,24 & 0,999 \\
\hline $21 / 07 / 2009$ & 33158,72 & 32790,28 & 0,989 \\
\hline $22 / 07 / 2009$ & 33039,90 & 32897,18 & 0,996 \\
\hline $23 / 07 / 2009$ & 33068,84 & 32839,87 & 0,993 \\
\hline 24/07/2009 & 33139,42 & 32934,65 & 0,994 \\
\hline $25 / 07 / 2009$ & 33107,82 & 32968,91 & 0,996 \\
\hline 26/07/2009 & 32943,68 & 32949,75 & 1,000 \\
\hline $27 / 07 / 2009$ & 33043,81 & 33096,42 & 1,002 \\
\hline $28 / 07 / 2009$ & 29551,18 & 29687,91 & 1,005 \\
\hline 29/07/2009 & 0,00 & 218,68 & 0,000 \\
\hline $30 / 07 / 2009$ & 22095,83 & 22232,86 & 1,006 \\
\hline $31 / 07 / 2009$ & 32560,90 & 32468,02 & 0,997 \\
\hline
\end{tabular}




\section{Balanço de massa do Alto Forno 1}

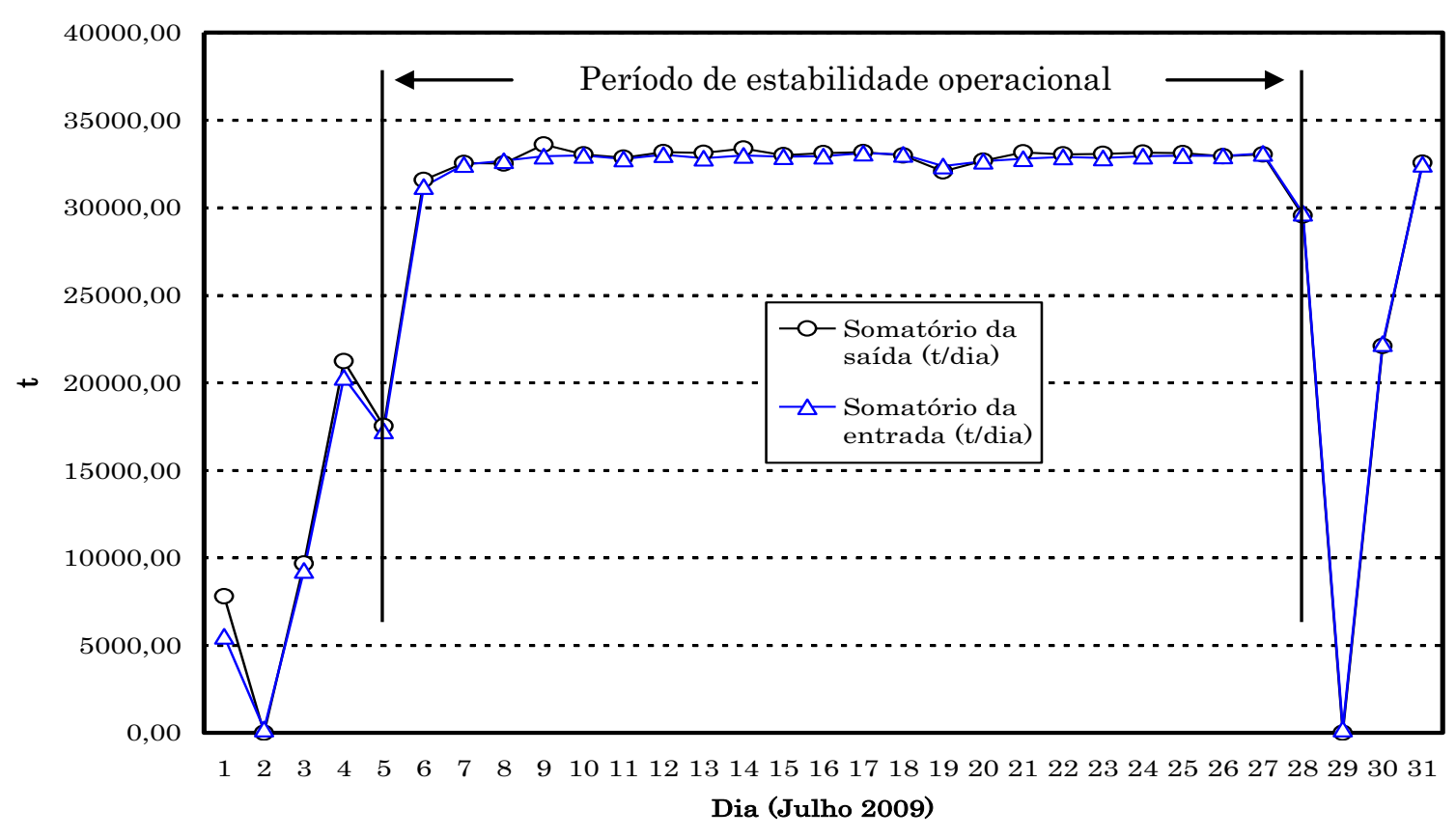

Figura 31 - Gráfico do balanço de vazão em massa

\subsection{2 - Relação entre vazão em massa de entrada e saída}

Os materiais ao serem carregados no Alto Forno sofrem uma reação química que se inicia nas camadas superiores da carga e se completa na zona de combustão e no cadinho. Parte da massa carregada é composta de materiais que se volatilizam no interior do Alto Forno, como é o caso do carvão pulverizado e do coque. De todo o carvão injetado e do coque carregado, somente o seu teor de cinzas é que se transforma efetivamente em massa de saída, sendo que o restante se transforma em gases de redução e voláteis que são incorporados ao gás gerado - o gás de Alto Forno - BFG.

A relação entre a vazão de entrada e a vazão de saída mostrada na Tabela 13 será mantida como referência para a avaliação do uso de plástico e pneus. A base para comparação será a curva mostrada no gráfico da Figura 32, que apresenta a razão entre a vazão em massa de saída em relação à vazão em massa de entrada no intervalo dos dias 06/07/09 a 28/07/09. Neste período, excluem-se do comportamento da operação/marcha do Alto Forno variações decorrentes de parada operacional. 
Gráfico da relação entre a massa de entrada e de saída do Alto Forno 1

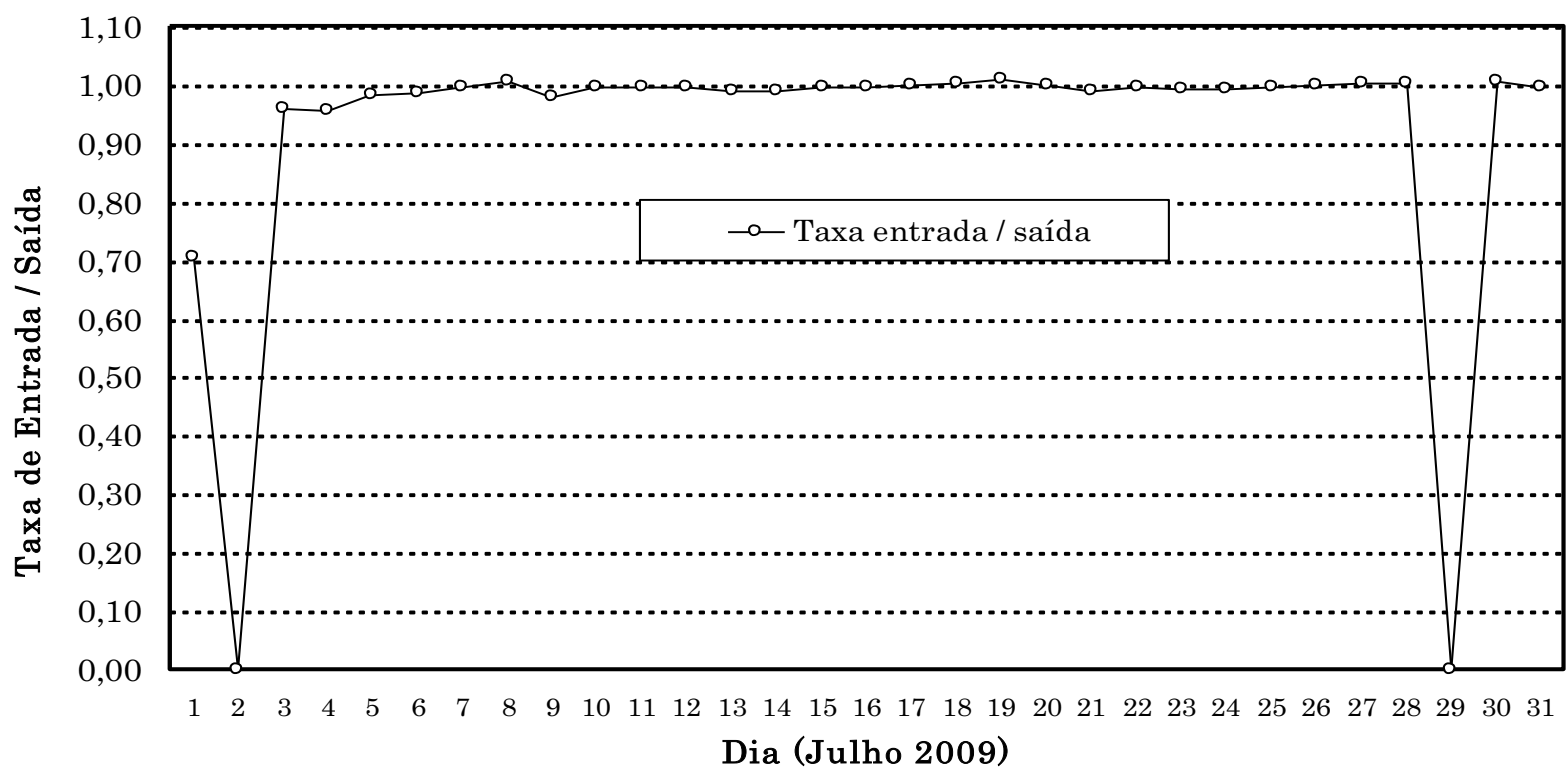

Figura 32 - Gráfico da relação da massa de entrada / saída

\subsection{3 - Parâmetro de correlação entre massa de entrada e saída}

A correlação entre a massa de saída e de entrada - Taxa saída/entrada - do Alto Forno 1 no período de 01 a 31/07/09 é o parâmetro utilizado na avaliação da variação da composição da massa de entrada em relação ao desempenho e balanço de massa real do Alto Forno 1. O balanço de massa para a injeção de plástico ou pneu está elaborado como base no carvão pulverizado injetado no Alto Forno 1.

O percentual de adição de plástico e pneu foi calculado visando manter a participação dos elementos químicos da composição original da mistura de carvões puros. O valor da composição química da mistura de carvões puros é calculado com base nos requisitos operacionais do Alto Forno e de qualidade do gusa produzido. Com base nesta premissa, na mistura considerada e no balanço geral de massa, os percentuais de participação de plástico e pneu na mistura de carvões é: plástico $=12 \% ;$ pneu $=4 \%$.

Na Tabela 14 observam-se os percentuais de cada elemento na composição do carvão puro injetado. O carvão injetado é sempre uma composição de até 3 carvões com composição química conhecida - qualidade; na Tabela 13, a mistura de carvões é composta de $20 \%$ do carvão 
tipo A (código GS 75) , 80\% do carvão tipo B (código COP 29) e 0\% do carvão tipo C (código MN1), resultando na Qualidade Total, que é a composição química média final decorrente da participação dos carvões A e B e C.

Tabela 14 - Composição de carvões e a análise química resultante

\begin{tabular}{|c|c|c|c|c|c|}
\hline Carvão A & \% & Carvão B & \% & Carvão C & \% \\
\hline GS 75 & 20 & COP 29 & 80 & MN 1 & 0 \\
\hline
\end{tabular}

\begin{tabular}{|c|c|c|c|c|}
\hline Elemento & Qualidade A & Qualidade B & Qualidade C & Qualidade Total \\
\hline $\mathrm{C}$ & 79,90 & 82,99 & 77,76 & 82,372 \\
\hline $\mathrm{H}$ & 5,29 & 3,76 & 5,25 & 4,066 \\
\hline $\mathrm{S}$ & 0,66 & 0,29 & 0,96 & 0,364 \\
\hline MV & 37,6 & 13,6 & 36,7 & 18,400 \\
\hline CINZA & 5,29 & 8,70 & 6,89 & 8,018 \\
\hline $\mathrm{O} 2$ & 7,50 & 3,03 & 7,75 & 3,924 \\
\hline $\mathrm{N}$ & 1,36 & 1,53 & 1,43 & 1,496 \\
\hline T. Fe & 4,98 & 4,41 & 7,54 & 4,524 \\
\hline $\mathrm{FeO}$ & 0 & 0 & 0 & 0 \\
\hline $\mathrm{SiO}_{2}$ & 58,05 & 45,3 & 56,34 & 47,850 \\
\hline $\mathrm{Al}_{2} \mathrm{O}_{3}$ & 21,2 & 37,6 & 19,03 & 34,320 \\
\hline $\mathrm{CaO}$ & 3,2 & 2,32 & 4,49 & 2,496 \\
\hline $\mathrm{MgO}$ & 2,4 & 0,98 & 3,02 & 1,264 \\
\hline $\mathrm{TiO}_{2}$ & 1 & 1,53 & 1,02 & 1,424 \\
\hline $\mathrm{Mn}$ & 0,1 & 0,02 & 0,08 & 0,036 \\
\hline $\mathrm{P}$ & 0,09 & 0,795 & 0,081 & 0,654 \\
\hline $\mathrm{S}$ & 1,82 & 0,208 & 0,92 & 0,530 \\
\hline $\mathrm{Zn}$ & 0,02 & 0,011 & 0,024 & 0,013 \\
\hline $\mathrm{Na}_{2} \mathrm{O}$ & 0,44 & 0,88 & 0,54 & 0,792 \\
\hline $\mathrm{K}_{2} \mathrm{O}$ & 1,7 & 1,53 & 1,51 & 1,564 \\
\hline
\end{tabular}

Na Tabela 15 são mostradas a qualidade e quantidade da composição do carvão com a adição de plástico - PL1. O resultado do balanço está mostrado na coluna Qualidade Total. Nesta tabela, a mistura de carvões é composta de $0 \%$ do carvão A, $88 \%$ do carvão B e $12 \%$ de plástico C - PL1, resultando na qualidade e quantidade mostrada na coluna Qualidade Total.

Os percentuais de variação de carbono, hidrogênio, enxofre e cinzas são obtidos em relação à mistura de carvões puros (entende-se por "variação" a variação média final dos elementos químicos carbono, hidrogênio, enxofre e cinzas, decorrente do uso de $12 \%$ de plástico PL1 misturado ao carvão A - GS75 com 0\% e ao carvão B - COP 29 com 88\%, comparados com seus valores iniciais quando da mistura original de carvões e sem a participação do plástico PL1). 
Destaca-se o aumento de $14,357 \%$ de hidrogênio e variações não relevantes de carbono e enxofre.

Tabela 15 - Composição de carvões e plástico com a análise química resultante

\begin{tabular}{|c|c|c|c|c|c|}
\hline Carvão A & \% & Carvão B & \% & Plástico C & \% \\
\hline GS 75 & 0 & COP 29 & 88 & PL1 & 12 \\
\hline
\end{tabular}

\begin{tabular}{|c|c|c|c|c|}
\hline Elemento & Qualidade A & Qualidade B & Qualidade C & Qualidade Total \\
\hline $\mathrm{C}$ & 79,90 & 82,99 & 77,81 & 82,368 \\
\hline $\mathrm{H}$ & 5,29 & 3,76 & 11,99 & 4,748 \\
\hline $\mathrm{S}$ & 0,66 & 0,29 & 0,9 & 0,363 \\
\hline $\mathrm{MV}$ & 37,6 & 13,6 & 36,7 & 16,372 \\
\hline $\mathrm{CINZA}$ & 5,29 & 8,7 & 4,9 & 8,244 \\
\hline $\mathrm{O}_{2}$ & 7,50 & 3,03 & 7,75 & 3,596 \\
\hline $\mathrm{N}$ & 1,36 & 1,53 & 1,43 & 1,518 \\
\hline $\mathrm{T} . \mathrm{Fe}$ & 4,98 & 4,41 & 7,54 & 4,785 \\
\hline $\mathrm{FeO}$ & 0 & 0 & 0 & 0 \\
\hline $\mathrm{SiO} \mathrm{O}_{2}$ & 58,05 & 45,30 & 56,34 & 46,625 \\
\hline $\mathrm{Al}_{2} \mathrm{O}_{3}$ & 21,2 & 37,6 & 19,03 & 35,372 \\
\hline $\mathrm{CaO}$ & 3,2 & 2,32 & 4,49 & 2,580 \\
\hline $\mathrm{MgO}$ & 2,4 & 0,98 & 3,02 & 1,225 \\
\hline $\mathrm{TiO}_{2}$ & 1 & 1,53 & 1,02 & 1,469 \\
\hline $\mathrm{Mn}$ & 0,1 & 0,02 & 0,08 & 0,027 \\
\hline $\mathrm{P}$ & 0,09 & 0,795 & 0,081 & 0,709 \\
\hline $\mathrm{S}$ & 1,82 & 0,208 & 0,92 & 0,293 \\
\hline $\mathrm{Zn}$ & 0,02 & 0,011 & 0,024 & 0,013 \\
\hline $\mathrm{Na}_{2} \mathrm{O}$ & 0,44 & 0,88 & 0,54 & 0,839 \\
\hline $\mathrm{K}_{2} \mathrm{O}$ & 1,7 & 1,53 & 1,51 & 1,528 \\
\hline
\end{tabular}

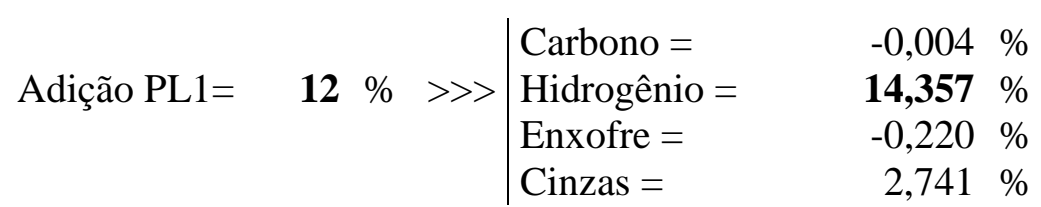

Na Tabela 16 são apresentadas a qualidade e quantidade da composição do carvão com a adição de pneu - PN1. O resultado do balanço está apresentado na coluna Qualidade Total. Nesta tabela a mistura de carvões é composta de $10 \%$ do carvão A, $86 \%$ do carvão B e $4 \%$ de pneu PN1, resultando na qualidade e quantidade mostradas na coluna Qualidade Total. Os percentuais 
de variação de carbono, hidrogênio, enxofre e cinzas são obtidos em relação à mistura de carvões puros.

Neste balanço, com a adição de $4 \%$ de pneu, ocorreu um aumento de $0,925 \%$ no enxofre e variações não relevantes de carbono e hidrogênio.

Tabela 16 - Composição de carvões e pneu com a análise química resultante

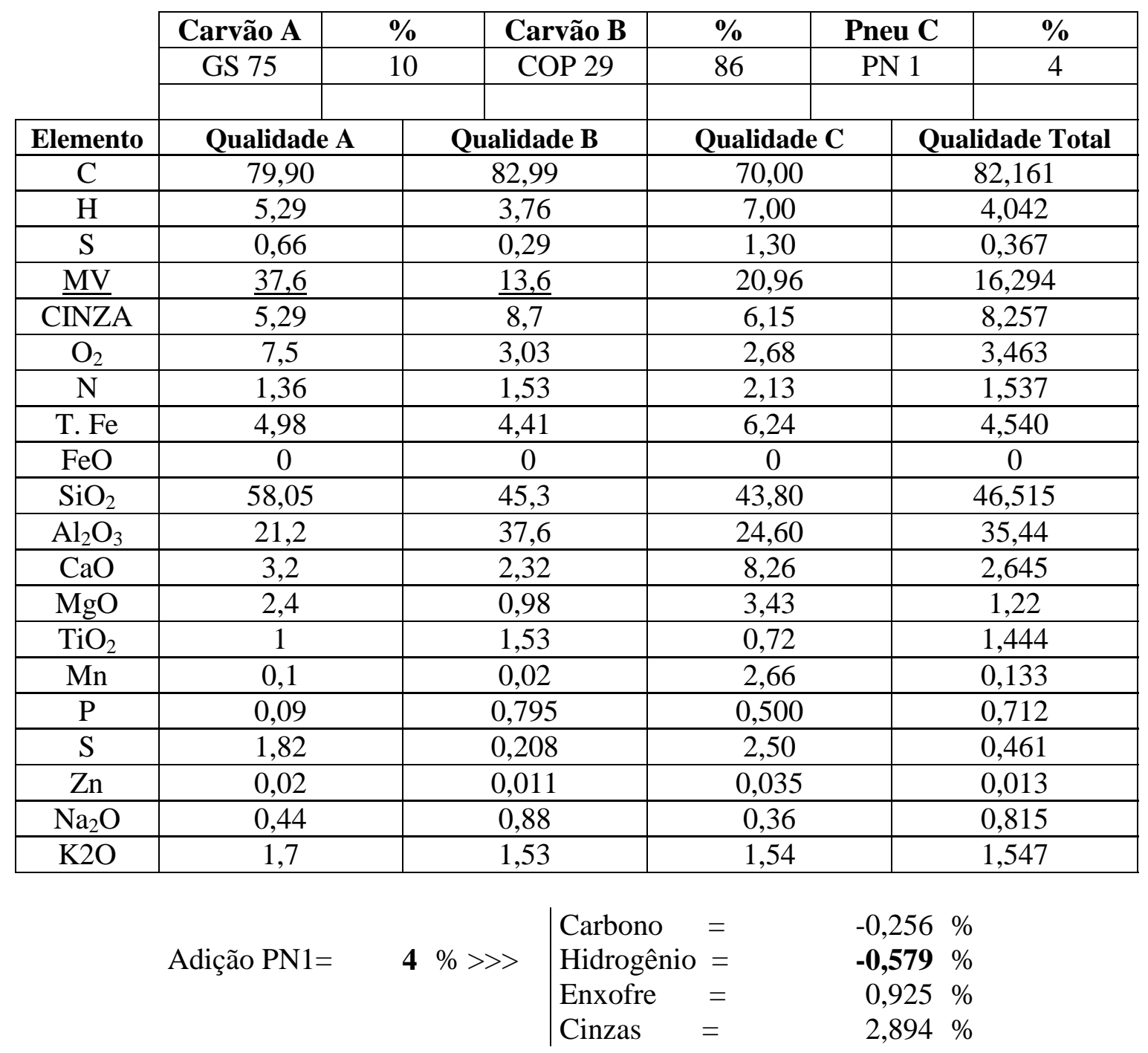




\section{5 - Balanço de Energia}

A segunda etapa de levantamento da viabilidade técnica para a injeção de plástico e/ou pneu no Alto Forno 1 da ArcelorMittal Tubarão é a da elaboração do balanço de energia real com base na informação da produção do Alto Forno no mês de julho de 2009 com dados coletados a partir do sistema informatizado de controle da produção. O mesmo volume de controle da Figura 29 é aqui utilizado para a análise do balanço de energia.

Da primeira Lei da Termodinâmica para volume de controle, obtém-se a equação (7).

$$
\frac{\mathrm{dE}_{\mathrm{vc}}}{\mathrm{dt}}=\dot{\mathrm{Q}}_{\mathrm{vc}}-\dot{\mathrm{W}}_{\mathrm{vc}}+\sum \dot{\mathrm{m}}_{\mathrm{e}}\left(\mathrm{h}_{\mathrm{e}}+\frac{\mathrm{v}_{\mathrm{e}}^{2}}{2}+\mathrm{gZ} \mathrm{Z}_{\mathrm{e}}\right)-\sum \dot{\mathrm{m}}_{\mathrm{s}}\left(\mathrm{h}_{\mathrm{s}}+\frac{\mathrm{v}_{\mathrm{s}}^{2}}{2}+\mathrm{g} \mathrm{Z}_{\mathrm{s}}\right)
$$

Para processos em regime permanente, a taxa de variação da energia no interior do volume de controle é zero; deste modo, a equação (8) representa a condição em regime permanente.

$$
0=\dot{\mathrm{Q}}_{\mathrm{vc}}-\dot{\mathrm{W}}_{\mathrm{vc}}+\sum \dot{\mathrm{m}}_{\mathrm{e}}\left(\mathrm{h}_{\mathrm{e}}+\frac{\mathrm{v}_{\mathrm{e}}^{2}}{2}+\mathrm{gZ} \mathrm{e}\right)-\sum \dot{\mathrm{m}}_{\mathrm{s}}\left(\mathrm{h}_{\mathrm{s}}+\frac{\mathrm{v}_{\mathrm{s}}^{2}}{2}+\mathrm{gZ} \mathrm{s}_{\mathrm{s}}\right)
$$

O regime permanente aplicado ao caso do Alto Forno 1 implica que o balanço de energia com a matéria prima atualmente em uso (carvão mineral pulverizado) será utilizado como parâmetro de comparação quando da utilização dos materiais alternativos; esta será a linha de referência para a avaliação final na utilização combinada de plástico e pneu em substituição parcial ao carvão mineral pulverizado.

Para tanto, admitiu-se que as perdas de energia decorrentes do sistema de resfriamento da carcaça e cadinho, perda por radiação térmica da carcaça e perda por equalização de pressão no carregamento, por exemplo, permanecerão inalteradas independentemente da alteração da composição da carga de carvão pulverizado ou plástico e pneu injetados. Entretanto, a contribuição energética decorrente da modificação na composição da carga de carvão será considerada mediante o aporte térmico/energia nos produtos de saída - gusa, escória, pó e gás. 


\subsubsection{Equacionamento do Balanço de Energia}

No equacionamento do balanço de energia as seguintes variáveis serão consideradas:

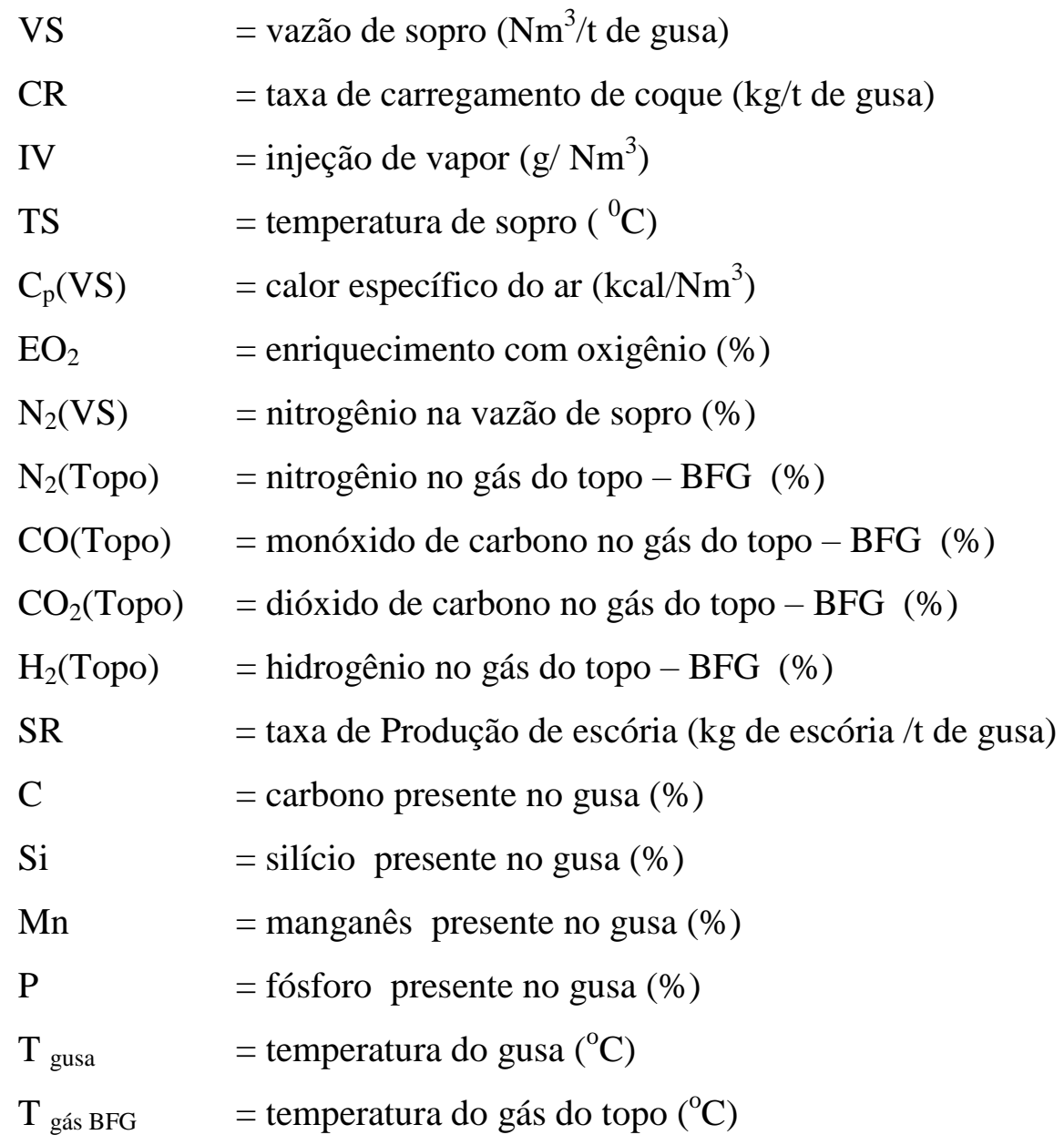

Para a realização do balanço de energia no Alto Forno 1 foram admitidas algumas premissas, a saber:

a) Não há realização de trabalho no volume de controle;

b) Despreza-se a energia cinética no processo;

c) A parcela de energia potencial é desprezível;

d) A análise será feita de forma específica, tomando-se por referência a quantidade produzida em tonelada de gusa.

Deste modo, obtém-se a equação (9). 
$0=-\mathrm{Q}_{\mathrm{vc}}+\sum \mathrm{m}_{\mathrm{e}} \mathrm{h}_{\mathrm{e}}-\sum \mathrm{m}_{\mathrm{s}} \mathrm{h}_{\mathrm{s}}$

Reescrevendo a equação (9) e mantendo válidas as condições de contorno para as novas variáveis descritas a seguir:

$\begin{array}{ll}\text { Energia térmica que entra (i, inlet }): & \mathrm{H}_{\mathrm{i}}=\sum \dot{m}_{e} \mathrm{~h}_{\mathrm{e}} \\ \text { Energia térmica que sai }(\mathrm{o}, \text { output }): & \mathrm{H}_{\mathrm{o}}=\sum \dot{m}_{s} \mathrm{~h}_{\mathrm{s}} \\ \text { Energia térmica perdida }(1, \text { loss }): & \mathrm{H}_{\mathrm{l}}=\mathrm{Q}_{\mathrm{vc}}\end{array}$

deduz-se que

$\mathrm{H}_{\mathrm{i}}=\mathrm{H}_{\mathrm{o}}+\mathrm{H}_{1}$

A discriminação das diversas energias térmicas envolvidas é realizada com base nos elementos envolvidos no processo de transformação que ocorre no Alto Forno. As quantidades de energia envolvidas na energia térmica que entra no Alto Forno são explicitadas na equação (11).

$\mathrm{H}_{\mathrm{i}}=\mathrm{H}_{\mathrm{i} 1}+\mathrm{H}_{\mathrm{i} 2}+\mathrm{H}_{\mathrm{i} 3}+\mathrm{H}_{\mathrm{i} 4}=\sum_{\mathrm{n}=1}^{\mathrm{n}=4} \mathrm{H}_{\mathrm{in}}$

sendo:

$\mathrm{H}_{\mathrm{i} 1}=$ calor de combustão do carbono (coque, carvão);

$\mathrm{H}_{\mathrm{i} 2}=$ calor sensível do ar de sopro;

$\mathrm{H}_{\mathrm{i} 3}=$ calor da redução indireta (reação pelo CO);

$\mathrm{H}_{\mathrm{i} 4}=$ calor de formação da escória;

As quantidades de energia envolvidas na energia térmica que sai do Alto Forno são explicitadas na equação (12). 
$\mathrm{H}_{\mathrm{o}}=\mathrm{H}_{\mathrm{o} 1}+\mathrm{H}_{\mathrm{o} 2}+\mathrm{H}_{\mathrm{o} 3}+\mathrm{H}_{\mathrm{o} 4}+\mathrm{H}_{\mathrm{o} 5}+\mathrm{H}_{\mathrm{o} 6}+\mathrm{H}_{\mathrm{o} 7}=\sum_{\mathrm{n}=1}^{\mathrm{n}=7} \mathrm{H}_{\mathrm{on}}$

sendo:

$\mathrm{H}_{\mathrm{o} 1}=$ calor da reação solution loss ${ }^{2}$;

$\mathrm{H}_{\mathrm{o} 2}=$ calor da redução do hidrogênio;

$\mathrm{H}_{\mathrm{o} 3}=$ calor sensível do gás BFG;

$\mathrm{H}_{04}=$ calor sensível do ferro gusa e da escória;

$\mathrm{H}_{\mathrm{o} 5}=$ calor de redução pelo carbono do silício, manganês e fósforo;

$\mathrm{H}_{\mathrm{o6}}=$ calor de decomposição do vapor - presente no ar de sopro;

$\mathrm{H}_{\mathrm{o} 7}$ = calor de evaporação da água - do coque, minério;

As quantidades de energia envolvidas na energia térmica perdida pelo Alto Forno são explicitadas na equação (13).

$\mathrm{H}_{1}=\mathrm{H}_{11}+\mathrm{H}_{12}+\mathrm{H}_{13}+\mathrm{H}_{14}=\sum_{\mathrm{n}=1}^{\mathrm{n}=4} \mathrm{H}_{1 \mathrm{n}}$

sendo:

$\mathrm{H}_{11}=$ calor removido/absorvido pelo sistema de resfriamento dos staves (trocadores de calor da carcaça, ventaneiras e cadinho do Alto Forno);

$\mathrm{H}_{12}=$ calor removido por radiação da carcaça do Alto Forno;

$\mathrm{H}_{13}=$ calor cedido pelo ar soprado no anel de vento do Alto Forno;

$\mathrm{H}_{14}=$ variação da entalpia no interior do cadinho do alto Forno.

Desta forma, a equação final representativa do balanço de energia no Alto Forno é expressa pela equação (14).

$\mathrm{H}_{\mathrm{i} 1}+\mathrm{H}_{\mathrm{i} 2}+\mathrm{H}_{\mathrm{i} 3}+\mathrm{H}_{\mathrm{i} 4}=\left(\mathrm{H}_{\mathrm{o} 1}+\mathrm{H}_{\mathrm{o} 2}+\mathrm{H}_{\mathrm{o} 3}+\mathrm{H}_{\mathrm{o} 4}+\mathrm{H}_{\mathrm{o} 5}+\mathrm{H}_{\mathrm{o} 6}+\mathrm{H}_{\mathrm{o} 7}\right)+\left(\mathrm{H}_{11}+\mathrm{H}_{12}+\mathrm{H}_{13}+\mathrm{H}_{14}\right)$

\footnotetext{
${ }^{2}$ Solution loss $=\mathrm{O}$ coque no estado sólido é parcialmente consumido pelo dióxido de carbono: $\mathrm{C}(\mathrm{s})+\mathrm{CO}_{2}(\mathrm{~g})=2 \mathrm{CO}(\mathrm{g})$.
} 


\subsubsection{Obtenção do Balanço de Energia}

O balanço de energia será elaborado como uma variável específica em relação à produção de gusa do Alto Forno. O resultado será na unidade específica de kcal/t de gusa. Da mesma forma, as massas envolvidas no cálculo serão apresentadas em uma unidade específica por unidade de gusa, sendo apresentada com terminação rate. Por exemplo, coque rate = massa de coque por tonelada de gusa produzido ( $\mathrm{kg} / \mathrm{t}$ de gusa).

\section{- Cálculo da energia de entrada $\left(\mathbf{H}_{\mathrm{i}}\right)$}

- $\mathrm{Hi}_{1}=$ calor de combustão do carbono (coque e carvão):

O calor de combustão do carbono é computado tomando-se a massa de cada componente de carbono multiplicado pelo respectivo poder calorífico (para o coque e para o carvão injetado), bem como a parcela dos componentes alternativos considerados (plástico e pneu), na temperatura de operação. A equação (15) apresenta a expressão correspondente.

$\mathrm{H}_{\mathrm{i} 1}=\mathrm{m}_{\text {coque }} \mathrm{PCI}_{\text {coque }}+\mathrm{m}_{\text {carvão }} \mathrm{PCI}_{\text {carvão }}+\mathrm{m}_{\text {plástico }} \mathrm{PCI}_{\text {plástico }}+\mathrm{m}_{\text {pneu }} \mathrm{PCI}_{\text {pneu }}$

O carvão pulverizado injetado é totalmente consumido no momento da injeção; o coque, por sua vez, é consumido de forma lenta e gradual ao longo das reações químicas em função da disponibilidade de oxigênio do ar soprado e do hidrogênio do vapor, tal como é apresentado nas reações que seguem:

$\mathrm{C}+1 / 2 \mathrm{O}_{2}=\mathrm{CO}$

e

$\mathrm{C}+\mathrm{H}_{2} \mathrm{O}=\mathrm{H}_{2}+\mathrm{CO}$

Assim sendo, a quantidade de carbono obtida a partir do coque será calculada de acordo com o balanço de entrada dos reagentes oxigênio e hidrogênio (provenientes da injeção de vapor no ar soprado), conforme equação (16). 
$\mathrm{m}_{\text {coque }}=\mathrm{VS}\left(0,21+\frac{\mathrm{EO}_{2}}{100}\right) \cdot\left(\frac{12}{11,2}\right)+\mathrm{VS} \cdot \mathrm{IV} \cdot 10^{-3} \cdot\left(\frac{12}{18}\right)-\mathrm{m}_{\text {carvão }}$

sendo:

VS = vazão de sopro $\left(\mathrm{Nm}^{3} / \mathrm{t}\right.$ de gusa $)$

$\mathrm{EO}_{2}=$ enriquecimento com oxigênio $(\%)$

IV = Injeção de vapor $\left(\mathrm{g} / \mathrm{Nm}^{3}\right)$

$11,2 / 12=$ relação em $\left(\mathrm{g} / \mathrm{Nm}^{3}\right)$ relativo à proporção entre $1 / 2 \mathrm{O}_{2} \mathrm{e} \mathrm{C}$

$18 / 12$ = relação em $(\mathrm{g} / \mathrm{g})$ relativo à proporção entre $\mathrm{H}_{2} \mathrm{O}$ e C

- $\mathrm{Hi}_{2}=$ calor sensível do ar de sopro:

O calor sensível do ar de sopro é obtido a partir da equação (17).

$\mathrm{H}_{\mathrm{i} 2}=\mathrm{VS} \cdot \mathrm{TS} \cdot \mathrm{C}_{\mathrm{p}}(\mathrm{VS})$

sendo:

TS $=$ Temperatura de sopro $\left({ }^{0} \mathrm{C}\right)$

$\mathrm{C}_{\mathrm{p}}(\mathrm{VS})=$ Calor específico do ar $\left(\mathrm{em} \mathrm{kcal} / \mathrm{Nm}^{3}\right)$

Para efeito deste trabalho, na ArcelorMittal Tubarão são utilizados os seguintes valores para o calor específico do ar nas condições de temperatura operacionais:

$$
\begin{aligned}
& \mathrm{Cp}(\mathrm{VS})=0,338 \mathrm{kcal} / \mathrm{Nm}^{3} \text { para }\left(1000^{\circ} \mathrm{C}\right) \\
& \mathrm{Cp}(\mathrm{VS})=0,340 \mathrm{kcal} / \mathrm{Nm}^{3} \text { para }\left(1100^{\circ} \mathrm{C}\right) \\
& \mathrm{Cp}(\mathrm{VS})=0,343 \mathrm{kcal} / \mathrm{Nm}^{3} \text { para }\left(1200^{\circ} \mathrm{C}\right) \\
& \mathrm{Cp}(\mathrm{VS})=0,345 \mathrm{kcal} / \mathrm{Nm}^{3} \text { para }\left(1300^{\circ} \mathrm{C}\right)
\end{aligned}
$$

- $\mathrm{Hi}_{3}=$ calor da redução indireta (reação pelo $\left.\mathrm{CO}\right)$;

O calor da redução indireta é obtido a partir da equação (18).

$\mathrm{H}_{\mathrm{i} 3}=\mathrm{Fe}(\mathrm{CO}) \cdot 60$

Nesta equação, o termo $\mathrm{Fe}(\mathrm{CO})$ representa o conteúdo de ferro reduzido pelo $\mathrm{CO}$, que pode ser estimado pela equação (19); as quantidades envolvidas no conteúdo de ferro reduzido pelo gusa e pelo hidrogênio são estimados pela seqüência de expressões definidas na reação $\mathrm{Fe}_{2} \mathrm{O}_{3}+3 \mathrm{H}_{2} \rightarrow 2 \mathrm{Fe}+3 \mathrm{H}_{2} \mathrm{O}$ e determinadas pelas equações (20) a (23). 
$\mathrm{Fe}(\mathrm{CO})=\mathrm{Fe}($ gusa $)-\mathrm{Fe}\left(\mathrm{H}_{2}\right)$

$\mathrm{Fe}($ gusa $)=998-10 \cdot(\mathrm{C}+\mathrm{Si}+\mathrm{P}+\mathrm{Mn})$

$\mathrm{Fe}\left(\mathrm{H}_{2}\right)=\mathrm{H}_{2}$ (entrada) $-\mathrm{H}_{2}($ saída $) \cdot \frac{(2 \cdot 55,84)}{(3 \times 22,4)}$

$\mathrm{H}_{2}($ entrada $)=\mathrm{VS} \cdot \mathrm{IV} \cdot 10^{-3} \cdot \frac{22,4}{18}$

$\mathrm{H}_{2}($ saída $)=\mathrm{VS} \cdot\left(\frac{\mathrm{N}_{2}(\mathrm{VS})}{\mathrm{N}_{2}(\text { Topo })}\right) \cdot \frac{\mathrm{H}_{2}(\text { Topo })}{100}$

Na equação (20), os termos C, Si, P e Mn referem-se aos percentuais de carbono, silício, fósforo e manganês presentes no ferro gusa.

- $\mathrm{Hi}_{4}=$ calor de formação da escória:

O calor de formação da escória é obtido a partir da equação (24).

$\mathrm{H}_{\mathrm{i} 4}=\mathrm{SR} \cdot \mathrm{C}_{\mathrm{p} \text { (escória) }}$

sendo:

SR = taxa de Produção de escória (kg de escória/tonelada de gusa)

$\mathrm{C}_{\mathrm{p}(\text { escória })}=140 \mathrm{kcal} / \mathrm{kg}{ }^{0} \mathrm{C}$

Os valores da energia total de entrada $\left(\mathrm{H}_{\mathrm{i}}\right)$, calculados a partir da metodologia estabelecida, para os dados operacionais do mês de julho de 2009, estão apresentados na Tabela 17. Tais resultados representam uma avaliação da condição da operação apenas com coque e carvão, isto é, sem a adição de pneus ou plásticos. 
Tabela 17 - Energia de entrada do Alto Forno 1 da ArcelorMittal Tubarão

\begin{tabular}{|c|c|c|c|c|c|}
\hline $\begin{array}{c}\text { Data de } \\
\text { aquisição dos } \\
\text { dados } \\
\text { operacionais }\end{array}$ & $\begin{array}{l}\text { H}_{\text {i1 }} \text { - Calor gerado na } \\
\text { Combustão do Carbono: } \\
\text { do Coque e do Carvão } \\
\text { injetado }\left(10^{3} \mathrm{kcal} / \mathrm{t} \text { gusa }\right)\end{array}$ & $\begin{array}{c}\mathbf{H}_{\mathbf{i} 2}-\text { Calor } \\
\text { sensível do ar } \\
\text { soprado } \\
\left(10^{3} \mathrm{kcal} / \mathrm{t} \text { gusa }\right) \\
\end{array}$ & $\begin{array}{l}\mathbf{H}_{\mathrm{i} 3} \text { - Calor gerado na } \\
\text { redução indireta do } \\
\text { Ferro pelo CO } \\
\left(10^{3} \mathrm{kcal} / \mathrm{t} \text { gusa }\right)\end{array}$ & $\begin{array}{c}\mathbf{H}_{\mathbf{i} 4}-\text { Calor de } \\
\text { formação da } \\
\text { escória } \\
\left(10^{3} \mathrm{kcal} / \mathrm{t} \text { gusa }\right)\end{array}$ & $\begin{array}{c}\mathbf{H}_{\mathbf{i}}-\text { Energia } \\
\text { Total de } \\
\text { entrada } \\
\left(10^{3} \mathrm{kcal} / \mathrm{t} \text { gusa }\right) \\
\end{array}$ \\
\hline 01/07/2009 & 678,86 & 371,28 & 66,99 & 20,31 & 1137,44 \\
\hline $02 / 07 / 2009$ & 0,00 & 0,00 & 0,00 & 0,00 & 0,00 \\
\hline $03 / 07 / 2009$ & 1075,99 & 574,65 & $-69,82$ & 42,40 & 1623,22 \\
\hline $04 / 07 / 2009$ & 892,07 & 488,17 & $-79,54$ & 43,51 & 1344,21 \\
\hline $05 / 07 / 2009$ & 685,05 & 380,98 & 2,56 & 48,72 & 1117,31 \\
\hline $06 / 07 / 2009$ & 676,26 & 392,22 & 5,24 & 35,32 & 1109,04 \\
\hline $07 / 07 / 2009$ & 637,84 & 373,42 & 13,54 & 35,03 & 1059,83 \\
\hline $08 / 07 / 2009$ & 623,39 & 374,39 & 17,64 & 34,27 & 1049,69 \\
\hline $09 / 07 / 2009$ & 624,59 & 373,11 & 16,54 & 32,64 & 1046,89 \\
\hline $10 / 07 / 2009$ & 617,42 & 376,04 & 19,63 & 32,11 & 1045,19 \\
\hline $11 / 07 / 2009$ & 618,81 & 376,33 & 18,45 & 32,76 & 1046,35 \\
\hline $12 / 07 / 2009$ & 623,64 & 379,73 & 17,11 & 32,70 & 1053,18 \\
\hline $13 / 07 / 2009$ & 625,85 & 377,78 & 15,22 & 33,77 & 1052,63 \\
\hline $14 / 07 / 2009$ & 620,22 & 374,54 & 14,74 & 34,26 & 1043,75 \\
\hline $15 / 07 / 2009$ & 623,93 & 378,70 & 17,10 & 35,66 & 1055,40 \\
\hline $16 / 07 / 2009$ & 624,85 & 377,35 & 15,15 & 36,56 & 1053,91 \\
\hline $17 / 07 / 2009$ & 616,02 & 375,40 & 17,75 & 35,29 & 1044,45 \\
\hline $18 / 07 / 2009$ & 614,02 & 375,19 & 18,82 & 34,37 & 1042,40 \\
\hline $19 / 07 / 2009$ & 620,44 & 382,44 & 19,87 & 33,68 & 1056,44 \\
\hline $20 / 07 / 2009$ & 614,20 & 374,54 & 19,50 & 33,14 & 1041,38 \\
\hline $21 / 07 / 2009$ & 619,46 & 377,86 & 18,64 & 33,14 & 1049,10 \\
\hline $22 / 07 / 2009$ & 613,76 & 374,09 & 18,33 & 33,44 & 1039,62 \\
\hline $23 / 07 / 2009$ & 607,63 & 373,74 & 21,50 & 34,36 & 1037,23 \\
\hline $24 / 07 / 2009$ & 623,21 & 370,33 & 15,42 & 34,40 & 1043,37 \\
\hline $25 / 07 / 2009$ & 617,54 & 373,20 & 18,84 & 33,67 & 1043,24 \\
\hline $26 / 07 / 2009$ & 615,78 & 375,45 & 17,56 & 33,18 & 1041,97 \\
\hline $27 / 07 / 2009$ & 608,66 & 371,87 & 18,57 & 32,97 & 1032,06 \\
\hline $28 / 07 / 2009$ & 600,44 & 365,60 & 17,41 & 32,89 & 1016,35 \\
\hline $29 / 07 / 2009$ & 0,00 & 0,00 & 0,00 & 0,00 & 0,00 \\
\hline $30 / 07 / 2009$ & 645,20 & 357,27 & 20,39 & 33,21 & 1056,06 \\
\hline $31 / 07 / 2009$ & 605,87 & 374,92 & 23,39 & 33,95 & 1038,14 \\
\hline
\end{tabular}

- Cálculo da energia de saída $\left(\mathbf{H}_{0}\right)$

- $\mathbf{H}_{01}=$ calor da reação solution loss:

O calor de reação solution loss é obtido a partir da equação (25).

$\mathrm{H}_{\mathrm{o} 1}=\mathrm{C}_{\mathrm{sol}} \cdot 3230$ 
A parcela $\mathrm{C}_{\mathrm{sol}}$ representa o carbono que participa na reacão solution loss. A parcela $\mathrm{C}_{\mathrm{gas}}$ representa a parcela de carbono disponivel para se transformar na forma gasosa. A parcela $C_{\text {in }}$ representa todo o carbono que entra no Alto Forno. A parcela $\mathrm{C}_{\mathrm{ot}}$ representa a parcela de carbono consumida pelo oxigenio formando o agente redutor - CO. A parcela Csi representa o carbono consumido nas reacoes com o silicio, manganês e fosforo e pode ser calculada pelas equações (26) a (30).

$$
\begin{aligned}
& \mathrm{C}_{\text {sol }}=\mathrm{C}_{\text {gás }}-\left(\mathrm{C}_{\mathrm{ot}}+\mathrm{C}_{\mathrm{si}}\right) \\
& \mathrm{C}_{\text {gás }}=\mathrm{C}_{\mathrm{in}}-10 \cdot \mathrm{C}_{\text {(gusa) }} \\
& \mathrm{C}_{\mathrm{in}}=\mathrm{CR} \cdot \mathrm{C}_{\text {coque }}+\mathrm{PCR} \cdot \mathrm{C}_{\text {carvão }}-\mathrm{m}_{\mathrm{Pó}} \cdot \mathrm{C}_{\mathrm{pó}} \cdot 2,0 \\
& \mathrm{C}_{\mathrm{ot}}=\mathrm{C}_{\mathrm{ot}} \cdot \mathrm{PCR}+\mathrm{C}_{\mathrm{ot}} \cdot \mathrm{CR} \\
& \mathrm{C}_{\mathrm{si}}=8,551 \cdot \mathrm{Si}_{\text {(gusa) }}+2,185 \cdot \mathrm{Mn}_{\text {(gusa) }}+9,687 \cdot \mathrm{P}_{\text {(gusa) }}
\end{aligned}
$$

sendo:

$$
\begin{aligned}
& \mathrm{CR}=\text { coke ratio }(\mathrm{kg} / \mathrm{t} \text { gusa }) \\
& \mathrm{PCR}=\text { Taxa de injeção de carvão }(\mathrm{kg} / \mathrm{t} \text { gusa }) \\
& \mathrm{m}_{\text {pó }}=\text { massa de pó }(\mathrm{kg} / \mathrm{t} \text { gusa }) \\
& \mathrm{C}_{\text {pó }}=\text { carbono contido no pó }(\%) \\
& \mathrm{C}_{\text {coque }}=\text { Carbono contido no coque } \\
& \mathrm{C}_{\text {carvão }}=\text { Carbono contido no carvão }
\end{aligned}
$$

- $H_{02}=$ calor da redução do hidrogênio:

O calor de redução do hidrogênio é obtido a partir da equação (31).

$$
\mathrm{H}_{\mathrm{o} 2}=\mathrm{Fe}\left(\mathrm{H}_{2}\right) \cdot 205
$$

sendo:

$$
\begin{aligned}
& \mathrm{Fe}\left(\mathrm{H}_{2}\right)=\left(\mathrm{H}_{2 \text { (entrada) }}-\mathrm{H}_{2 \text { (sáíd) })}\right) \cdot \frac{(2 \times 55,84)}{(3 \times 22,4)} \\
& \mathrm{H}_{2 \text { (entrada) }}=\mathrm{VS} \cdot \mathrm{IV} \cdot 10^{-3} \frac{22,4}{18} \\
& \mathrm{H}_{2 \text { (saída) }}=\mathrm{VS} \cdot\left(\frac{\mathrm{N}_{2 \text { (VS) }}}{\mathrm{N}_{2 \text { (Topo })}}\right) \cdot\left(\frac{\mathrm{H}_{2(\text { Topo })}}{100}\right)
\end{aligned}
$$


- $\mathrm{Ho}_{3}=$ calor sensível do gás BFG:

O calor sensível do gás BFG é obtido a partir da equação (35).

$\mathrm{H}_{\mathrm{o} 3}=\dot{\mathrm{m}}_{\mathrm{sopro}} \cdot \frac{\mathrm{N}_{2 \text { sopro }}}{\mathrm{N}_{2 \text { gás BFG }}} \cdot \mathrm{T}_{\text {gás BFG }} \cdot 10^{-2} \cdot\left(\mathrm{CO}_{\text {gás }} \cdot 0,312+\mathrm{CO}_{2, \text { gás }} \cdot 0,412+\mathrm{N}_{2, \text { gás }} \cdot 0,311+\mathrm{H}_{2, \text { gás }} \cdot 0,307\right)$

\section{$\mathrm{Ho}_{4}$ = calor sensível do gusa e da escória:}

O calor sensível do ferro gusa e da escória é obtido a partir da equação (36).

$\mathrm{H}_{\mathrm{o} 4}=$ gusa rate $\cdot\left[(300+0,205) \cdot \mathrm{T}_{\text {gusa }}-1400\right]+$ escória rate $\cdot\left[(400+0,288) \cdot \mathrm{T}_{\text {gusa }}-1400\right]$

- $\mathrm{Ho}_{5}=$ calor de redução pelo carbono do silício, manganês e fósforo:

O calor de redução é obtido a partir da equação (37).

$\mathrm{H}_{\mathrm{o} 5}=[7460 \cdot(\mathrm{Si})+1680 \cdot(\mathrm{Mn})+5810 \cdot(\mathrm{P})] \cdot 10$

- $\mathrm{Ho}_{6}=$ calor de decomposição do vapor (presente no ar de sopro):

O calor de decomposição do vapor do ar de sopro é obtido a partir da equação (38).

$\mathrm{H}_{\mathrm{o} 6}=\mathrm{V}_{\text {sopro }} \cdot \varphi_{\text {sopro }} \cdot 10^{-3} \cdot 3191$

sendo:

$\mathrm{V}_{\text {sopro }}=$ volume de sopro $\left(\mathrm{Nm}^{3} / \mathrm{t}\right.$ de gusa $)$

$\varphi_{\text {sopro }}=$ umidade de sopro $\left(\mathrm{g} / \mathrm{Nm}^{3}\right)$

- $\mathrm{Ho}_{7}=$ calor de evaporação da água (do coque, minério):

O calor de evaporação da água é obtido a partir da equação (39).

$\mathrm{H}_{\mathrm{o} 7}=\left(\right.$ coque rate $\cdot \varphi_{\text {coque }}+\min$ erio rate $\left.\cdot \varphi_{\text {min erio }}+\sin \operatorname{ter} \operatorname{rate} \cdot \varphi_{\text {sinter }}+\operatorname{sucata} \cdot \varphi_{\text {sucata }}\right) \cdot 615$

No sínter consideram-se as parcelas: direta, pátio, small sinter e pelota; em sucatas, considera-se aço e gusa. Na Tabela 18 são apresentados o resultado do cálculo da energia de saída do Alto Forno 1 da ArcelorMittal Tubarão, calculados a partir da metodologia estabelecida, para os dados operacionais do mês de julho de 2009. A energia perdida $\left(\mathrm{H}_{1}\right)$ é obtida por diferença, através da equação (10). A Tabela 19 e a Figura 33 apresentam os valores consolidados para os três blocos de energia analisados. 


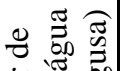

完 䒕 药

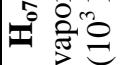

$\because$

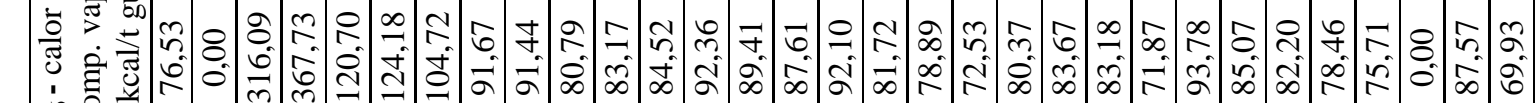

تصن

西

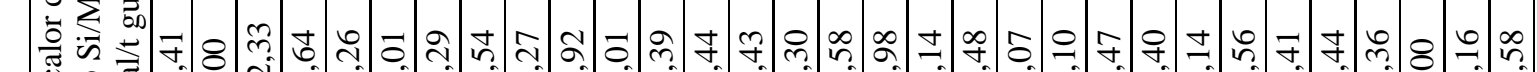

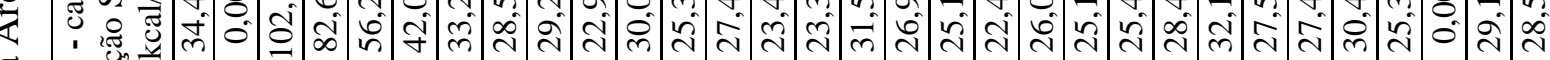

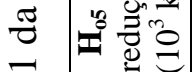

:

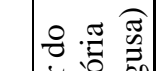

పัర

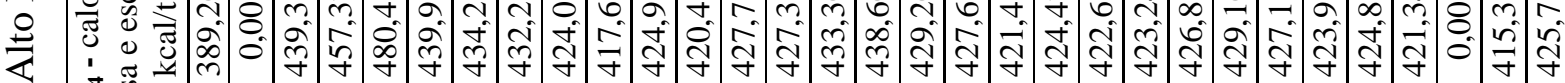

方

晃

宁

$\circ \approx \overparen{0}$

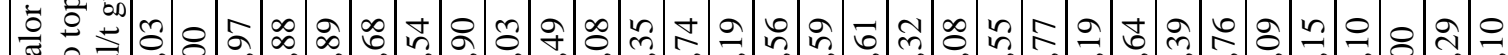

$\frac{\pi}{60}$

(1)

,

3

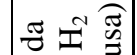

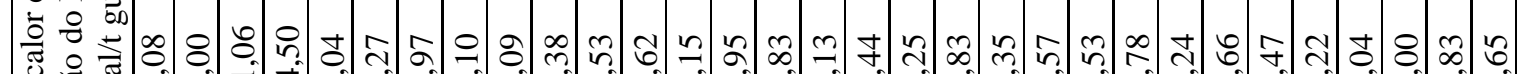
: $\stackrel{2}{0}$

ชี

పั0

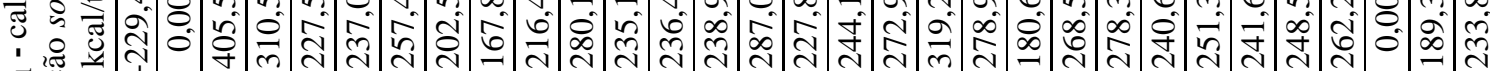

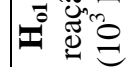

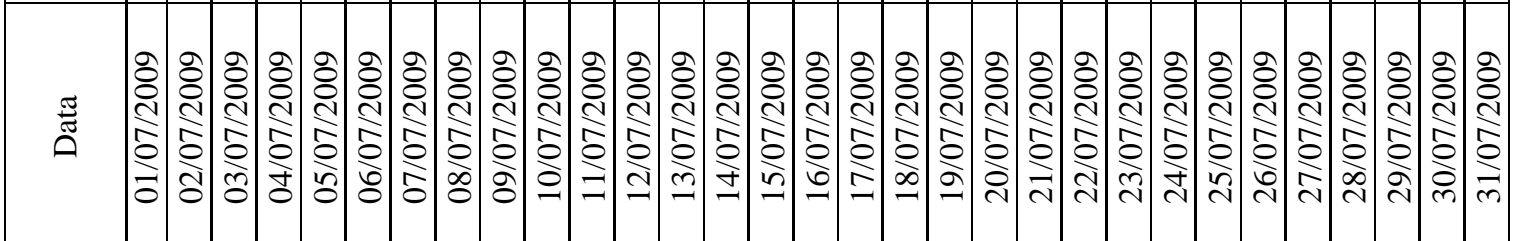


Tabela 19 - Balanço de energia do Alto Forno 1 da ArcelorMittal Tubarão

\begin{tabular}{|c|c|c|c|c|}
\hline $\begin{array}{c}\text { Data de aquisição } \\
\text { dos dados } \\
\text { operacionais }\end{array}$ & $\begin{array}{c}\mathbf{H}_{\mathbf{i}} \text { - Energia Total } \\
\text { de entrada } \\
\left(10^{3} \mathrm{kcal} / \mathrm{t} \text { gusa }\right)\end{array}$ & $\begin{array}{c}\mathbf{H}_{\mathbf{o}} \text { - EnergiaTotal } \\
\text { de saída } \\
\left(10^{3} \mathrm{kcal} / \mathrm{t} \text { gusa }\right)\end{array}$ & $\begin{array}{c}\mathbf{H}_{\mathbf{l}}-\text { Energia } \\
\text { Perdida } \\
\left(10^{3} \mathrm{kcal} / \mathrm{t} \text { gusa }\right)\end{array}$ & $\mathbf{H}_{\mathbf{l}} / \mathbf{H}_{\mathbf{i}}$ \\
\hline 01/07/2009 & 1137,44 & 355,66 & 781,77 & 0,687 \\
\hline $02 / 07 / 2009$ & 0,00 & 0,00 & 0,00 & 0,000 \\
\hline 03/07/2009 & 1623,22 & 1428,35 & 194,87 & 0,120 \\
\hline $04 / 07 / 2009$ & 1344,21 & 1388,45 & $-44,24$ & $-0,033$ \\
\hline $05 / 07 / 2009$ & 1117,31 & 1021,83 & 95,48 & 0,085 \\
\hline 06/07/2009 & 1109,04 & 969,37 & 139,68 & 0,126 \\
\hline $07 / 07 / 2009$ & 1059,83 & 941,95 & 117,88 & 0,111 \\
\hline $08 / 07 / 2009$ & 1049,69 & 861,43 & 188,27 & 0,179 \\
\hline $09 / 07 / 2009$ & 1046,89 & 822,02 & 224,86 & 0,215 \\
\hline $10 / 07 / 2009$ & 1045,19 & 838,86 & 206,33 & 0,197 \\
\hline $11 / 07 / 2009$ & 1046,35 & 923,71 & 122,64 & 0,117 \\
\hline $12 / 07 / 2009$ & 1053,18 & 883,09 & 170,09 & 0,162 \\
\hline $13 / 07 / 2009$ & 1052,63 & 899,80 & 152,83 & 0,145 \\
\hline $14 / 07 / 2009$ & 1043,75 & 892,30 & 151,45 & 0,145 \\
\hline $15 / 07 / 2009$ & 1055,40 & 945,97 & 109,43 & 0,104 \\
\hline $16 / 07 / 2009$ & 1053,91 & 905,12 & 148,79 & 0,141 \\
\hline $17 / 07 / 2009$ & 1044,45 & 890,55 & 153,91 & 0,147 \\
\hline $18 / 07 / 2009$ & 1042,40 & 910,59 & 131,80 & 0,126 \\
\hline $19 / 07 / 2009$ & 1056,44 & 950,70 & 105,73 & 0,100 \\
\hline $20 / 07 / 2009$ & 1041,38 & 923,69 & 117,69 & 0,113 \\
\hline $21 / 07 / 2009$ & 1049,10 & 829,31 & 219,79 & 0,210 \\
\hline $22 / 07 / 2009$ & 1039,62 & 913,12 & 126,50 & 0,122 \\
\hline $23 / 07 / 2009$ & 1037,23 & 915,66 & 121,56 & 0,117 \\
\hline $24 / 07 / 2009$ & 1043,37 & 905,46 & 137,91 & 0,132 \\
\hline $25 / 07 / 2009$ & 1043,24 & 896,66 & 146,57 & 0,140 \\
\hline $26 / 07 / 2009$ & 1041,97 & 879,80 & 162,17 & 0,156 \\
\hline $27 / 07 / 2009$ & 1032,06 & 890,56 & 141,51 & 0,137 \\
\hline $28 / 07 / 2009$ & 1016,35 & 885,00 & 131,34 & 0,129 \\
\hline $29 / 07 / 2009$ & 0,00 & 0,00 & 0,00 & 0,000 \\
\hline $30 / 07 / 2009$ & 1056,06 & 834,93 & 221,13 & 0,209 \\
\hline $31 / 07 / 2009$ & 1038,14 & 871,85 & 166,29 & 0,160 \\
\hline
\end{tabular}




\section{Balanço de Energia - AF1}

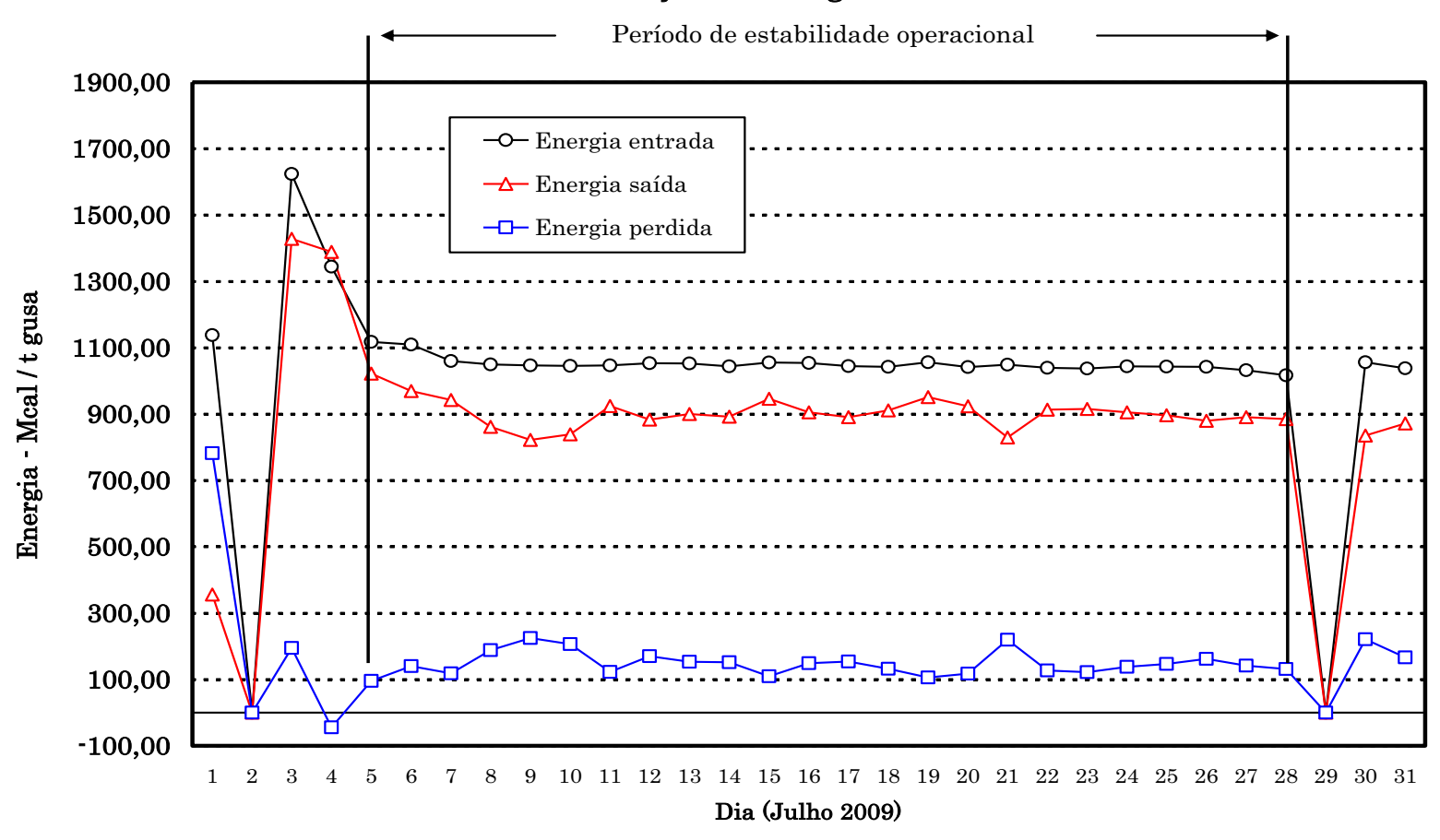

Figura 33 - Gráfico do balanço de energia do Alto Forno 1

Considerando-se apenas o período de estabilidade operacional, observa-se da Tabela 19 que há uma variação das perdas (parcela $\mathrm{Hl}$ ) em relação à energia de entrada (Hi) entre $9 \% \mathrm{e}$ 21\%; recorda-se que, no estabelecimento da metodologia, as "perdas" correspondem a parcelas térmicas não aproveitadas no processo de conversão de energia do Alto Forno, mas que, no entanto, podem representar aporte energético em outros processos com potencial relevância em termos de eficiência energética.

Com base em tais resultados, dispõe-se de uma base consistente de informações para a realização de uma série de ensaios com substituição de parte do carvão e coque por pneus ou plástico, nas proporções analisadas como adequados à manutenção da qualidade do produto final; a partir dos resultados experimentais pode-se, com o emprego das parcelas de pneu e/ou plástico da equação (15), avaliar o aumento ou redução das perdas de energia no processo com substituição energética das fontes de energia de entrada do Alto Forno.

Para uma decisão acerca de futuros ensaios com os produtos alternativos considerados, é necessário realizar uma estimativa preliminar acerca da atratividade econômica da substituição energética aqui proposta, análise que será realizada no item a seguir. 


\section{DISCUSSÃO DOS RESULTADOS}

A massa de injeção de plástico está estimada em 12 em relação à massa de injeção de carvão pulverizado, conforme mostra a Tabela 15 do item 3.5.3. Este percentual é obtido em função da análise química final da mistura carvão + plástico e pode variar em função da composição química de cada componente da mistura. Com base nos dados operacionais de julho de 2009 do Alto Forno 1, a Tabela 20 apresenta o consumo estimado em t/dia de plástico + carvão.

Tabela 20 - Estimativa de consumo de carvão + plástico

\begin{tabular}{|c|c|c|c|c|}
\hline Data & $\begin{array}{c}\text { Carvão Total } \\
\text { Realizado }=100 \% \\
\text { (t/dia) }\end{array}$ & $\begin{array}{c}\text { Carvão Estimado } \\
=88 \% \\
\text { (t/dia) }\end{array}$ & $\begin{array}{c}\text { Plástico Estimado } \\
=12 \% \\
\text { (t/dia) }\end{array}$ & $\begin{array}{c}\text { Carvão + Plástico } \\
\text { Estimado }=100 \% \\
(\mathrm{t} / \mathrm{dia})\end{array}$ \\
\hline $01 / 7 / 2009$ & 0,00 & 0,00 & 0,00 & 0,00 \\
\hline $02 / 7 / 2009$ & 0,00 & 0,00 & 0,00 & 0,00 \\
\hline $03 / 7 / 2009$ & 79,00 & 69,52 & 9,48 & 79,00 \\
\hline $04 / 7 / 2009$ & 0,00 & 0,00 & 0,00 & 0,00 \\
\hline $05 / 7 / 2009$ & 349,00 & 307,12 & 41,88 & 349,00 \\
\hline $06 / 7 / 2009$ & 1107,00 & 974,16 & 132,84 & 1107,00 \\
\hline $07 / 7 / 2009$ & 1168,00 & 1027,84 & 140,16 & 1168,00 \\
\hline $08 / 7 / 2009$ & 1255,00 & 1104,40 & 150,60 & 1255,00 \\
\hline 09/7/2009 & 1225,00 & 1078,00 & 147,00 & 1225,00 \\
\hline $10 / 7 / 2009$ & 1268,00 & 1115,84 & 152,16 & 1268,00 \\
\hline $11 / 7 / 2009$ & 1291,00 & 1136,08 & 154,92 & 1291,00 \\
\hline $12 / 7 / 2009$ & 1293,00 & 1137,84 & 155,16 & 1293,00 \\
\hline $13 / 7 / 2009$ & 1285,00 & 1130,80 & 154,20 & 1285,00 \\
\hline $14 / 7 / 2009$ & 1258,00 & 1107,04 & 150,96 & 1258,00 \\
\hline $15 / 7 / 2009$ & 1311,00 & 1153,68 & 157,32 & 1311,00 \\
\hline $16 / 7 / 2009$ & 1288,00 & 1133,44 & 154,56 & 1288,00 \\
\hline $17 / 7 / 2009$ & 1292,00 & 1136,96 & 155,04 & 1292,00 \\
\hline $18 / 7 / 2009$ & 1289,00 & 1134,32 & 154,68 & 1289,00 \\
\hline $19 / 7 / 2009$ & 1291,00 & 1136,08 & 154,92 & 1291,00 \\
\hline $20 / 7 / 2009$ & 1292,00 & 1136,96 & 155,04 & 1292,00 \\
\hline $21 / 7 / 2009$ & 1350,00 & 1188,00 & 162,00 & 1350,00 \\
\hline $22 / 7 / 2009$ & 1344,00 & 1182,72 & 161,28 & 1344,00 \\
\hline $23 / 7 / 2009$ & 1396,00 & 1228,48 & 167,52 & 1396,00 \\
\hline $24 / 7 / 2009$ & 1272,00 & 1119,36 & 152,64 & 1272,00 \\
\hline $25 / 7 / 2009$ & 1305,00 & 1148,40 & 156,60 & 1305,00 \\
\hline $26 / 7 / 2009$ & 1301,00 & 1144,88 & 156,12 & 1301,00 \\
\hline $27 / 7 / 2009$ & 1304,00 & 1147,52 & 156,48 & 1304,00 \\
\hline $28 / 7 / 2009$ & 1180,00 & 1038,4 & 141,60 & 1180,00 \\
\hline $29 / 7 / 2009$ & 0,00 & 0,00 & 0,00 & 0,00 \\
\hline $30 / 7 / 2009$ & 788,00 & 693,44 & 94,56 & 788,00 \\
\hline $31 / 7 / 2009$ & 1331,00 & 1171,28 & 159,72 & 1331,00 \\
\hline
\end{tabular}




\subsection{Características do plástico a ser injetado}

A característica do plástico a ser injetado será o tipo granulado com tamanho de partícula entre 0,2 a 1,0 mm. Conforme mostra as Figuras 11 e 12 do item 2.2.5, nesta especificação a combustibilidade do plástico aproxima-se da do carvão pulverizado.

\subsection{Custo do plástico a ser injetado}

O custo da injeção de plástico depende da participação do plástico na composição final do material de injeção (carvão + plástico). Através do custo de cada material obtém-se a variação do custo final da mistura de carvão + plástico em relação ao uso exclusivo do carvão, conforme equação (40).

$$
\mathrm{E}=(\mathrm{C} . \mathrm{PCI}+\mathrm{P} . \mathrm{PPI})-\mathrm{PCI}
$$

sendo:

$$
\begin{aligned}
& \mathrm{E}=\text { Equivalência de custo } \\
& \mathrm{C}=\text { Fração de participação de carvão na mistura } \\
& \mathrm{P}=\text { Fração de participação de plástico na mistura } \\
& \text { PCI =Custo do carvão injetado, US\$ / t } \\
& \text { PPI =Custo do plástico injetado, US\$ / t }
\end{aligned}
$$

Com base nos dados atuais, os seguintes valores podem ser considerados razoáveis para uma boa estimativa da equivalência de custos:

$$
\begin{aligned}
& \text { - Custo do carvão }(\mathrm{PCI})=\mathrm{US} \$ 125 / \mathrm{t} \\
& \text { - Custo do plástico }(\mathrm{PPI})=\mathrm{US} \$ 378 / \mathrm{t} \\
& \text { - } \mathrm{C}=0,88 \\
& \text { - P }=0,12
\end{aligned}
$$


Deste modo,

$E=(0,88.125+0,12.378)-125$

$\mathrm{E}=+\mathrm{US} \$ 30,36 / \mathrm{t}$

Este resultado mostra que a mistura composta por $88 \%$ de carvão e $12 \%$ de plástico resulta num acréscimo de custo de US\$ 30,36 / t em relação ao uso exclusivo do carvão.

\subsection{Estimativa da taxa de injeção de pneu}

A massa de injeção de pneu está estimada em $4 \%$ em relação à massa de injeção de carvão pulverizado, conforme mostra a Tabela 16 do item 3.5.3. Este percentual é obtido em função da análise química final da mistura carvão + pneu e pode variar em função da composição química de cada componente da mistura. Com base nos dados operacionais de Julho de 2009 do Alto Forno 1, a Tabela 21 apresenta o consumo estimado em t/dia de pneu + carvão.

\subsection{Características do pneu a ser injetado}

A característica do pneu a ser injetado será o tipo moído com tamanho de partícula entre 0,074 e 0,104 mm. Conforme apresentado nas Tabelas 10 e 11 do item 2.3, nesta especificação a taxa de combustão do pneu aproxima-se da do carvão pulverizado.

\subsection{Custo do pneu a ser injetado}

O custo da injeção de pneu depende da participação do pneu na composição final do material de injeção (carvão + pneu). Através do custo de cada material, pode-se obter a variação do custo final da mistura de carvão + pneu em relação ao uso exclusivo do carvão, pelo emprego da equação (40), considerando-se neste caso P a fração da participação de pneu na mistura e PNI o custo do pneu injetado, US\$ / t. 
Tabela 21 - Estimativa de consumo de carvão + pneu

\begin{tabular}{|c|c|c|c|c|}
\hline Data & $\begin{array}{l}\text { Carvão Total } \\
\text { Realizado }=100 \% \\
\qquad(\mathrm{t} / \mathrm{dia})\end{array}$ & $\begin{array}{c}\text { Carvão Estimado } \\
=96 \% \\
\text { (t/dia) }\end{array}$ & $\begin{array}{l}\text { Pneu Estimado } \\
=4 \% \\
\text { (t/dia) }\end{array}$ & $\begin{array}{c}\text { Carvão + Pneu } \\
\text { Estimado }=100 \% \\
(\mathrm{t} / \mathrm{dia})\end{array}$ \\
\hline $1 / 7 / 2009$ & 0,00 & 0,00 & 0,00 & 0,00 \\
\hline $2 / 7 / 2009$ & 0,00 & 0,00 & 0,00 & 0,00 \\
\hline $3 / 7 / 2009$ & 79,00 & 75,84 & 03,16 & 79,00 \\
\hline $4 / 7 / 2009$ & 0,00 & 0,00 & 0,00 & 0,00 \\
\hline $5 / 7 / 2009$ & 349,00 & 335,04 & 13,96 & 349,00 \\
\hline $6 / 7 / 2009$ & 1107,00 & 1062,72 & 44,28 & 1107,00 \\
\hline $7 / 7 / 2009$ & 1168,00 & 1121,28 & 46,72 & 1168,00 \\
\hline $8 / 7 / 2009$ & 1255,00 & 1204,80 & 50,20 & 1255,00 \\
\hline $9 / 7 / 2009$ & 1225,00 & 1176,00 & 49,00 & 1225,00 \\
\hline $10 / 7 / 2009$ & 1268,00 & 1217,28 & 50,72 & 1268,00 \\
\hline $11 / 7 / 2009$ & 1291,00 & 1239,36 & 51,64 & 1291,00 \\
\hline $12 / 7 / 2009$ & 1293,00 & 1241,28 & 51,72 & 1293,00 \\
\hline $13 / 7 / 2009$ & 1285,00 & 1233,60 & 51,40 & 1285,00 \\
\hline $14 / 7 / 2009$ & 1258,00 & 1207,68 & 50,32 & 1258,00 \\
\hline $15 / 7 / 2009$ & 1311,00 & 1258,56 & 52,44 & 1311,00 \\
\hline $16 / 7 / 2009$ & 1288,00 & 1236,48 & 51,52 & 1288,00 \\
\hline $17 / 7 / 2009$ & 1292,00 & 1240,32 & 51,68 & 1292,00 \\
\hline $18 / 7 / 2009$ & 1289,00 & 1237,44 & 51,56 & 1289,00 \\
\hline $19 / 7 / 2009$ & 1291,00 & 1239,36 & 51,64 & 1291,00 \\
\hline $20 / 7 / 2009$ & 1292,00 & 1240,32 & 51,68 & 1292,00 \\
\hline $21 / 7 / 2009$ & 1350,00 & 1296,00 & 54,00 & 1350,00 \\
\hline $22 / 7 / 2009$ & 1344,00 & 1290,24 & 53,76 & 1344,00 \\
\hline $23 / 7 / 2009$ & 1396,00 & 1340,16 & 55,84 & 1396,00 \\
\hline $24 / 7 / 2009$ & 1272,00 & 1221,12 & 50,88 & 1272,00 \\
\hline $25 / 7 / 2009$ & 1305,00 & 1252,80 & 52,20 & 1305,00 \\
\hline $26 / 7 / 2009$ & 1301,00 & 1248,96 & 52,04 & 1301,00 \\
\hline $27 / 7 / 2009$ & 1304,00 & 1251,84 & 52,16 & 1304,00 \\
\hline $28 / 7 / 2009$ & 1180,00 & 1132,80 & 47,20 & 1180,00 \\
\hline $29 / 7 / 2009$ & 0,00 & 0,00 & 0,00 & 0,00 \\
\hline $30 / 7 / 2009$ & 788,00 & 756,48 & 31,52 & 788,00 \\
\hline $31 / 7 / 2009$ & 1331,00 & 1277,76 & 53,24 & 1331,00 \\
\hline
\end{tabular}

Com base nos dados atuais, os seguintes valores podem ser considerados razoáveis para uma boa estimativa da equivalência de custos:

$$
\begin{aligned}
& \text { Custo do carvão }(\mathrm{PCI})=\mathrm{US} \$ 125 / \mathrm{t} \\
& \text { Custo do pneu }(\mathrm{PNI})=\mathrm{US} \$ 20 / \mathrm{t} \\
& \mathrm{C}=0,96
\end{aligned}
$$




$$
\begin{aligned}
& P=0,04 \\
& E=(0,96 \times 125+0,04 \times 20)-125 \\
& E=-U S \$ 4,20 / t
\end{aligned}
$$

Neste caso, observa-se que a mistura composta por $96 \%$ de carvão e $4 \%$ de pneu resulta numa redução de custo de US\$ 4,20 / t em relação ao uso exclusivo do carvão.

\subsection{Avaliação de resultados}

Conforme mostra o balanço de massa, o uso de plástico e pneu é possível quando adicionado na mistura de carvão pulverizado. A participação do plástico e do pneu ocorre de forma exclusiva, ou seja, carvão + plástico ou carvão + pneu.

A participação de cada material é calculada de forma a manter a composição química final da mistura equivalente quando do uso exclusivo do carvão; para que esta condição seja alcançada, para a composição química estabelecida neste estudo:

Com uso do plástico: $88 \%$ de carvão + $12 \%$ de plástico

Com uso do pneu: $96 \%$ de carvão $+4 \%$ de pneu

Com base na configuração do balanço de energia real do Alto Forno 1, o efeito da injeção do plástico ou pneu poderá ser avaliado através da obtenção do novo balanço de energia decorrente das novas entradas e saídas, conforme o caso. Este balanço fornece uma avaliação qualitativa do desempenho operacional do Alto Forno com o uso do plástico ou pneu.

A utilização do plástico na proporção de $12 \%$ eleva o custo da mistura (carvão + plástico) em US\$ 30,36 / t, tornando-se inviável do ponto de vista econômico. Entretanto, há possibilidade de redução deste custo através de acordos ou incentivos governamentais e que não foram avaliados neste trabalho.

A utilização do pneu na proporção de $4 \%$ reduz o custo da mistura (carvão + pneu) em US\$ 4,20 / t, sinalizando a viabilidade desta substituição do ponto de vista econômico. 


\section{CONCLUSÕES}

A utilização de plástico ou pneu como material de injeção no Alto Forno contribui para o processo de redução do minério de ferro em ferro gusa, devido ao fato de os mesmos conterem em suas composições químicas carbono e hidrogênio.

A proporção de plástico na mistura com carvão pulverizado deve ser de $12 \%$ para manter o equilíbrio da composição química final da mistura. Deve ser do tipo granulado com tamanho de partícula entre 0,2 e 1,0 mm. Nesta especificação, a combustibilidade do plástico aproxima-se da do carvão pulverizado. Observou-se, na análise de estimativa de custos realizada, que a mistura de plástico + carvão eleva o custo total da mistura em US\$ 30,36 / t em relação ao custo do uso exclusivo de carvão.

A proporção de pneu na mistura com carvão pulverizado deve ser de $4 \%$ para manter o equilíbrio da composição química final da mistura. Deve ser do tipo moído com tamanho de partícula entre 0,074 e 0,104 mm. Nesta especificação, a taxa de combustão do pneu aproxima-se da do carvão pulverizado. A mistura de pneu + carvão reduz o custo total da mistura em US\$ 4,20 / t em relação ao custo do uso exclusivo de carvão.

As análises realizadas indicam um potencial uso do pneu em associação com carvão em altos fornos, mantendo-se a qualidade atual do produto final obtido nesse processo. Há que se observar que existe legislação federal que regulamenta que fabricantes de pneus dêem destinação final ambientalmente adequada aos mesmos, ao cabo de sua utilização (Resolução CONAMA 416, de 30/09/2009, que substitui a Resolução CONAMA n 258, de 26 de agosto de 1999), fato positivo do ponto de vista de tal aplicação.

Tal como ocorre com outros produtos alternativos, o setor siderúrgico deve enfrentar dificuldades na substituição, em especial pela concorrência com o setor cimenteiro. A este respeito, a Resolução CONAMA 264, de 26/08/1999 estabelece procedimentos, critérios e aspectos técnicos específicos de licenciamento ambiental para o co-processamento de resíduos em fornos rotativos de clínquer, para a fabricação de cimento, prática que tem sido utilizada com regularidade por este setor desde então. 
Sugere-se que alguns estudos possam ser realizados a título de continuidade da presente análise:

- aplicação, em escala experimental, da injeção de pneu no alto Forno 1, na proporção sugerida nas análises realizadas (mantida a qualidade do produto final), visando estabelecer uma base comparativa em termos da melhoria ou não da eficiência energética do equipamento;

- análise das perdas levando em conta a avaliação exergética do Alto Forno1, visando identificar potenciais melhorias de projeto ou "retrofit" do equipamento;

- comparação metodológica de diferentes abordagens empregadas por fabricantes de altos fornos com relação à modelagem do balanço de energia em tais componentes térmicos. 


\section{REFERÊNCIAS}

ASUNAMA, M. et al. Development of waste plastics injection process in blast furnace. ISIJ International, v.40, p. 244-251, 2000.

CHU, M.; NOGAMI, H.; YAGI, J. Numerical analysis on injection of hydrogen bearing materials into blast furnace. ISIJ International, v.44, p. 801-808, 2004.

ASSIS, P.S. (Coord.) Injeção de materiais pulverizados em altos fornos. Associação brasileira de metalurgia e materiais, São Paulo, 1993.

ERTEM, M.E.; GÜRGEN, S. Energy balance analysis for Erdemir blast furnace number one. Applied Thermal Engineering, v.26, p. 1139-1148, 2006.

Fonte=Ambientebrasil.Disponível em: $\quad$ http://ambientes.ambientebrasil.com.br/residuos/ reciclagem/reciclagem_de_plastico.html> acesso em: 21/05/2009.

GUPTA, S.; SAHAJWALLA, V.; WOOD, J. Simultaneous combustion of waste plastics with coal for pulverized coal injection application. Energy fuels, v.20, p. 2557-2563, 2006.

KIM, D. et al. Waste plastics as supplemental fuel in the blast furnace process: improving combustion efficiencies. Journal of hazardous materials, v.B94, p. 213-222, 2002.

LAGARINHOS, C.A.F.; TENORIO, J.A.S. Tecnologias utilizadas para a reutilização, reciclagem e valorização energética de pneus no Brasil. Polímeros: ciência e tecnologia, v.18, p. 106-118, 2008.

MONTEIRO, L.P.C.; MAINER, F.B. Queima de pneus inservíveis em fornos de clinquer. Engevista, v.10, p. 52-58, 2008.

NOGAMI, H.; YAMAOKA, H.; TAKATANI, K. Raceway design for the innovative blast furnace. ISIJ International, v.44, p. 2150-2158, 2004. 
NOZDRACHEV, V.A. et al. Development of the technology of injection of liquid and gaseous fuels into blast furnaces (analysis of world practice in the period 1993-1997). Metallurgist, v.42, p. 343-348, 1998.

OGAKI, Y. et al. Recycling of waste plastic packing in a blast furnace system. NKK Technical review, v.84, p. 01-07, 2001.

OLIVEIRA, G.M.; OLIVEIRA, V.A.; CADIDO, L.S.; ASSIS, P.S. Estudo do fluxo de materiais pulverizados em simulador de injeção de ventaneiras de altos-fornos através de vídeo-fotografia. Tecnologia em metalurgia e materiais, v.3, p. 07-15, 2007.

RESOLUÇÃO CONAMA 258, de 26/08/1999 -

RESOLUÇÃO CONAMA 264, de 26/08/1999 - Licenciamento de fornos rotativos de produção de clínquer para atividades de co-processamento de resíduos.

RESOLUÇÃO CONAMA 416, de 30/09/2009 - Dispõe sobre a prevenção à degradação ambiental causada por pneus inservíveis e sua destinação ambientalmente adequada, e dá outras providências.

SERRA, N.; LEITE, C.A.G. Gestão ambiental de pneus inservíveis no Brasil: identificação de fluxos e contribuição para políticas publicas de destinação. Instituto de pesquisas tecnológicas IPT, 2004.

SILVA, A.M. Estudo da combustão dos carvões e misturas com coque verde de petróleo injetadas em altos fornos. Dissertação (Mestrado em Engenharia Mecânica) - Faculdade Engenharia do Campus de Guaratinguetá, Universidade Estadual Paulista, Guaratinguetá, 2006.

SONTAG, R.E; WYLEN, G.J; BORGNAKE, C. Fundamentos da termodinâmica. Editora Edgard Blücher, 2003. 
ANEXO 1

DASDOS OPERACIONAIS DO ALTO FORNO 1 DA ARCELORMITTAL TUBARAO

Período de aquisição: 01 a 31 de Julho de 2009 


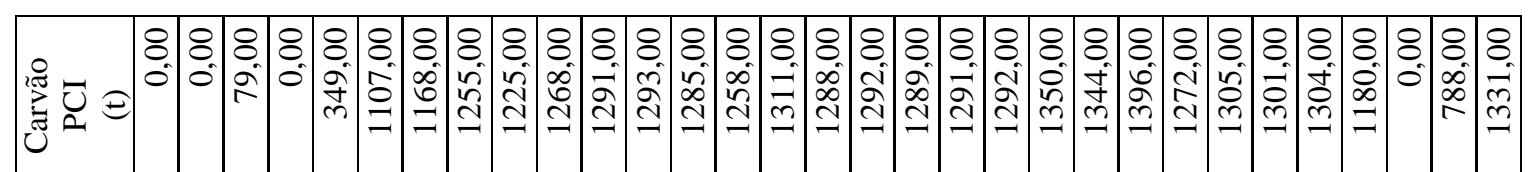

○ =

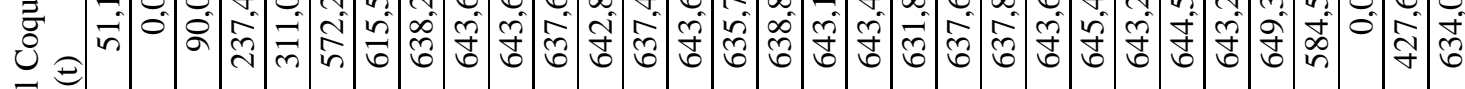
葛

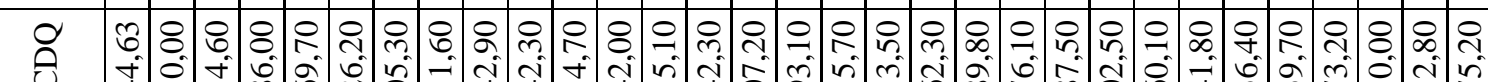

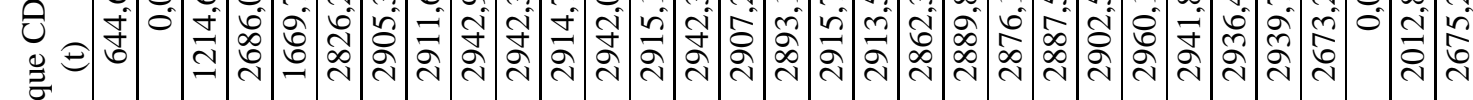
ठ

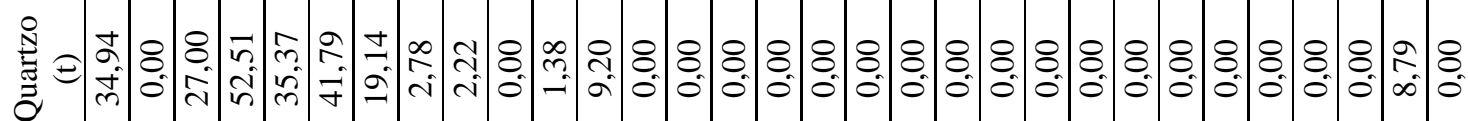

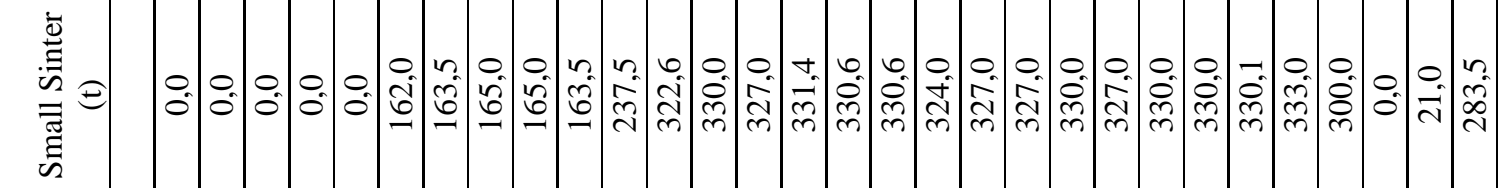

$\stackrel{\tilde{0}}{\tilde{0}}$

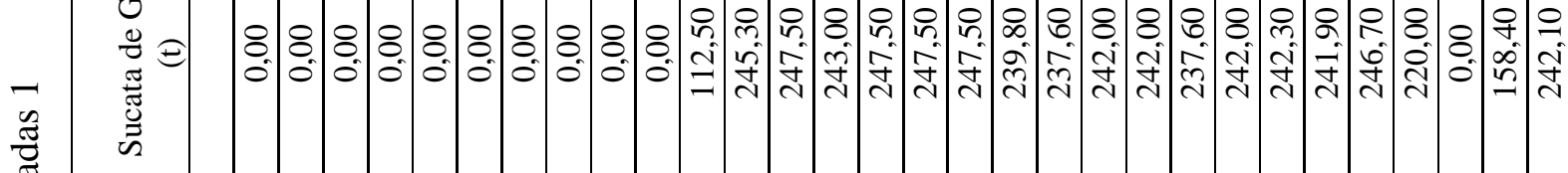

咅
$\frac{7}{4}$
$\frac{\pi}{8}$
$\frac{7}{7}$
4

遮

$\frac{1}{4}$
$\frac{\pi}{0}$
$\frac{\pi}{0}$
$\frac{\pi}{6}$

z $\stackrel{\mathscr{\Xi}}{\mathscr{n}}$

\% \&

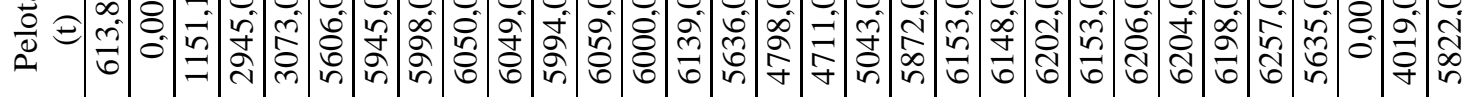

串

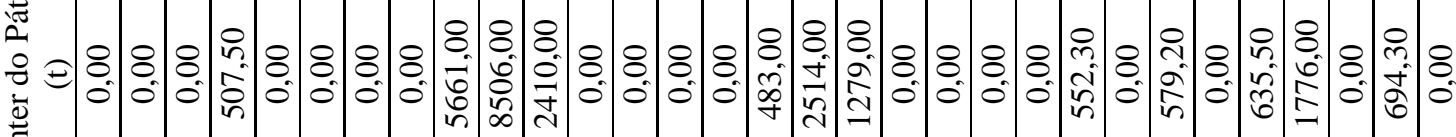
总

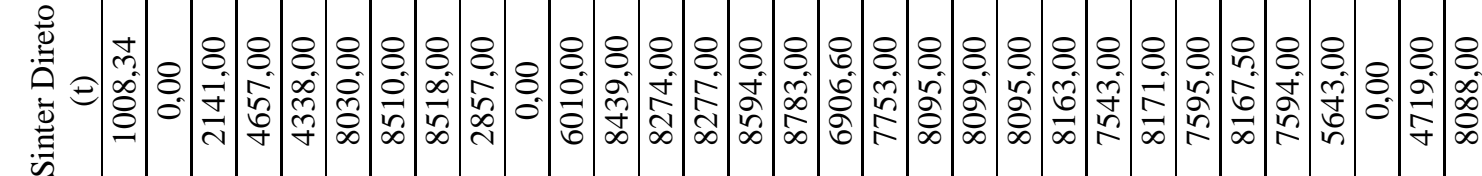

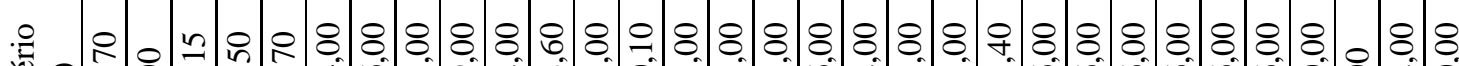

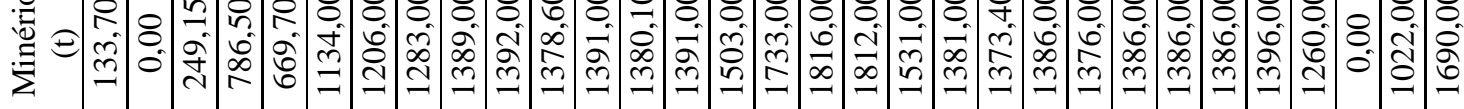

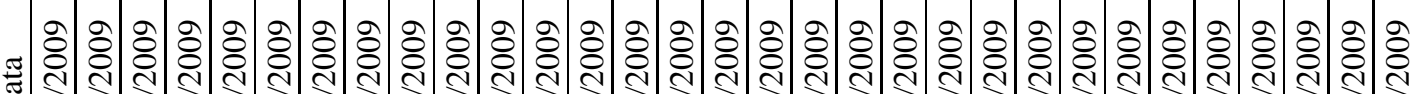

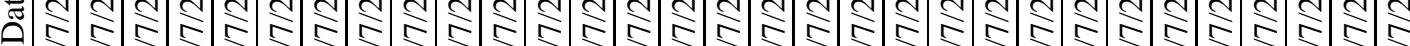

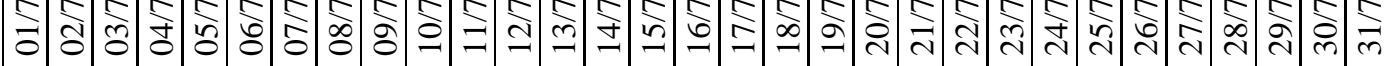




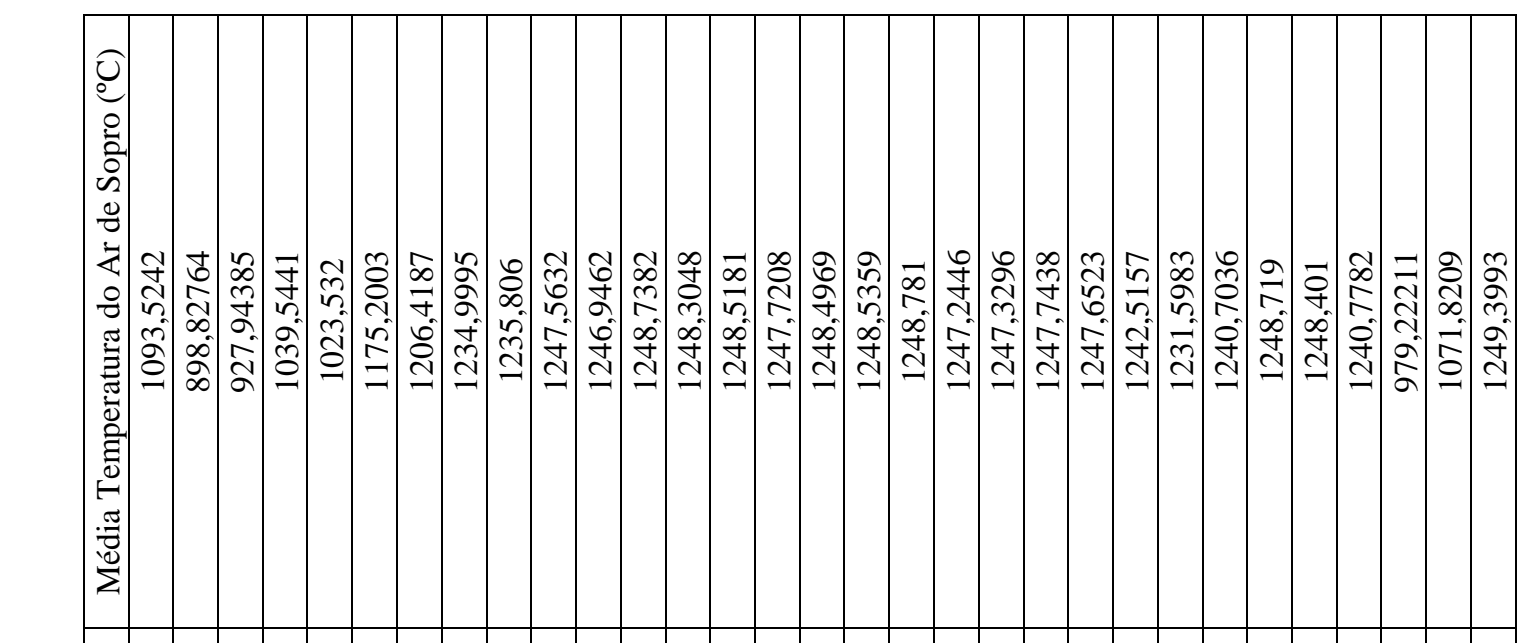

ล

艺

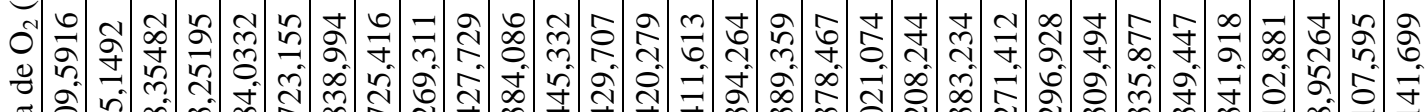

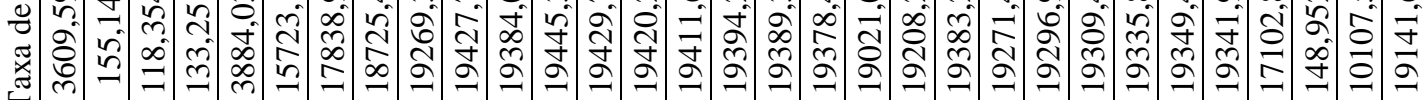

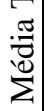

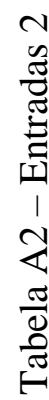

疍

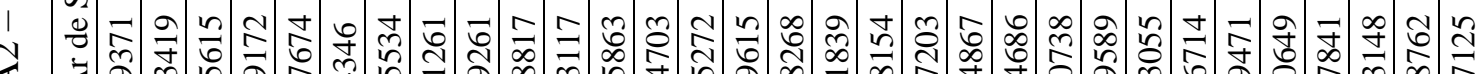

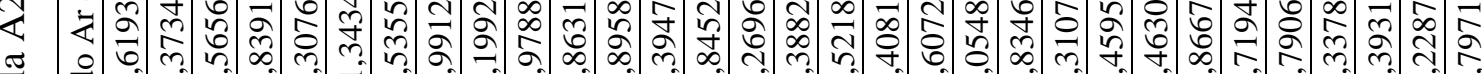

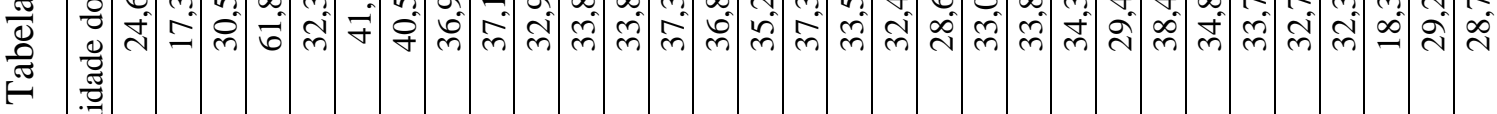

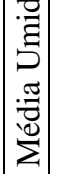

है

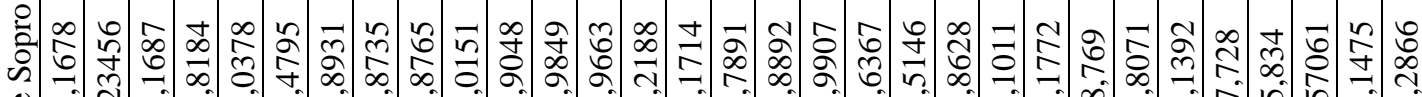

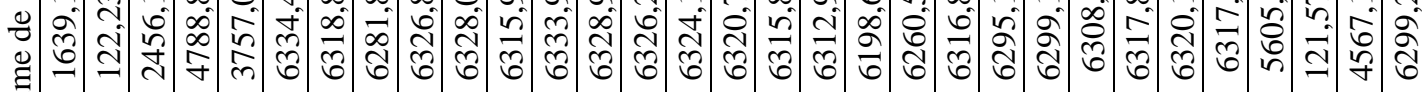

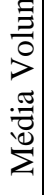

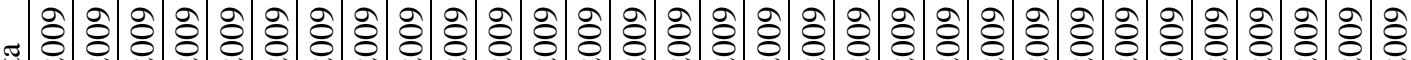
苟 a 


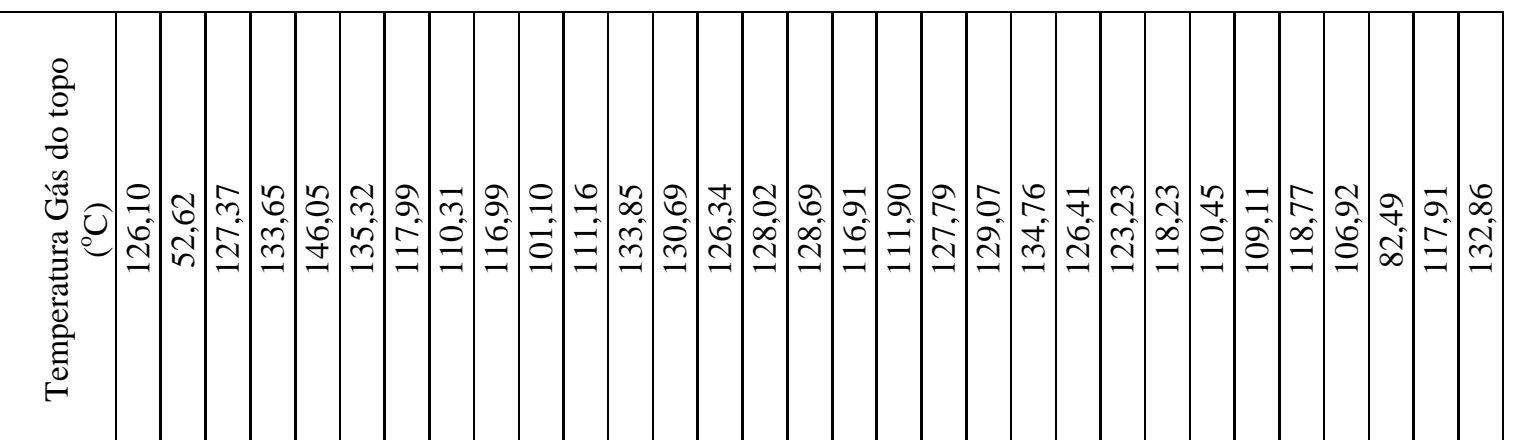

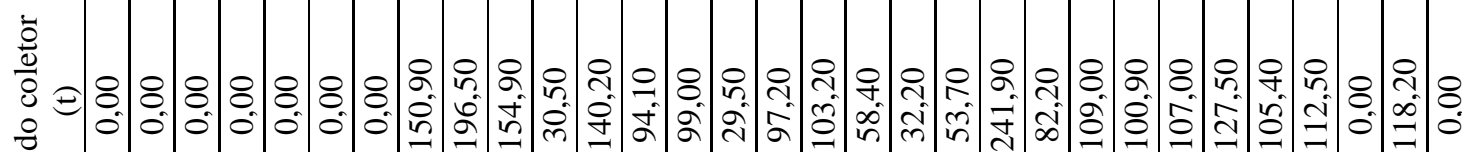
$\stackrel{\circ}{2}$

䍃

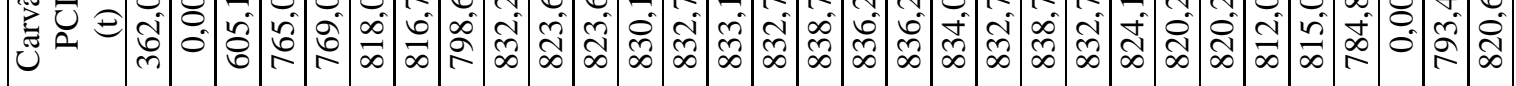

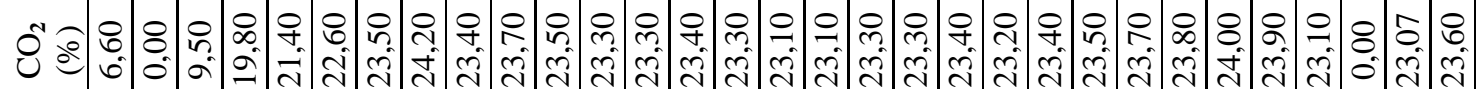

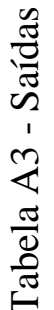

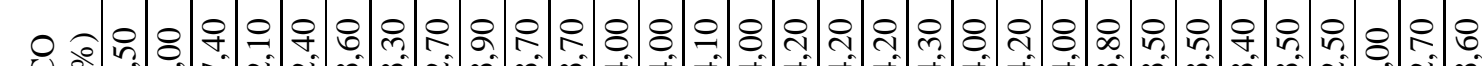

- 00 -

4

Z

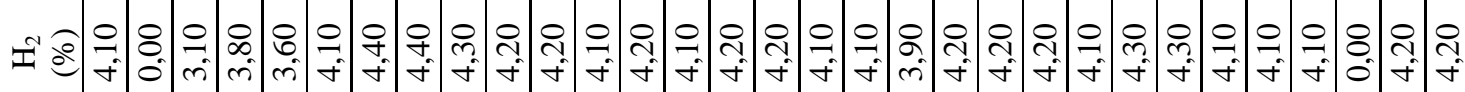

0

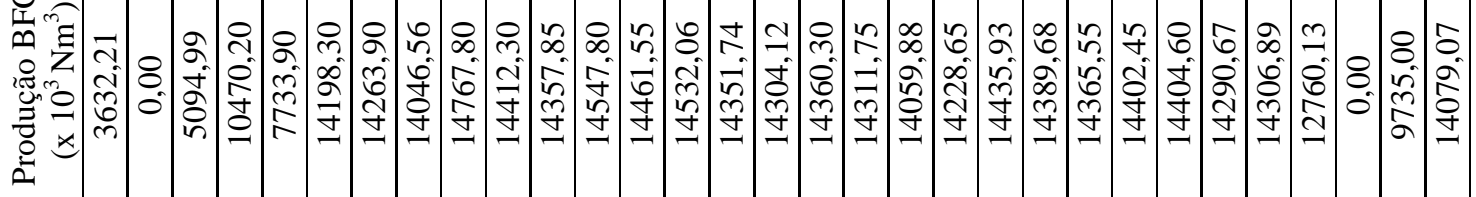

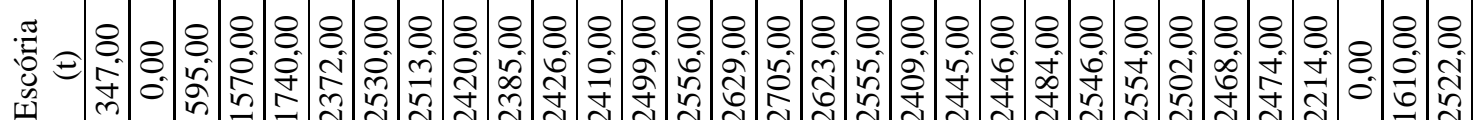

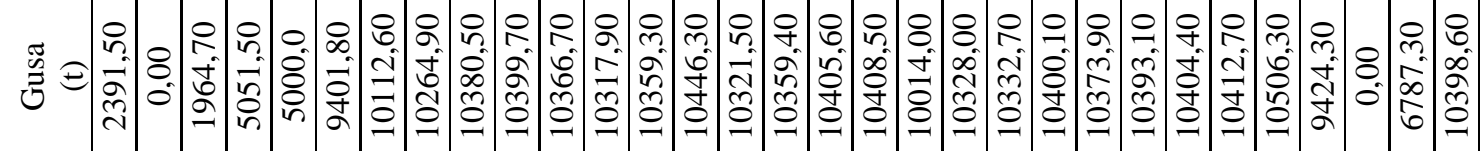
‡

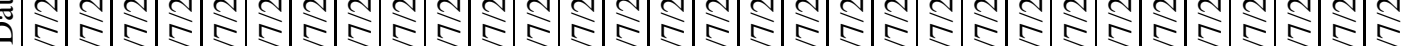

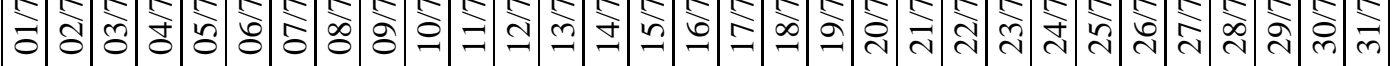




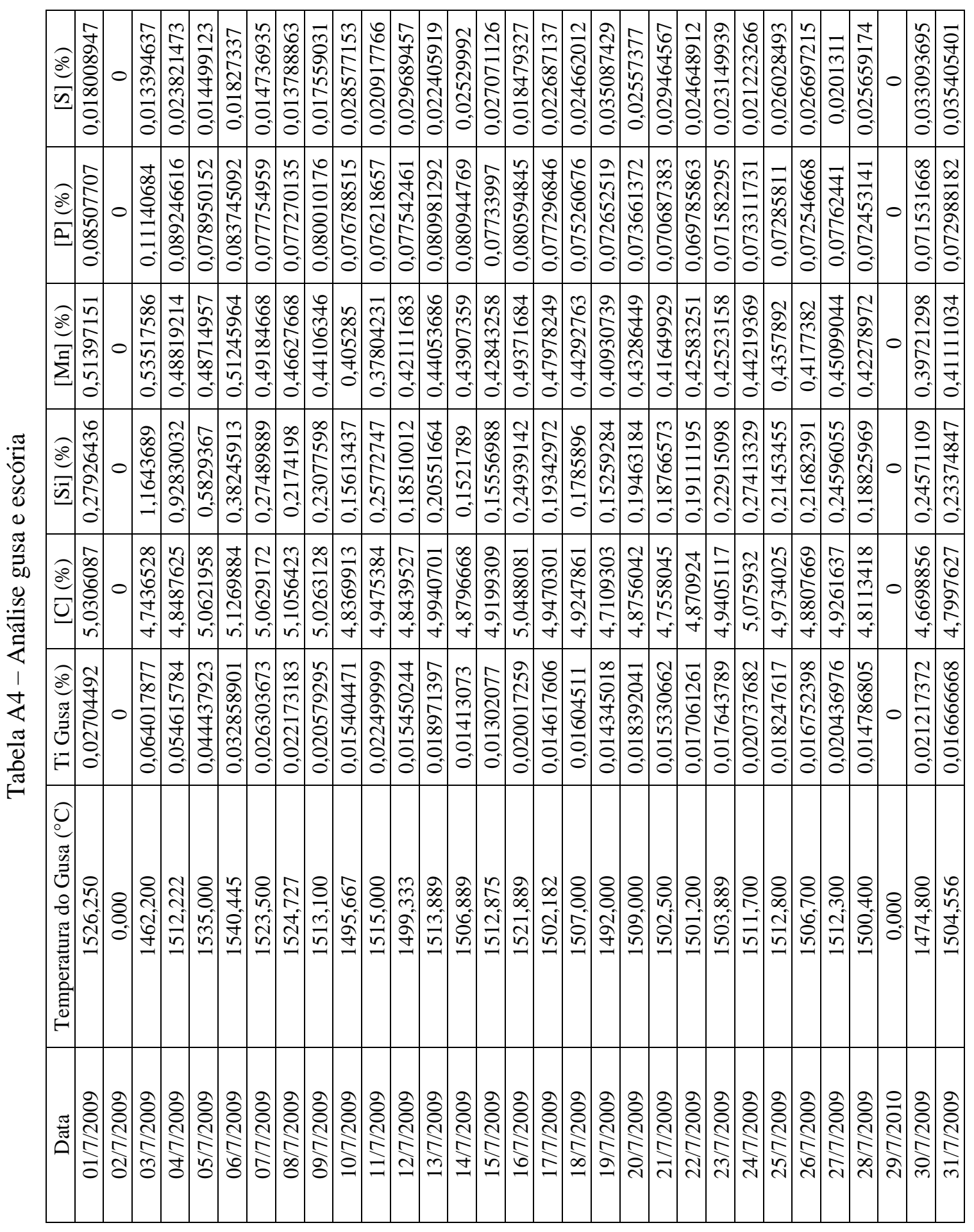




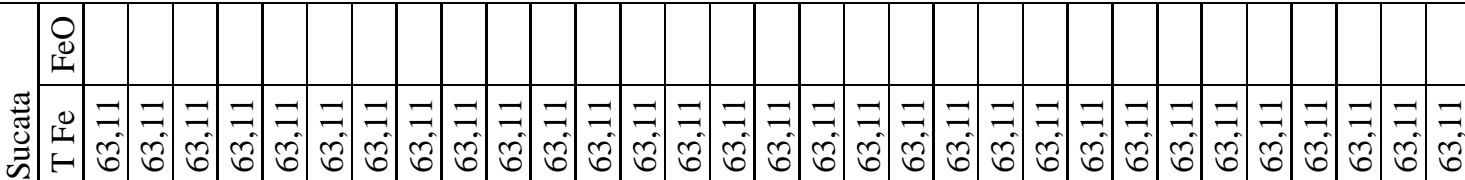

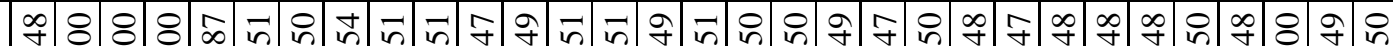

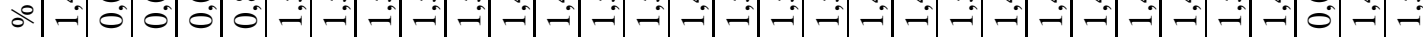
จ० 类 के

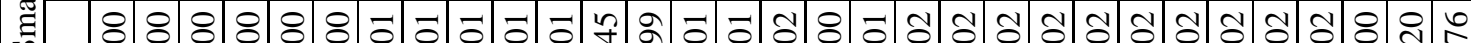

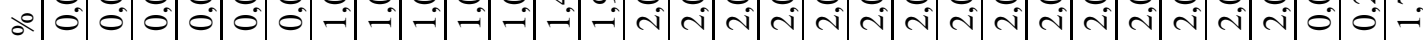
. , 8 so

包 \& \&

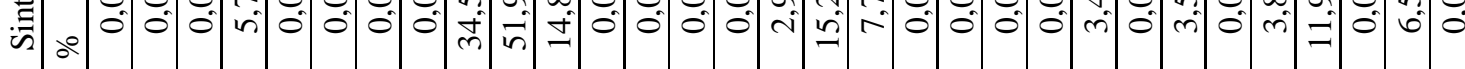

\section{○े}

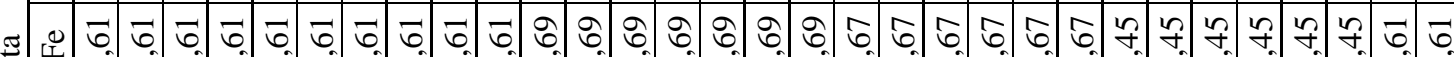
के है

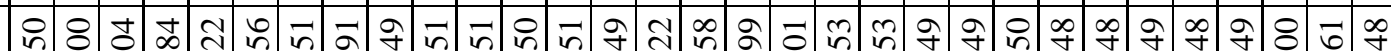

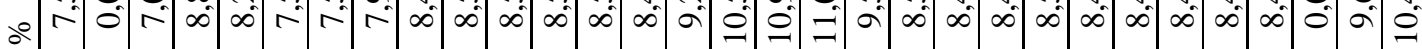

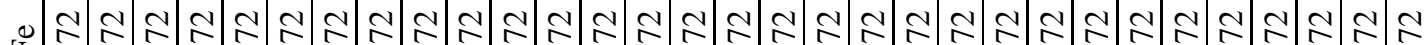
\# दू ¿ f $\& \bar{n}$ 유

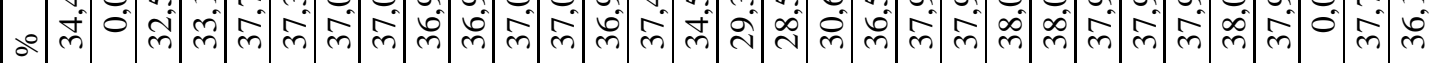
$>$ ๑

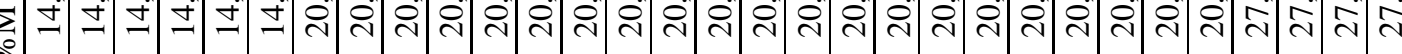

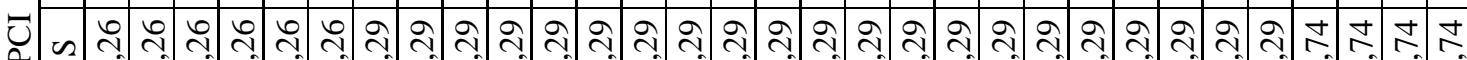

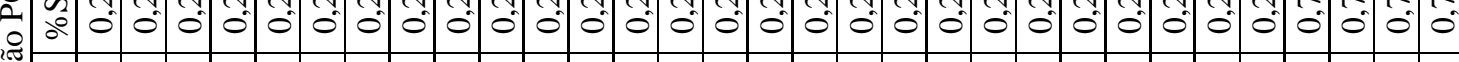

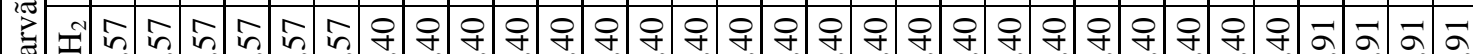

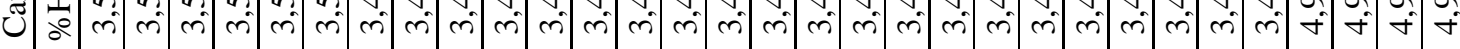

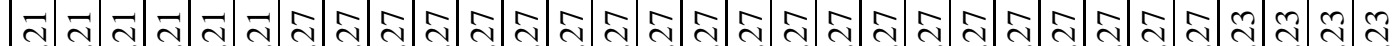

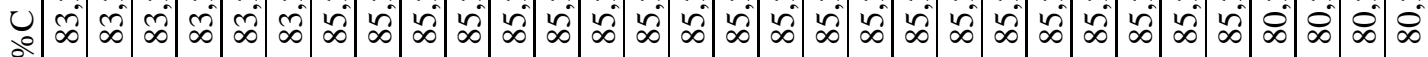

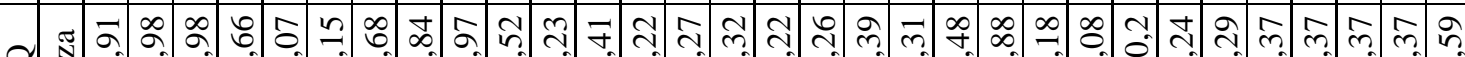

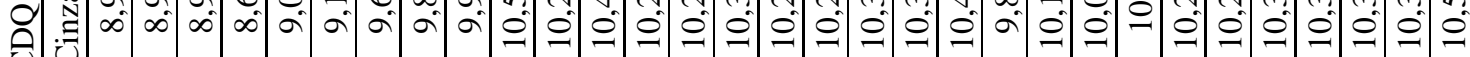
$\stackrel{2}{2}$

ఫั

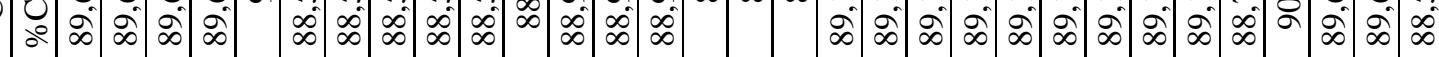

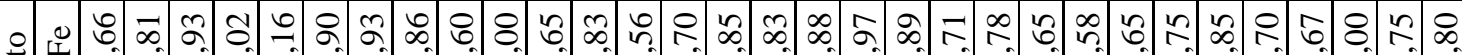
氕 a

竎

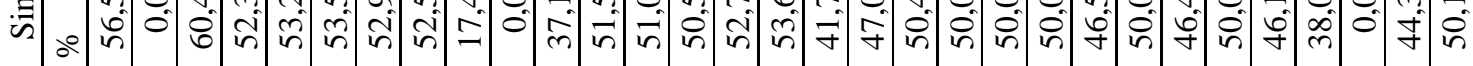

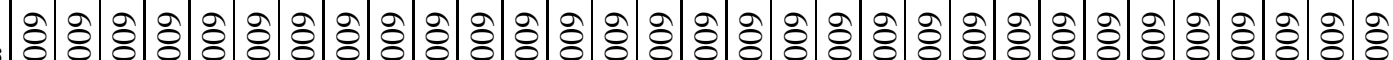
0
$\pi$
2

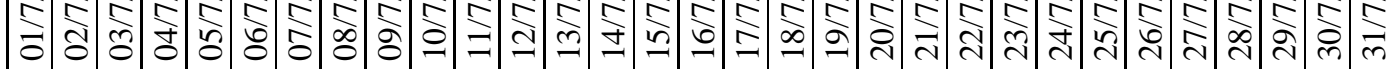

